
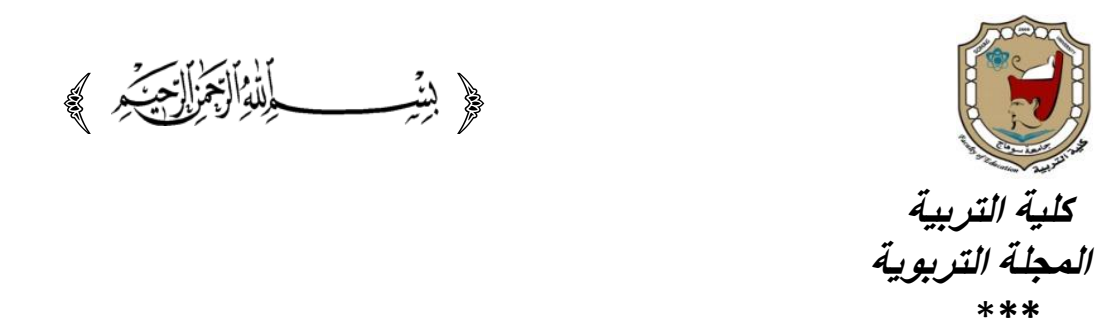

\title{
تصور هقتزح
}

لتحول مدارس الدهمج إلى بيئة هدربية أهنة

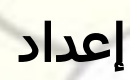

د/ عبد العزيز شوق السلمي

أستاذ مساعد التربية الخاصة

كلية الاراسات العليا التريوية

جامعة الملك عبد العزيز

المملكة العربية السعودية
د/ إسماعيل خالد علي المكاوي مدرس أصول التربية كلية التربية جامعة الأزهر بالادقهية

\section{DOI: 10.12816/EDUSOHAG. 2020.}

$$
\text { المجلة التربوية ـ العلد الخامس والسبعوز - يوليو ·r.r. }
$$

Print:(ISSN 1687-2649) Online:(ISSN 2536-9091) 


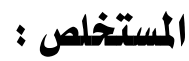

هدف البحث إلى تقديم تصور مقترح لتحول مدارس الدمج إلى بيئة مدرسية آمنة، وذلك في ضوء متغيرات : النوع (ذكر - أنثى) ، التخصص (علمي - أدبي) ، وعدد سنوات الخبرة (أقل من • سنوات، ه - • سنوات، ـ 1 سنوات فأكثر) ولتحقيق ذلك الهذف تم تحديد مفهوم البيئة المدرسية الآمنة وخصائصها ومقوماتها، ومبررات تحول مدارس الدمج إلى بيئة مدرسية آمنة، كما تم تصميم استبانة للتعرف على جواتب التحول إلى بيئة مدرسية آمنة، التهات وذللك في مجالات (الروئية والأهداف) ، (الترابط والثقة والتواصل الفعال) ، (القيادة المهنية) ، (التركيز على التعليم الهادف) ، (المجتمعات المهنية وييئات التعلم) ، (المحاسبية المهنية). وطبقت على عينة عشوائية بلغت (ODV) من معلمي مدارس الدمج في مصر والسعودية، وقد أظهرت النتائج أن مجالات تحول مدارس الدمج إلى بيئة مدرسية آمنة متوفرة بدرجة متوسطة ، كما أوضحت النتائج وجود فروق ذات دلالة إحصائية بين استجابات المعلمين

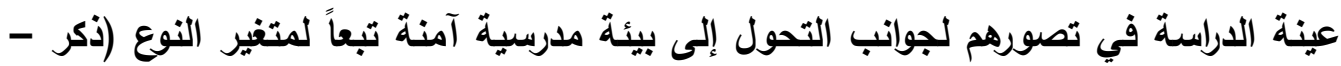

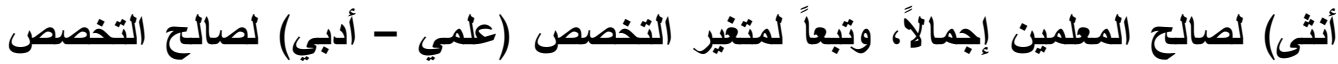
الأدبي إجمالاً، وتبعاً لمتفير مكان الإقامة (السعودية - مصر) لصالح المعلمين والمعلمات من المنات السعودية، وتبعاً لمتغير عدد سنوات الخبرة، لصالح الفئة أقل من ه سنوات بالنسبة لإجمالي الاستبانة.

الكلمات المفتاحية: بيئة مدرسية آمنة - الدمج- خصائص البيئة المدرسية الآمنة مقومات البيئة المدرسية الآمنة. 
تصور مقترح لتحول مدارس الدمج إلى بيئة مدرسية آمنة.

\title{
A Suggested Proposal for transforming inclusive schools into
}

\section{a safe school environment}

\begin{abstract}
:
The current research aimed at providing a Proposal for transforming inclusive schools into a safe school environment in light of: Gender (male/female), Specialization (scientific - literary), and the number of years of experience (less than 5 years, 5-10 years, 10 years or more). To achieve this goal, the concept of a safe school environment, its characteristics and components, and justifications for transforming inclusive schools into a safe school environment were identified.

A questionnaire was also designed to identify aspects of the transformation into a safe school environment, in the following areas: (vision and goals), (interdependence, trust and effective communication), (professional leadership), (focus on meaningful education), (professional societies and learning environments), (professional accounting).

Participants were randomly selected, they were (557) teachers at inclusive schools in Egypt and Saudi Arabia. Findings revealed that the fields of transformation of inclusive schools into a safe school environment are available at a moderate degree. Findings also revealed statistically significant differences between the teachers' responses in their perception of transformation aspects into a safe school environment according to gender (male - female) in favor of male, and according to the Specialization (scientific - literary) in favor of literary, and according to the place of residence (Saudi Arabia - Egypt) in favor of teachers from Saudi Arabia. Finally, according to the number of years of experience, in favor of the category less than 5 years in relation to the total questionnaire.
\end{abstract}

Keywords: safe school environment - Inclusion - characteristics of safe school environment - elements of safe school environment. 


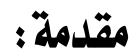

يأتي شعور الفرد بالأمن في قاعدة هرم ماسلو للحاجات الإنسانية بعد الحاجة إلى دإئ

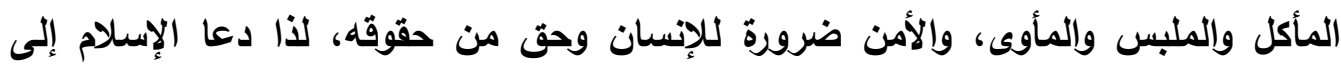
المحافظة على نعمة الأمن، والذي يمثل مضمون مقاصد الثريعة الإسلامية : (حفظ الاين، والنفس، والعرض، والنسل والمال). وللبيئة التي يعيش فيها الإنسان تأثيرها وانعكاساتها على سلوكياته وتصرفاته، لذان عهدت المجتمعات إلى المؤسسات التربوية بأن تنوب عنه في تحقيق أهداف التربية وتثكيل

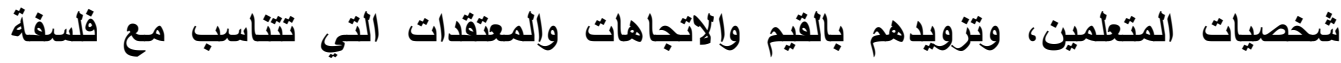

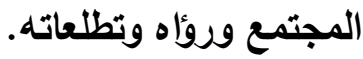
ويعد مدخل المدرسة الآمنة من المداخل الديثة التي تعمل على إيجاد بيئة مدرسية يسودها الحب والأمن ، والرعاية ، والثقة، كما تعمل على إيجاد مدارس تتميز بتوفير معايير

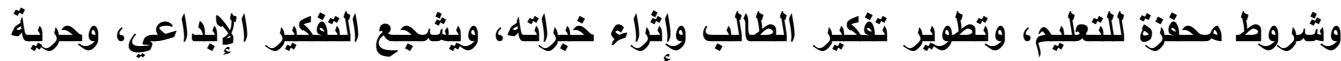

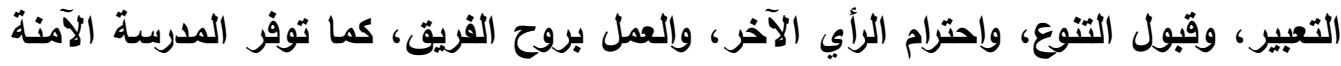

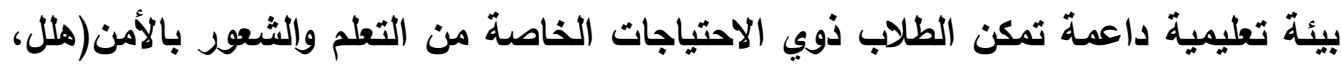
. ( $\{r \Lambda: r \cdot 1 \Lambda$ ومن خلال العدرسة الآمنة يتم تعزيز جهود التعليم والتعلم بتوفير بيئة داعمة تتضمن سلامة وصحة جميع العاملين في المنظومة التعليمية من معلمين وطلاب، لضمان أفضل أداء

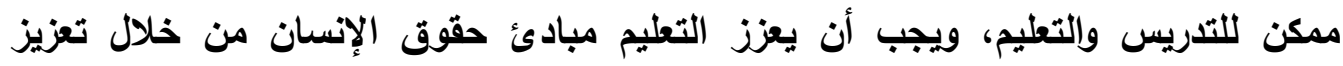

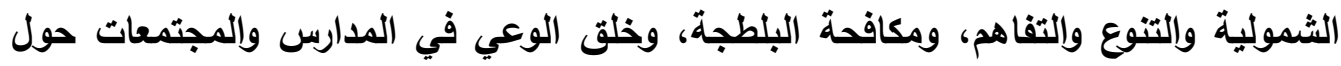

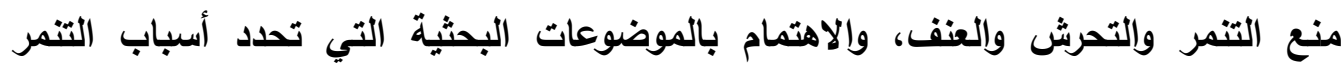

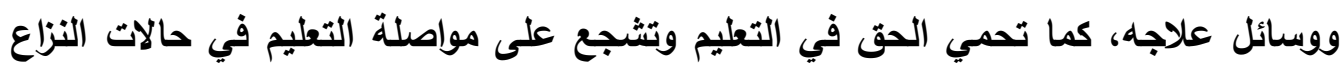

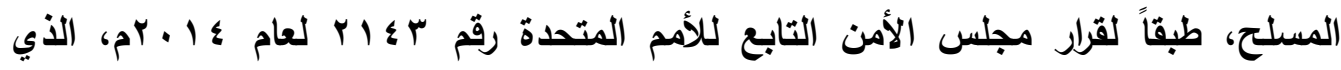

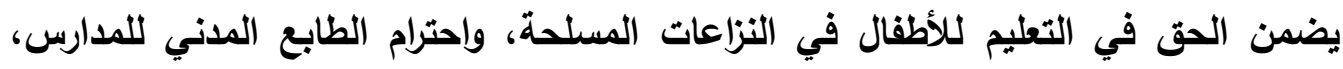
وضمان التحقيق في الهجمات على المدارس ومقاضاة المسؤولين عنها(وزير، والمحمدي، 
والواقع أن مدارسنا صارت - في كثير من الأحيان - مجتمعاً مصغراً تتمازج فيه بعض العادات السيئة ، والأفكار المنحرفة والتجارب السلبية، وزيادة معدلات التنمر وحالات العنف ، وفي بعض الأحيان تصبح المدارس ميداناً لترويج مختلف أنواع المخدرات.

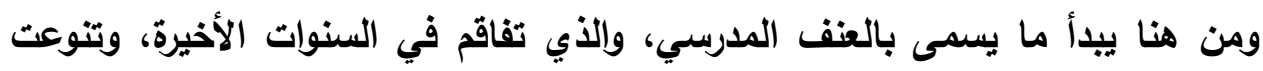

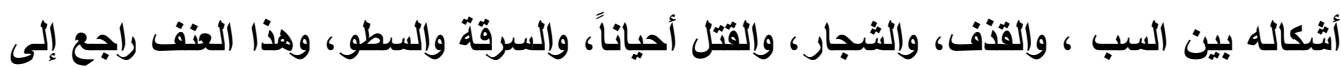
أسباب عديدة منها: تأثير وسائل الإعلام السلبي من خلال مثاهدة الطلاب لأفلام العنف

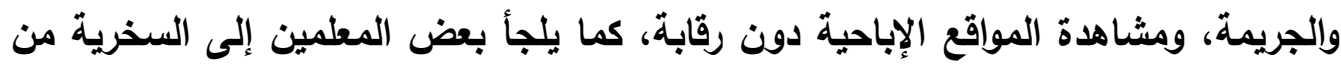

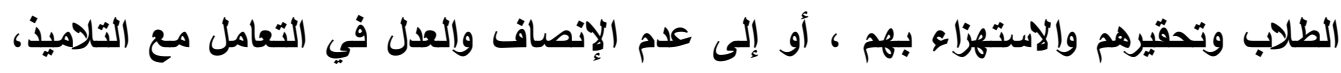
وتحرش بعض المعلمين بالتلميذات، في ظل غياب دور بعض الأسر في تعليم الأخلاق، وعدم

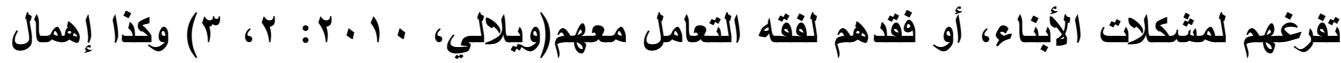
الأنثطة التريوية، وعدم استغلالها بالثكل الأمثل في تحقيق ما قد تعجز عنه المقاء المقرات

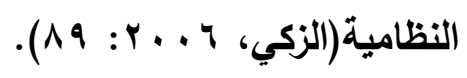

ويعد توفير بيئة مدرسية آمنة ضرورة ملحة، لأن هؤلاء الطلاب هم المستقبل، فالمستقبل مرهون بهم ويمدى تعلمهم، ويتطبيق ما تعلموه من علوم ومعارف ومهارات،

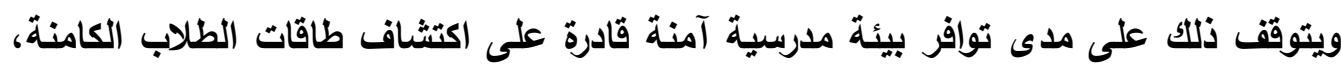
واستثمارها، وتتميتها، وتوجيهها في مسارات عملية وتطبيقية، وتعبر عن مستواهم الحقيقي والارتقاء بهم في مراحل تعليمية وحياتية أخرى، وتوفير هذه البيئة التربوية الآمنة ليس مكلفاً

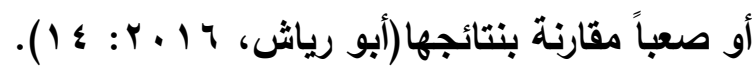
ويرى (Parker \& Lepper, 1992: 625-633) أن الجو التطليمي الآمن الذي

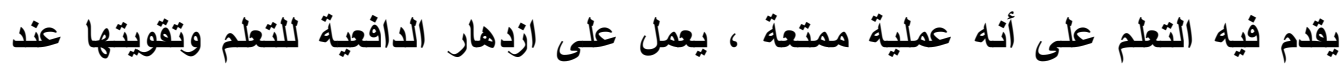

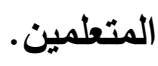
ومع توالي التطورات العالمية ، برزت للمدرسة أهداف جديدة من أهمها: تحسين الصحة

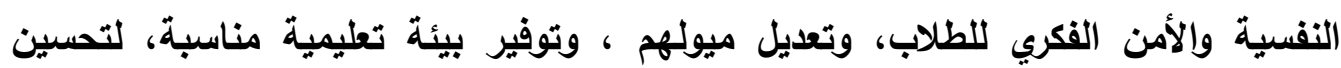

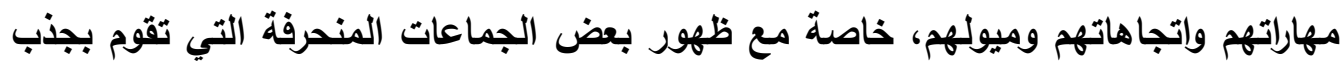

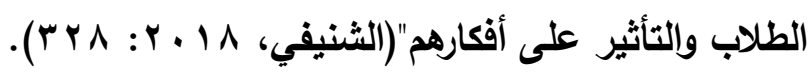


ومن هنا كان الاهتمام كبيراً بضرورة أن تكون المدرسة بيئة تريوية آمنة، حاضنة للطلاب، وضرورة توفير ما تتطلبه هذه البيئة من مقومات ومكونات مادية ويشرية ومعنوية، ويقدر توافر هذه المقومات والمكونات تنجح المدرسة بتأدية رسالتها وتحقيق أهدافها، ووجود

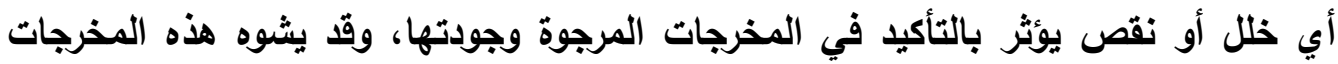

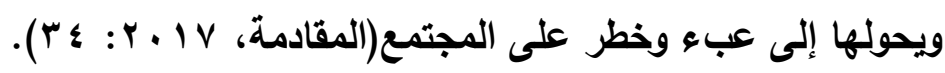

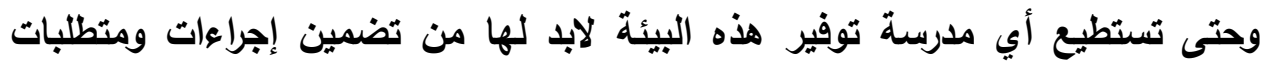

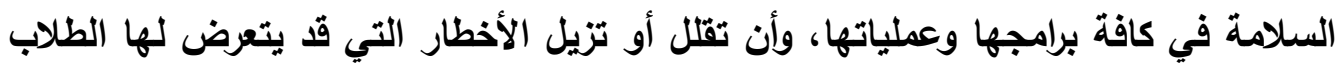
والمعلمون وجميع العاملين في المدرسة. ويجب أن يؤخذ بعين الاعتبار أن معظم حالات

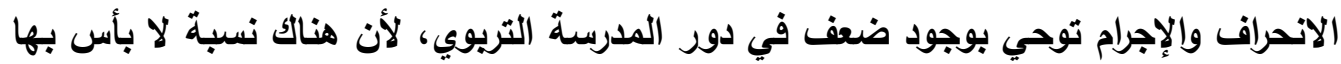

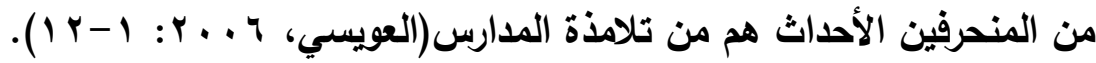
ويشكل عام يقع عبء تحقيق الأمن المدرسي وإيجاد بيئة مدرسية آهنة، على جميع عناصر العملية التعليمية من مطلمين وطلاب وآباء وأفراد في المجتمع المحلي المحيط بالمدرسة؛ فالمجتمع يتحمل مسؤولية شخصية في الحد من مخاطر العنف، وتحقيق النظام والمحافظة عليه، وإظهار الاحترام المتبادل بين الجميع، والتأكد من تقليم المساعدة للطلاب

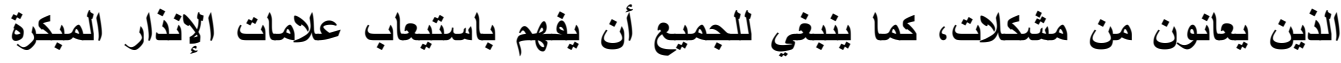
التي تساعد في التعرف على الطلاب الذين قد يكونون سبياً (Early Warning Sings) رئيساً في الإخلال بالأمن المدرسي، كما ينبغي للجميع أن يستعدوا للتصرف بثكل ملائم الطبات وسليم عند حودث المواقف الطارئة والأزمات التي تعرض الأمن المدرسي للخطر( Dwyer et .(al., $1998: 2$ وتؤكد المدرسة الآمنة على عدم استخدام أساليب العنف المادي واللفظي تجاه التلاميذ

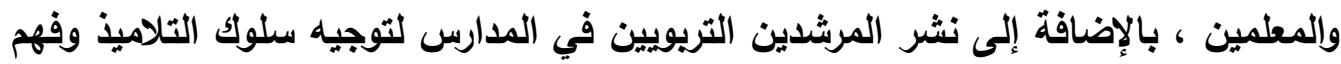
مستوياتهم وحل مشكلاتهم بأساليب تريوية حديثة ، كل ذلتك يؤدي إلى إيجاد بيئة مدرسية

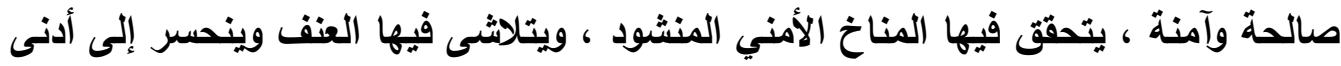

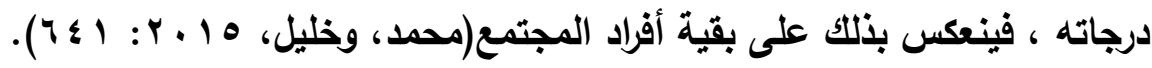


وفي إطار استثمار طاقات الطلاب، ورعاية ذوي الاحتياجات الخاصة، وتحفيز قدراتهر

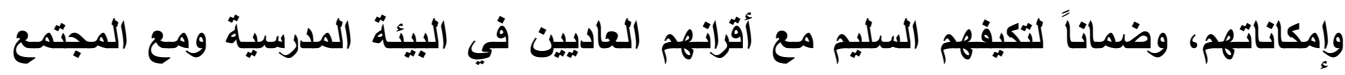

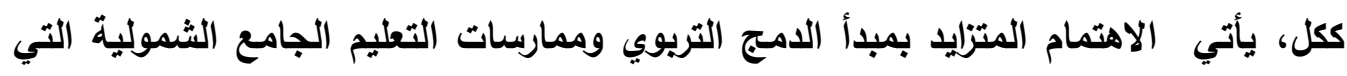

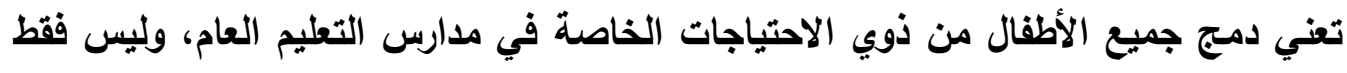

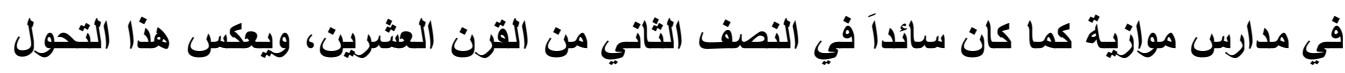

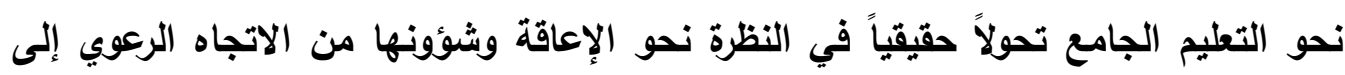

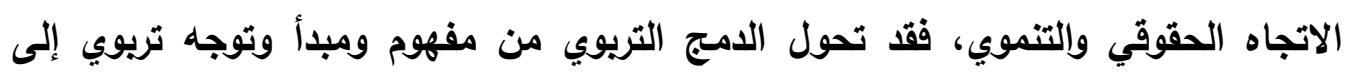

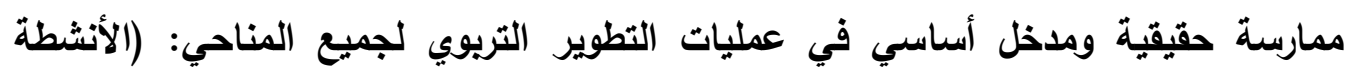
المنهجية- طرائق التريس - أساليب التقويم- البيئة المدرسية- الإدارة التريوية)(الموسى، التئ، . ( $9:$. 4 .

ويهاف دمج المعاق مع أقرانه العاديين إلى تنمية خصائصه النفسية والاجتماعية، مما

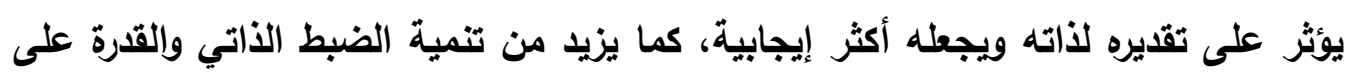

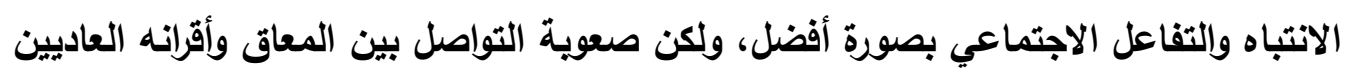

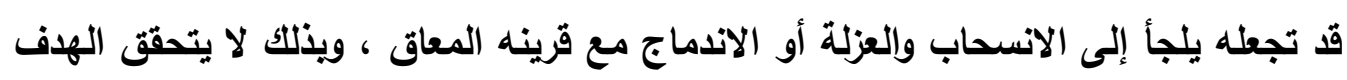

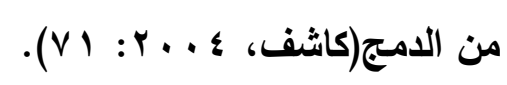

وينظر الدمج إلى التنوع كقاعدة، ويتطلب تعليماً عالي الجودة، من خلال توفير مناهج

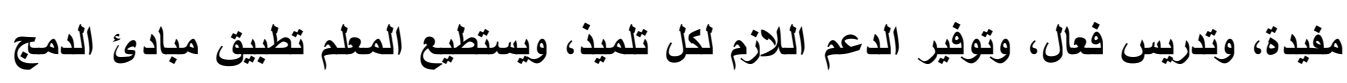

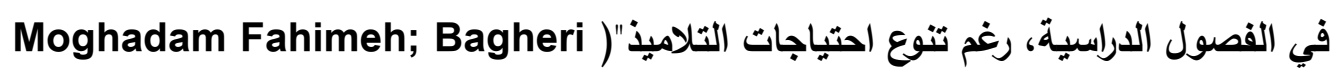

.(Somayeh 2018, PP. 7-8

والامج عملياً يعني تقيم برامج تعليمية ملائمة لكل الطلاب، بحيث تكون هذه البرامج

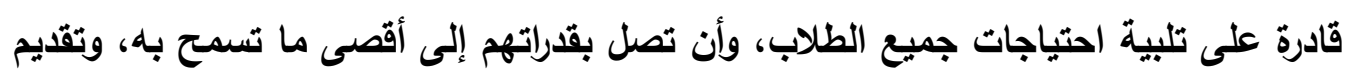

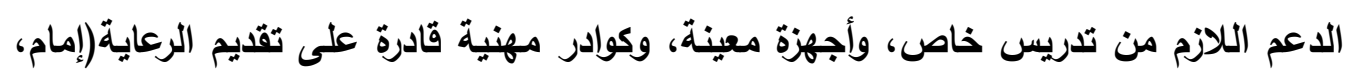

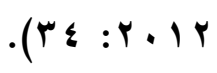


وينتج أسلوب الدمج آثاراً نفسية طية لاى كل من يخضع لهذا الأسلوب، فيعتز بقدراته، ويقدر إمكاناته، ويحس بوجوده، ويشعر بالآخرين من حوله، ويتمكن من التنافس مع أقرانه والتحاور فيما بينهم، ويمتد هذا التوافق النفسي والاجتماعي خارج المدرسة، لكن للامبج أحياناً - ردود فعل سلبية، تبدو في السخرية والتهكم اللأن يصدران من بعض الأشخاص تجاه ذوي الاحتياجات الخاصة ، فضلاً عن رفض بعض الأسر إلحاق أبنائهم ذوي الاحتياجات الخاصة

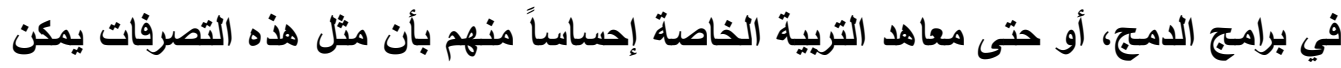
أن تلحق الضرر بهم، أو تنال من مكانتهم الاجتماعية، وهناك بعض المظاهر السلبية الأخرى

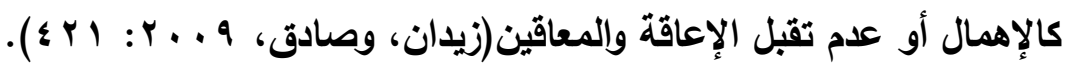
والتنوع في البيئة المدرسية -تطبيقاً لنظام الدمج - سلاح ذو حدين، فإذا كان التنوع في خصائص الطلاب، وقراتهم، وإمكاناتهم ، ومواهبهم مدعوماً بخدمات الإرشاد والتوعية ، ومراعاة الأمن النفسي والجسدي والاجتماعي والفكري للطلاب، فإن المجتمع المدرسي يزداد تماسكاً، ويدعم النمو المتكامل لشخصية الطلاب، إلا أن إساعة استخدام هذا التنوع، وزيادة وتيرة القلق والخوف والاضطرابات بين الطلاب العاديين وذوي الاحتياجات الخاصة؛ كل ذلك فئل يؤثثر - ولا شك- في مستوى الأمان المطلوب للبيئة المدرسية بشكل خاص والمجتمع بشكل عام، حيث إن إهمال متطلبات التعليم والتعلم لدى الطلاب يؤدي إلى تراجع مستوى الأمان ،

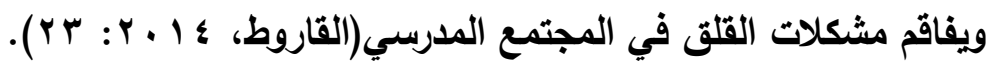
وقد تناولت العديد من الدراسات الأمن والبيئة المدرسية الآمنة من عدة جوانب؛

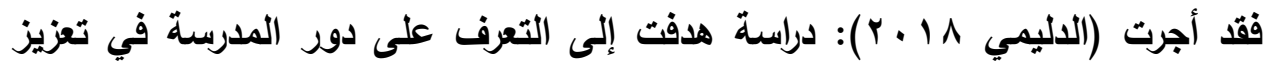
الأمن النفسي لدى طالبات المرحلة الثانوية ، واستخدمت المنهج الوصفي التحليلي ، وتبين

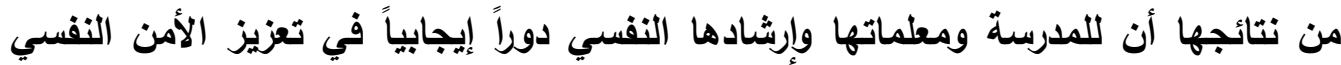
وخلق بيئة نفسية آمنة للمدرسة كمؤسسة تريوية تعليمية تؤدي دورها بسهولة ويسر.

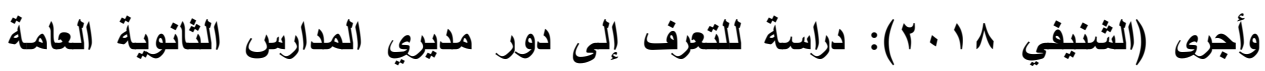
بمدينة الرياض في توفير بيئة تعليمية آمنة للطلاب من وجهة نظر المعلمين ، وتم استخدم

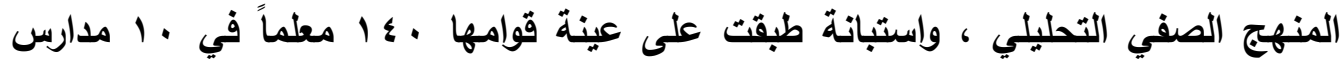
حكومية وأظهرت نتائج الدراسة أن قادة المدارس الثانوية يقومون بأدوارهم في توفير بيئة \%VV.9. تعليمية آمنة للطلاب بنسبة 


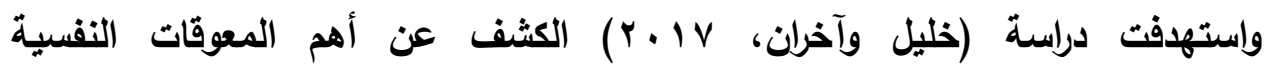
والاجتماعية لتجرية الدمج الثامل للتلاميذ ذوي الإعاقة بددارس التعليم العام بمحافظة

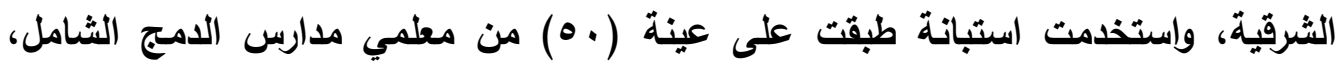
وكثفت النتائج عن أن أكثر المعوقات النفسية للامج الثامل تتمثل في : قلثة التذخلات النفسية للمدرسة للتظلب على المشكلات النفسية التي تطرأ على كل تلميذ، وعدم مساعدتهم في التظلب على الإحباطات التي تواجههم، وعدم تنفيذ أنثطة اجتماعية تثري العلاقة بين التلاميذ ذوي الإعاقة والتلاميذ العاديين، وقصور الامج الثامل في إثباع رغبات وميول التلاميذ ذوي الإعاقة النفسية، والقصور في التفاعل الإيجابي بين التلاميذ العاديين عذدما يمارسون الأنثطة مع أقرانهم ذوي الإعاقة.

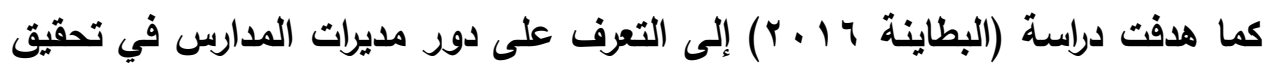
بيئة مدرسية آمنة في مدارس منطقة الباحة ، واستخدمت استبانة طبتت على عينة قوامها

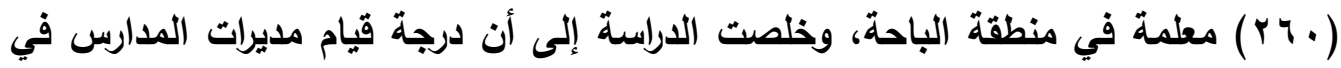
منطقة الباحة بأدوارهن في تحقيق البيئة المدرسية الآمنة من وجهة نظر المعلمات كانت التهات كبيرة.

وأجرى (جاب الله 10 +rم) دراسة تهاف إلى التعرف على مشكلات التدريس للطلاب ذوي الاحتياجات الخاصة في مرحلة التطليم الابتدائي بمنطقة القصيم من وجهة نظر المطلمين والمشرفين ومديري المدارس، واستخدمت المنهج الوصفي التحليلي، وتوصلت إلى أن هناك

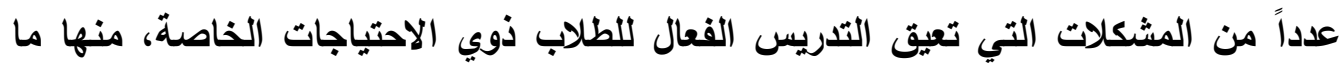

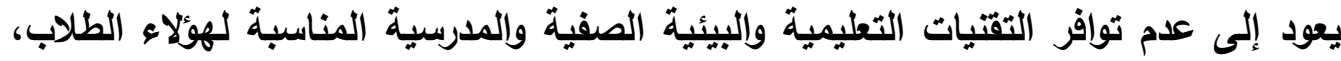
إلى جانب تعدد وتناقض اللوائح الإدارية المنظمة لتطليم وتطلم هؤلاء الطلاب.

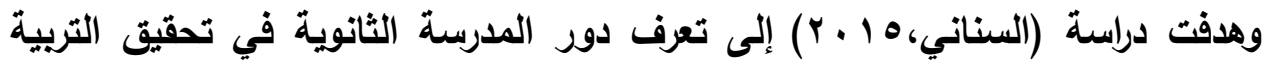
الأمنية لاى الطلاب في المدينة المنورة من خلال دور المطلم، والإرثاد الطلابي، والأنثطة الطلابية، والتعرف على المعوقات التي تحول دون تحقيقها في المدرسة الثانوية، واستخدمت التانية المنهج الوصفي التحليلي في بناء أداتي الدراسة : الاستبانة، ويطاقة تحليل محتوى، ويلغ التئية

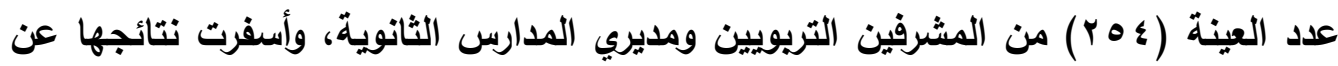


أن دور المدرسة الثانوية في تعقيق التربية الأمنية لاى الطلاب قد جاء بلرجة متوسطة، كما أن المعوقات التي تحول دون تحقيق التربية الأمنية لدى الطلاب كانت بلرجة مرتفعة.

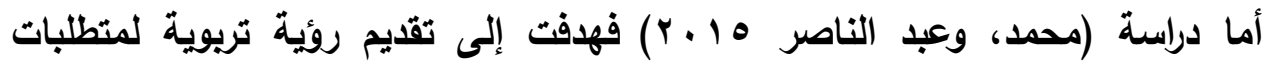
تحقيق التربية الأمنية بمرحلة التعليم الأساسي، من خلال الكثف عن واقع التربية الأمنية بالمرحلة الابتدائية واستخدمت الاراسة المنهج الوصفي التحليلي وتبين من نتائجها أن العملية التريوية الأمنية في حاجة ماسة إلى منهج علمي واضح المعالم يتم من خلاله تفعيل علاقة القطاعات الأمنية بالمؤسسات التعليمية. ويحثت دراسة جيتز وميكلنوش (Gietz, \& Mclnosh, 2014) تصورات الطلاب لبيئتهم المدرسية (على وجه التحديد : الأمان المدرسي ، والاندماج في المدرسة، والحالات التي تعرضت للتنمر) وعلاقتها بالتحصيل الدراسي، وشارك في هذه الدراسة (9 ج 9) من طلاب

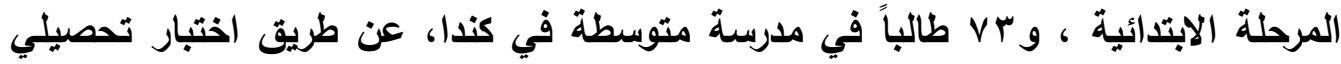

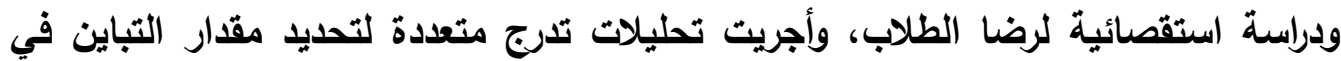
تحصيل الطلاب الأي تفسره تصوراتهم للبيئة المدرسية ، وأظهرت النتائج أن تصورات الطلاب

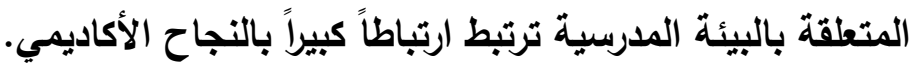
بينما هدفت دراسة (قطامي 9 . . ب) إلى الكشف عن مدركات الطلبة لبيئة التعلم الآمنة وعلاقتها بدافعيتهم للتعلم ، وتم استخدام المنهج الوصفي ومقياسين : مقياس بيئة التعلم الآمنة ، ومقياس الدافعية للتعلم، والتي تم تطبيقها على عينة عشوائية مكونة من (TV) طالباً وطالبة من طلاب الصف العاشر الأساسي بعمان. وأظهرت النتائج أن مستوى مدركات الطلبة لبيئة التعلم الآمنة كان متوسطاً، ووجود علاقة إيجابية دالة إحصائياً بين مدركات الطلبة لبيئة التعلم الآمنة ود/فعيتهم للتعلم.

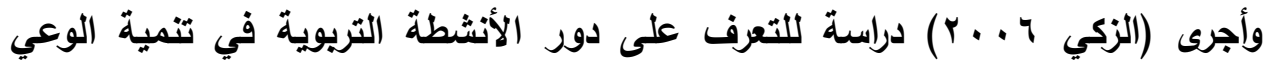

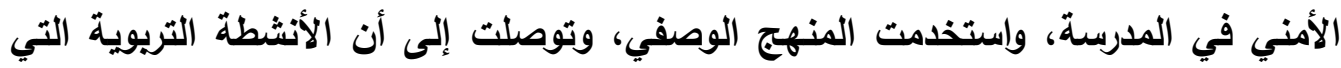
يمارسها الطلاب داخل المدرسة يمكن أن تحقق العديد من الأهداف والغايات التريوية التي قد الت التهي تعجز عن تحقيقها المقررات والمناهج النظامية. 
وأسفرت نتائج دراسة (الضمراني، ^ . . ب ) عن أن الأطفال الصم وضعاف السمع يجدون صعوية في التواصل والتخاطب مع الآخرين، مما يؤدي إلى ضيق الأبناء وتوترهم في كثير من المواقف، وأنهم يميلون إلى العنف الإثاري أو الجسدي واستخدام القوة البذنية في التعامل مع الإن الأشياء والأشخاص.

ويحثت دراسة (Koth, et al, 2008) التباين في تصورات الطلاب للمناخ المدرسي استناداً إلى مجموعة من العوامل الصفية والمدرسية، وتأثير تلك العوامل على تصوراتهر

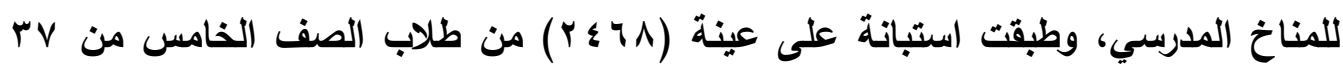
مدرسة ابتدائية عامة، وتوصلت النتائج إلى أن العوامل الفردية (العرق والجنس) تمثل أكبر نسبة من التباين في تصورات الطلاب للمناخ المدرسي، والعوامل المتعلقة بالمدرسة(حجم المبلة المدرسة، ودولان أعضاء هيئة التدريس)، ثم العوامل الخاصة بالفصول الدراسية (مثل بان خصائص المعلم، وحجم الصف، وتركيز الطلاب الذين يعانون من مشكلات سلوكية) وكلها عوامل هامة في تصور الطلاب للبيئة المدرسية، وأن مراعاة تلك العوامل يسهم في تحسين المناخ المدرسي. ويتضح من الدراسات السابقة أنها لم تهنم بتقديم تصور مقترح لتحول مدارس الدمج إلى بيئة مدرسية آمنة، فقد ركزت غالبية الدراسات السابقة على دور المدرسة الثانوية في لهابي

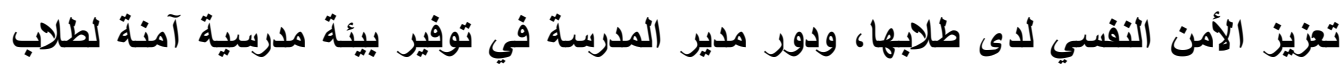

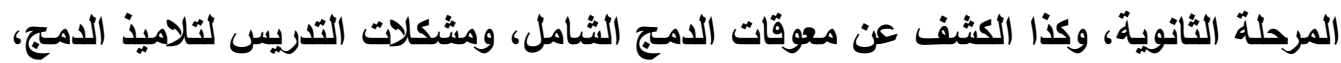
أو التعرف على متطلبات التربية الأمنية بالتعليم الأساسي، ودراسة العلاقة بين تصورات

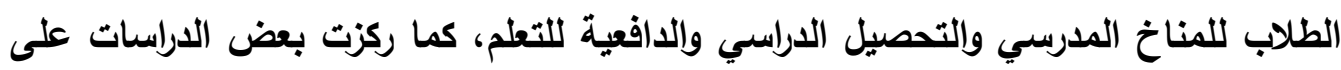
دور الأنشطة التربوية في تنمية الوعي الأمني وصعويات التواصل مع التلاميذ ذوي الإعاقة.

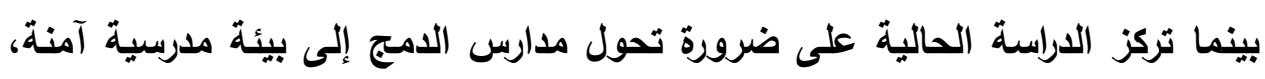
تلك المدارس التي تضم طلاب ذوي قدرات، ومهارات، وإمكانات متباينة، ولهم خصائص عقلية ونفسية ويدنية ومهارات اجتماعية مختلفة، ويينهم فروق فردية كبيرة، ويميل بعض طلابها

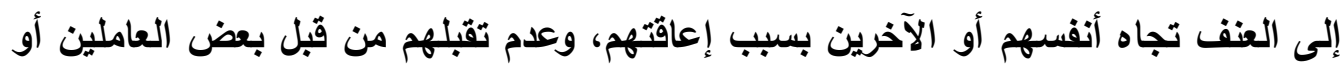
الأقران بمدارس الامهج، في محاولة للإسهام في نجاح نظام الامجج والحد من سلبياته. 


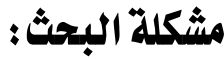

يعد توافر بيئة مدرسية آهنة أمر بالغ الأهمية للتنمية الأكاديمية والاجتماعية السليمة للطلاب، حيث تؤثر تصورات الطلاب للبيئة المدرسية على تحصيلهج الأكاديمي، ويكون الطلاب أكثر تركيزاً على التعلم، لذا ينبغي أن يسعى المجتمع إلى أن يكون الطلاب والعاملين

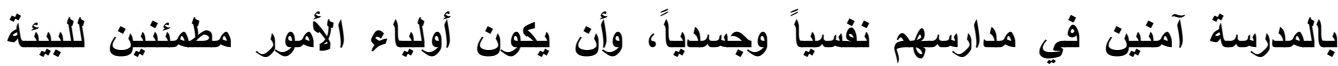

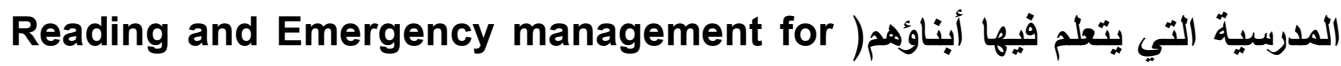
.(school, 2018, P.1

وتواجه الدرسة حالياً الكثير من الاتهامات بأنها أحد الأسباب الرئيسة في انتشار ظاهرة العنف في المجتمع، وهو ما يتناقض مع رسالتها الأولى ومسؤوليتها الجوهرية في تعديل وترقية السلوك السيء لاى التلاميذ، والواقع أن هناك الكثير من التوقعات التي يبرزها المجتمع في مجال التربية المدرسية بثأن تحقيق الأمن والسلامة لتلاميذها، بيد أن رسالة المدرسة يمكن أن تتحقق بشكل أفضل، فيما لو اتجهت ضمن أهدافها إلى تحقيق الأمن ونبذ الهب

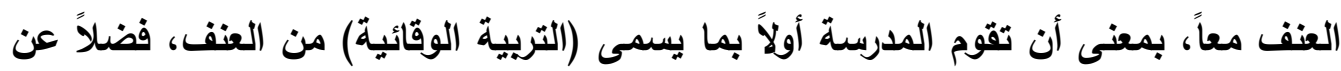
المشاركة الفاعلة في تفعيل الأمن المدرسي، وتحقيق مبادئ التربية الأمنية في الواقع التريوي

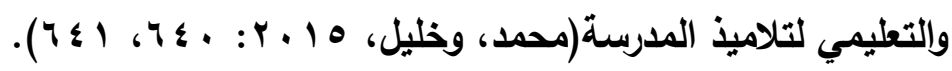
ويذكر المركز الوطني لإحصاءات التعليم (NCES) في تقرير مؤثرات الجريمة

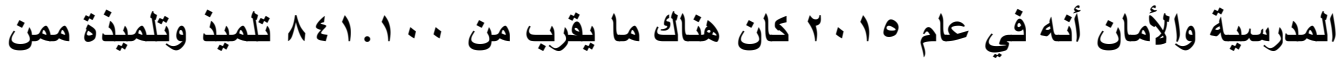

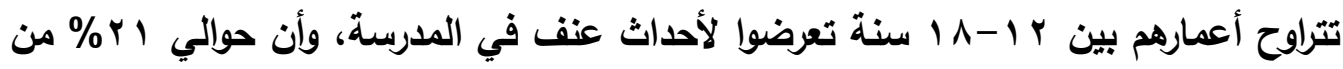
الطلاب في نفس المرحلة العمرية تعرضوا للتنمر في الددرسة خلال اليوم الداسيي( Reading .(and Emergency management for school, 2018, P.1 وتثير بعض الداسات المتعلقة بالجريمة والجنوح والتي أجريت في المملكة العربية السعودية أن معظم المجرمين بدأ انحرافهم بالهروب من المدرسة والانقطاع عن التعليم، وأن المستوى التعليمي متلنٍ لديهم حيث لم يكملوا تعليمهج(عبد المحمود، ب . . ب: ه ؛). 
والطفل المعاق الذي لم تتوفر له بيئة اجتماعية صحية ، تمكنه من النماء السليم، قـ يتعرض للحرمان أو الإساءة، أو الاضطرابات النفسية والعقلية، ويتعرض للانحرافات أو أو الو

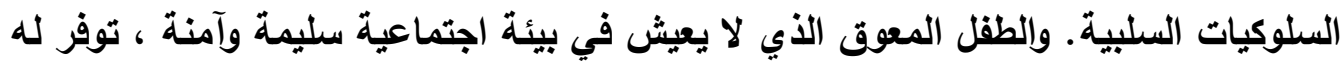

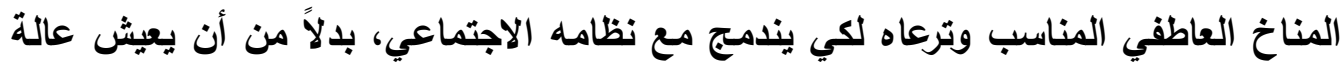

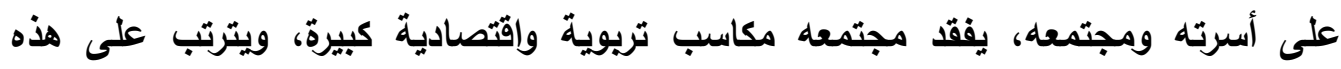

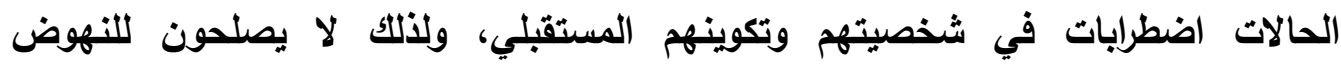

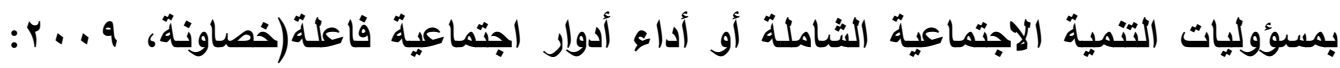

هذا ويعد إيجاد بيئة تعليمية آمنة يسودها روح التعاون بين المعلمين والمتعلمين والإدارة والمدرسة أمر ضروري لتنمية الدافعية للتطلم، فعندما يشعر المتعلم بالأمان تختفي حاجاته

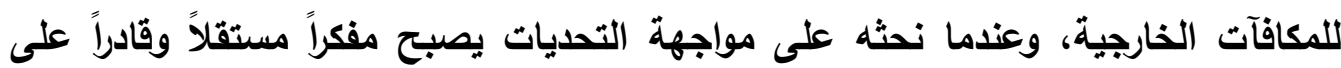

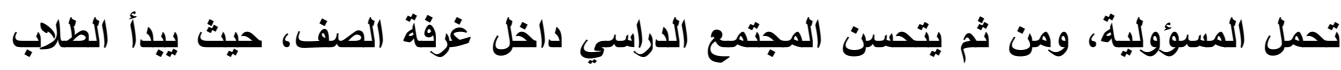

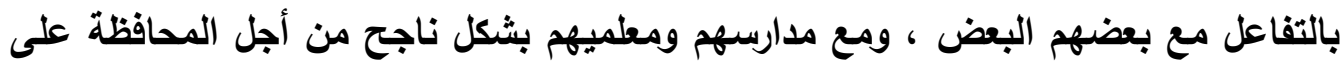

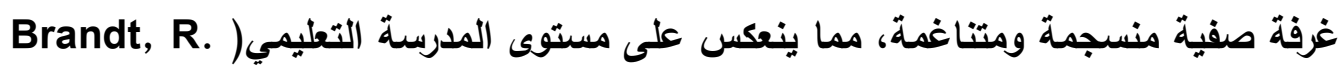
.(1995, PP.13-16

ومدارس الامج معنية بتعليم الطلاب العاديين وذوي الاحتياجات الخاصة، والإعاقة قد

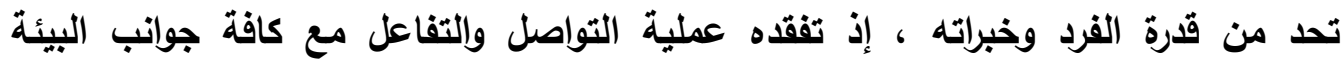
المحيطة به، وهذا الافتقاد له دلالة بالنسبة للأدوار التي يمكن أن يؤديها الطقل داخل الإطار

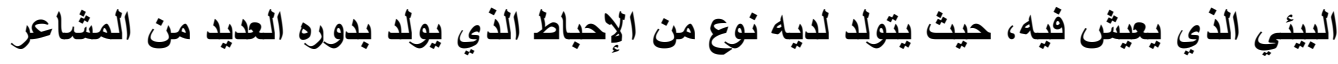
المختلفة من الغضب والعدوان نحو الآخرين، وهذه المشاعر والإحباطات تنعكس على تقدير الإهاطي

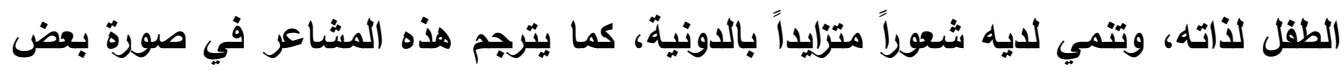

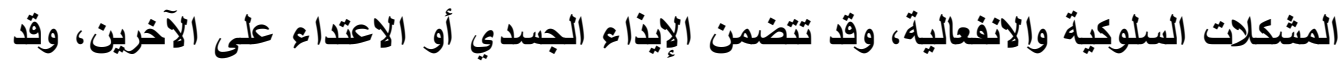

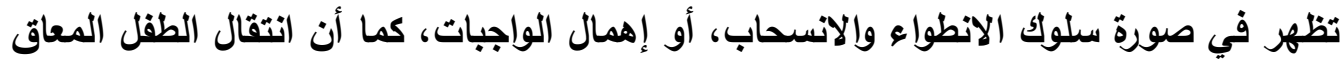
من الأسرة إلى الدرسة يؤدي إلى أن يواجه الطفل بعض الصعويات في التوافق مع زملائائه وميع المناخ المدرسي ككل، مما ينعكس بدوره على ظهور وتكرار المشكلات السلوكية، كما يعاني الأفراد المعاقون من تدنٍ في تقدير الذات ، ويعد الثعور بعدم القيمة تجرية مباشرة 
تعزز بالانتقادات السلبية والقاسية ، سواءً من قبل الأسرة أو المدرسين أو الأقران(كاشف،

$$
\cdot(V \cdot: Y \cdot \varepsilon
$$

ويرى بين باركر وليبر (Parker \& Lepper, 1992, 625-633) أن الجو التعليمي الآمن الذي يقدم فيه التعليم على أنه عملية ممتعة ، يعمل على ازدهار الدافعية للتعلم وتقويتها عند المتعلمين. وأكدات نتائج دراسة (محمد، وخليل، 10 • ب) أن هناك قصوراً واضحاً في تفعيل آليات التربية الأمنية وتدعيمها في جميع مدارس المرحلة الابتدائية في مصر، وأن العملية التربوية الأمنية في حاجة ماسة إلى منهج علمي واضح المعالم، كما يفتقر تحقيق الأمن المدرسي إلى التخطيط الواعي والواقي من جانب القائمين على التعليم في مختلف المراحل التعليمية. وأظهرت نتائج دراسة (Gietz, \& Mclnosh, 2014) أن تصورات الطلاب المتعلقة بالبيئة المدرسية ترتبط ارتباطاً كبيراً بالنجاح الأكاديمي، وقدمت توصيات لتعزيز البيئة المدرسية

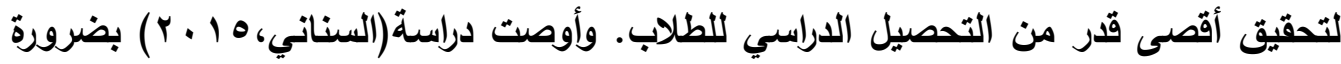
تثكيل لجان متخصصة على مستوى وزارة التربية والتعليم لوضع حلول مناسبة للمعوقات

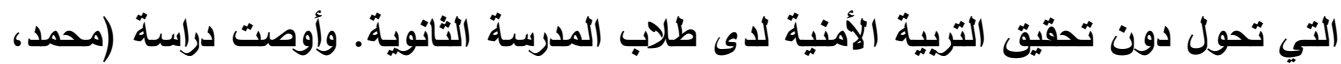
وعبد الناصر، 10 ـ ب) بضرورة وضع مواد دراسية حول الوقاية من الجريمة وكيفية تحصين

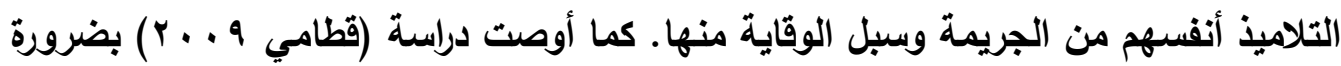
الاهتمام بتحسين البيئة الصفية ، وتثجيع وتدعيم ثقافة المدرسة الآمنة. وتتفق دراسة كلاً من توماس ويويير(Thomas \& Bauer, 1994) و(عبد الرحمن سليمان، 1. ..ب: ه1 11 ) على أن ذوي الإعاقة السمعية أقل قبولاً من الأقران العاديين، وأكثر دونية، ويجدون صعوية في إقامة علاقات صداقة، ويعانون من مشكلات التوافق الاجتماعي، وعلاقات التفاعل الاجتماعي التي تستلزم الضحك والكلام والمناقشة، كما أنهم أقل توافقاً من الناحية النفسية،

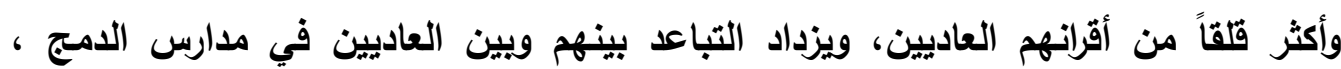

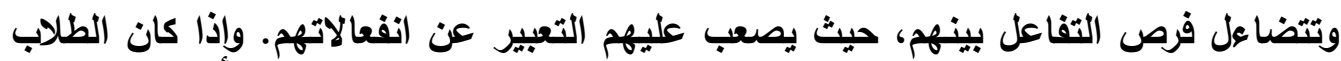
في البيئة المدرسية العادية في حاجة إلى بيئة مدرسية آمنة ، فإن طلاب مدارس الدمج إليها أحوج. لذا تتحدد مشكلة البحث الحالي في الحاجة الماسة إلى تحول مدارس الدمبج - التي تجمع بين الطلاب العاديين وذوي الاحتياجات الخاصة في بيئة تعليمية واحدة، ويتباين طلابها 
في الخصائص النفسية والجسدية، والعقلية، والمهارات الاجتماعية، والمنطلبات، والقدرات، والاهتمامات ويينهم فروق فردية كبيرة- إلى بيئة مدرسية آمنة، الأمر الذي دفع الباحثان للقيام بهذا البحث.

لذا بحاول البحث الحالي الإجابة عن السؤال الرئيس التالي:

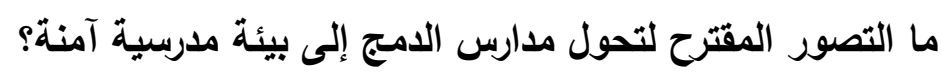
ويتفرع عن هذا السؤال الرئيس التساويلات الفرعية التالية:

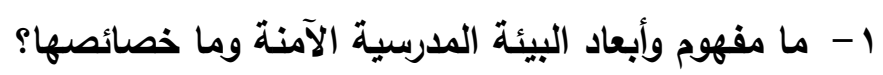

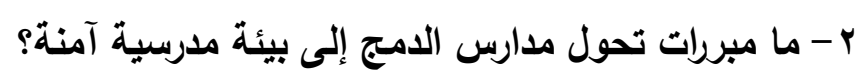
r- إلى أي مدى تختلف استجابات معلمي مدارس الامج حول أبعاد تحول المدرسة

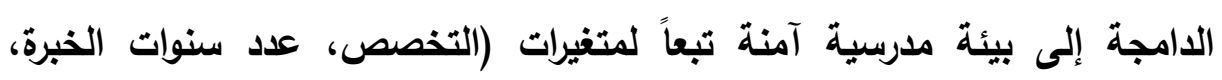

$$
\text { (النوع) }
$$

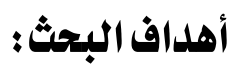

يستهدف البحث الحالي تقديم تصور مقترح لتحول مدارس الامج إلى بيئة مدرسية آمنة، لما لألك من أهمية في دعم نظام الدمج وتفعيل إيجابياته، ويالتالي الإسهام في نجاح نظام الامج، وكذا التعرف على مفهوم البيئة المدرسية الآمنة، وخصائصها، وأبعادها

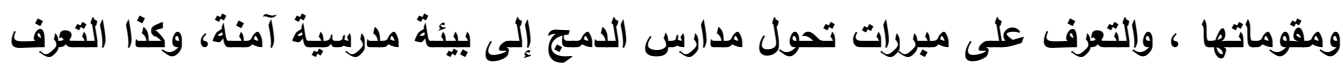
على الفروق في استجابات معلمي مدارس الامج في مصر والسعودية حول أبعاد تحول

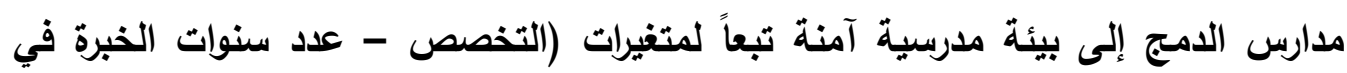
(التدريس- - النوع). 


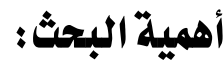

يستمد البحث الحالي أهميته من تعرضه لموضوع تحول مدارس الدمج إلى بيئة مدرسية

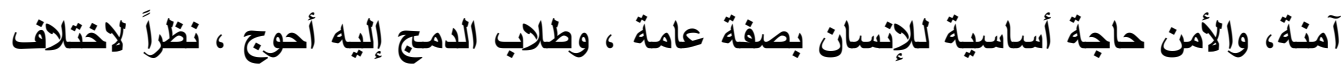
البيئة التربوية واختلاف القدرات والإمكانات والميول والاهتمامات، وتنوع الفروق الفردية بين الطلاب بارجة كبيرة، وتنوع السمات والخصائص النفسية والعقلية والاجتماعية لايهم ، وهو ما يتطلب توفير بيئة مدرسية آمنة لتعزيز ثقة الطلاب بأنفسهم وتحقيق أمنهم نفسياً ويدنياً واجتماعياً وفكرياً، الأمر الذي يفرض ضرورة مدريه تحول مدارس الدمج إلى بيئة مدرسية آمنة.

\section{منهج البحث وأداته :}

اعتمد البحث الحالي على المنهج الوصفي التحليلي باعتباره المنهج الأمثل في تحديد مفهوم البيئة المدرسية الآمنة وخصائصها وأبعادها ومقوماتها، ومبررات تحول مدارس الدمج الدي إلى بيئة مدرسية آمنة، وبيان الفروق في استجابات معلمي مدارس الامج حول أبعاد تحول

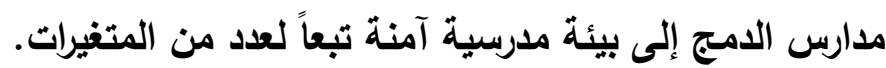

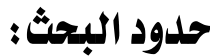

- - الحدود الموضوعية: تصور مقترح لتحول مدارس الدمج إلى بيئة مدرسية آمنة.

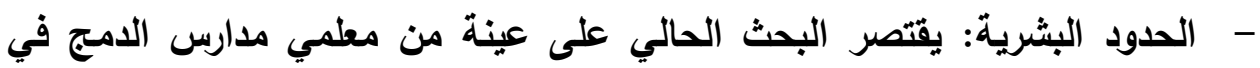
المملكة العربية السعودية ومصر. - الددود المكانية: اقتصرث الدراسة على عينة من مدارس الدمج بالمملكة العربية

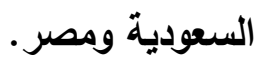

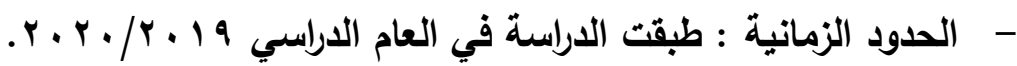




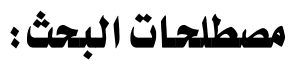

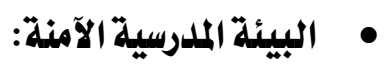

المدرسة الآمنة هي المكان الذي يستطيع فيه التلاميذ أن يتطموا ، ويستطيع المطلمون أن يقوموا بمهامهم في بيئة يسودها الدفء والترحيب، وهي المكان الذي ينمو فيه المناخ الدياخ

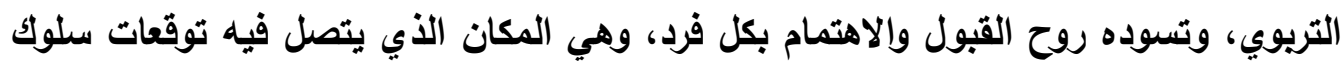
الأفراد وآمالهم بشكل واضح ويعزز فيه سلوك الأفراد بشكل ثابت ويتم فيه ممارسة السلوك بثكل واضح وشرعي(.(2001). (Souderton Area School District). وتعرف البيئة المدرسية الآمنة في هذه الدراسة بأنها: بيئة تعليمية منضبطة نفسياً

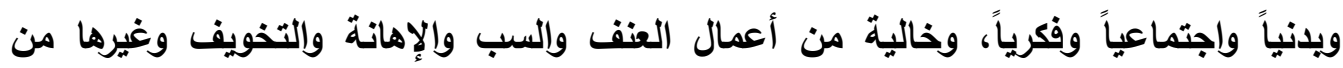
الأفعال العدوانية، وتعزن العلاقات الإيجابية والأمان لاى الطلاب والعاملين، وتتيح لهم الفرصة

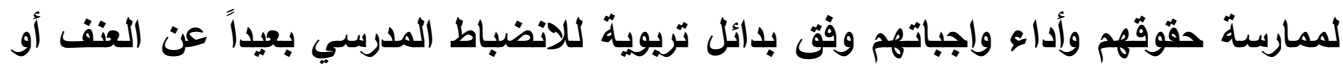
الإهانة أو التخويف.

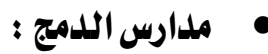

يثير مفهوم الدمج إلى: الأسلوب الذي يسمح بوضع الأطفال ذوي الاحتياجات الخاصة

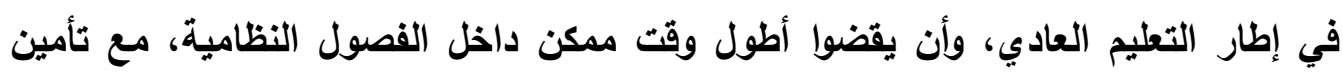

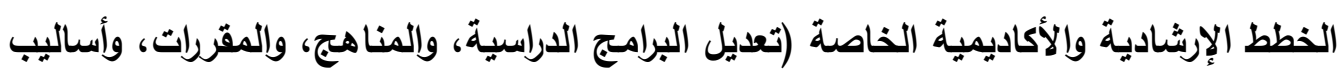

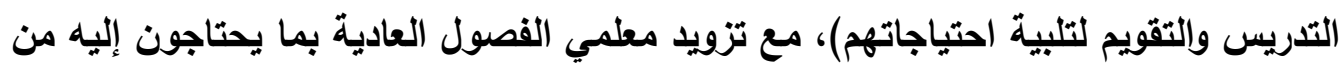

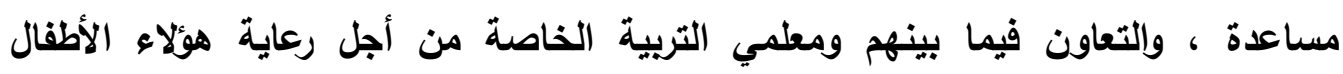

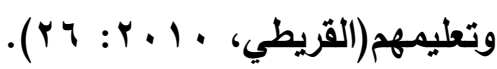
ويقصد بدارس الدمج في هذه الدراسة: الددارس العادية التي يتلقى فيها الطلاب العاديون تعليمهم مع أقرانهم من الطلاب ذوي الاحتياجات الخاصة وفق نظام الدمج. 


\section{الإطار النظري للبحث :}

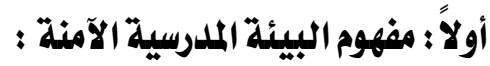

المعنى اللغوي للأمن: أمن: الأمان والأمانة بمعنى. وقد أمنت فأنا آمن، وآمنت غيري

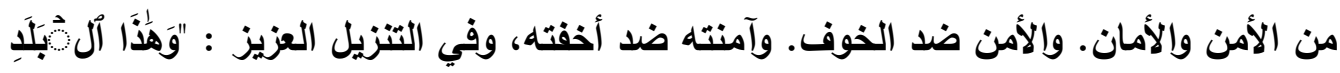

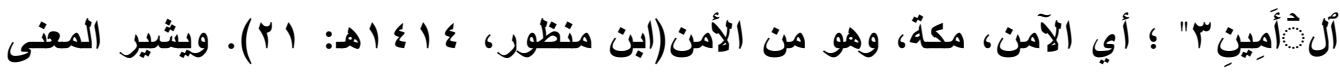

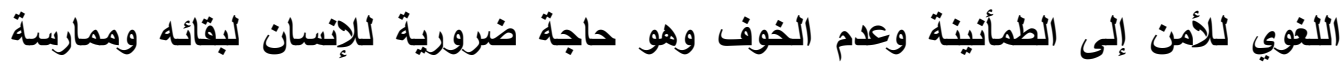
حياته.

واصطلاهاً: تعرف المدرسة الآمنة بأنها: بيئة تعليمية تمكن الطلاب من ممارسة

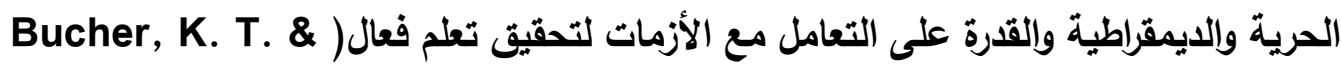
.(manning, M. L.(2003), PP.160-164 والبيئة الددرسية الآمنة هي: بيئة خالية من أعمال العنف والسب والثتتم والذوف وغيرها من الأفعال العدوانية بين الطلاب ، وخلق بيئة منضبطة وعادلة ومتساوية الفرص بين الإنة

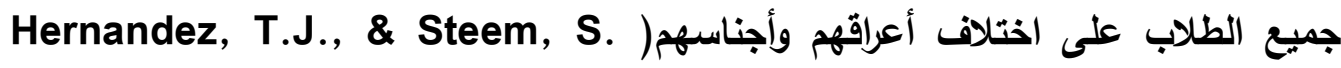
.(R.(2004), PP.256-262 والمدرسة الآمنة هي التي تقدم التدريب والخبرة والمساعدات المهنية لتأسيس بيئة

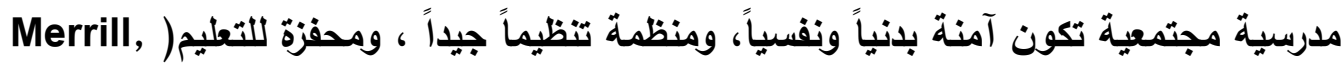
.(M. L, et al, 2012, 280-286 وعبر عنها (Merrow, 2004:19 ) بأنها: تلك المدارس التي تثثمل المناخ الددرسي العام الذي يسمح للطلاب والمعلمين والإداريين والموظفين والززوار بالتفاعل بطريقة إيجابية مع المهمات التعليمية للمدرسة، وتعزز العلاقات الإيجابية بين العاملين والطلاب، ومن ثم الأمان العاطفي والفكري للطلاب. ويعرف سكويلتش (Squelch. J. (2001), 138) الددرسة الآمنة بأنها: الددرسة التي تظلو من الخطر والأذى، حيث يستطيع المتعلمون وغيرهم والمطلمون أن يعملوا ويتعلموا

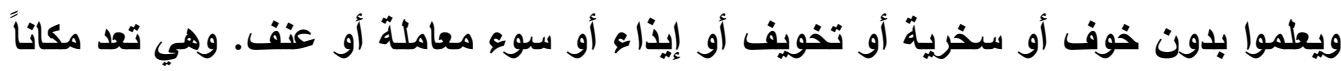
صحياً فهو آمن بدنياً ونفسياً واجتماعياً. 
وهي تلك البيئة التي تحمي رفاهية الطلاب النفسية والبلنية والاجتماعية، ويمكن للبيئة المدرسية الآمنة أن تحقق التعلم الفعال ويالتالي المساهمة في تطوير مهارات الطلاب وإنتاجية أعضاء المجتمع، وذلك يتطلب وجود مناخ نفسي واجتماعي إيجابي، ومشاركة الجميع في المدرسة (الطلاب- الإداريين- المعلمين- أولياء الأمور - والمستثارين التريويين، والتمريض...الخ)(78-77) :

ويمكن تعريف المدرسة الآمنة بأنها: المدرسة التي توفر المناخ المدرسي الشامل

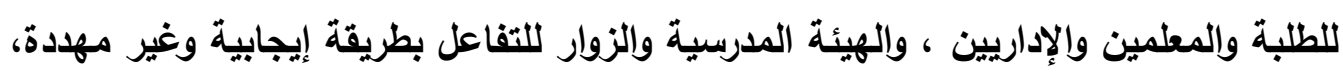

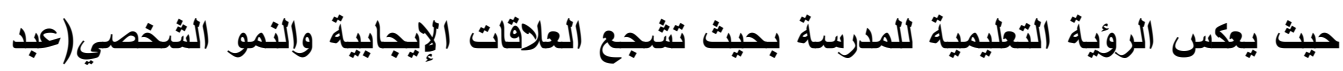

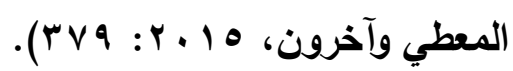

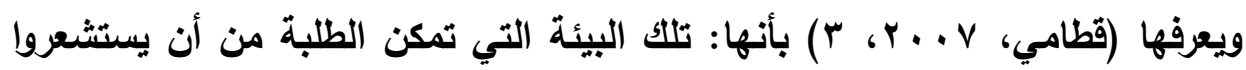
الأمن ، وإلحرية والايمقرطية، وإلحب، والدفء حتى يحدث التعلم".

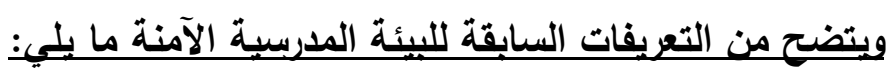
- أن البيئة المدرسية الآمنة تتطلب تخطيطاً وعملاً تعاونياً منظماً بين العاملين بالمدرسية بالتنسيق مع الجهات المعنية بتعليم الطلاب وأولياء الأمور لتوفير الدعم والمساندة اللازمة للمساهمة في توفير بيئة مدرسية آمنة.

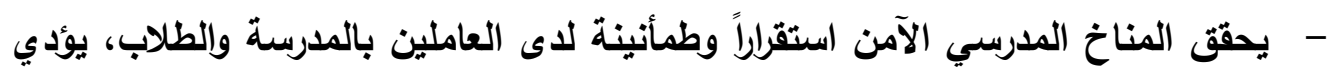

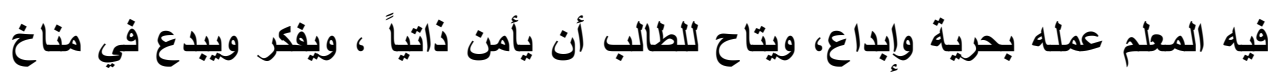
مدرسي تسوده الديمقرطية والمودة بين العاملين والطلاب ، ويين الطلاب ويعضهم البعض. - تلدعم البيئة المدرسية الآمنة التنوع والاختلاف ، فهي تدرب الطلاب على قبول الطلاب

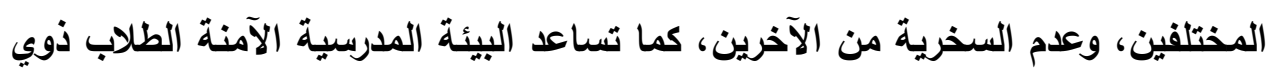
الاحتياجات الخاصة على تنمية مهاراتهم، الأمر الذي يسهم في إحداث التكيف الأبه الاجتماعي بين الطلاب العاديين وذوي الاحتياجات الخاصة، ويين الطلاب ومحيطهر الاجتماعي، وهو جوهر نظام الامج وهدفه الأسمى. 
ثانياً : خصائص البيئة المدرسية الآمنة :

ثمة خصائص وسمات تميز المدرسة الآمنة عن غيرها من المدارس ومنها أنها تركز على التحصيل الأكاديمي والعلاقات الإيجابية بين الطلاب والمعلمين والمجنمع المحلي، إضافة

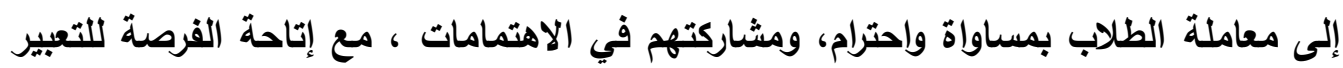

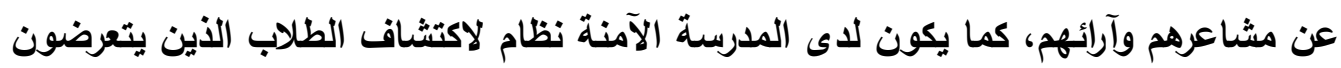

للعنف أو الإهمال(Dwyer, K. D., Osher, \& C. Warger.(1998), PP.3-5 ). ويحدد سابون (Sapon, 2010) خمس خصائص وميزات للمجتمعات التعليمية الآمنة

1- الأمان: فالبيئة الآمنة تسمح بالنمو والاكتشاف، ويمكن للطالب الذي يشعر بالأمان أن يجرب يخاطر ويغامر ويطلب المساعدة ويشعر بالفرح والابتهاج بإنجازاته. ץ- التواصل المفتوح: في البيئات الآمنة تؤخذ حاجات الطلبة والفروق الفردية بينهم بعين

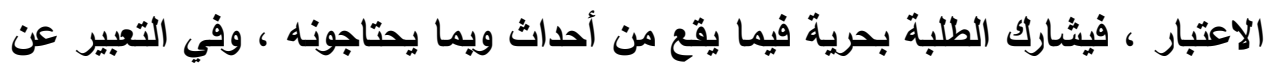
قلقهم، كون جميع الطلاب لهم الحق في الثُعور بالأمان. r- الحب المتبادل: يشجع الطلبة في البيئات الصفية الآمنة على التعرف على زملاء صفهر

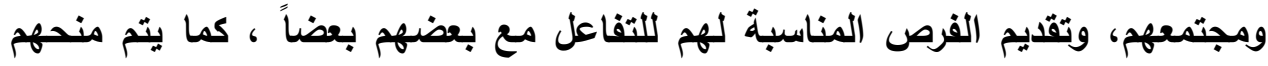
فرصاً واستراتيجيات أخرى لتعلم الإدلاء بآراء طيية تجاه زملائهم.

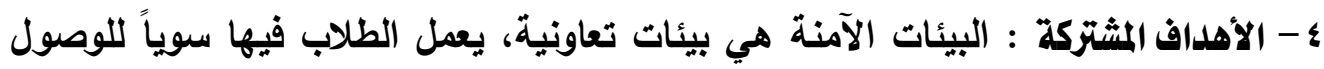

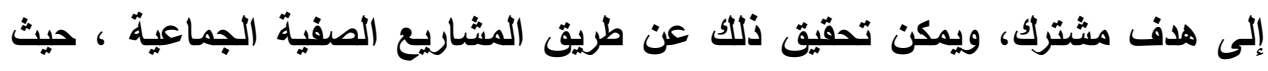
يعمل الطلبة على تحقيق هدف من الأهداف عن طريق التفاعل والدعم المشترك. هـ الترابطوالثقة : يشعر الطلبة في بيئات التعلم الآمنة بأنهم جزء من الكل، فهم يعرفون

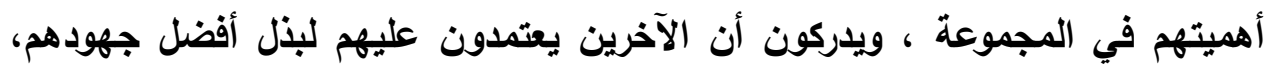
فالثقة والترابط يعنيان المشاركة بالأثياء بأفراحها وأتراحها". وأكلت الجمعية الأمريكية لتعليم العوم ( National Research Council

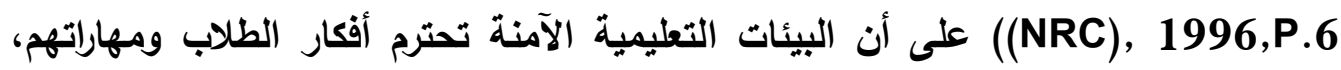


وتدعم التعاون بينهم، كما تعمل على تيسير الحوارات القائمة على فهم مشترك لقوانين الحوار

ويؤكد (Purkey, 1999) أن هناك خمس ركائز قوية للأمن المدرسي ينبغي أن تعمل

جميعاً في تناغم؛ حتى يتحقق الأمن والأمان في البيئة المدرسية وهي : الناس (People): فينبغي أن يعمل أعضاء هيئة التدريس والعاملون في المدرسة كأسرة واحدة؛ ولذلك ينبغي التدريب على التقليل من الضغوط، وإدارة الصراعات والعلاقات طويلة المدى بين الطلاب والمعلمين ، وضرورة الاحترام للجميع. الأماكن (Places) : فينبغي الاهتمام بالبيئة المادية للمدرسة بما فيها الإضاءة

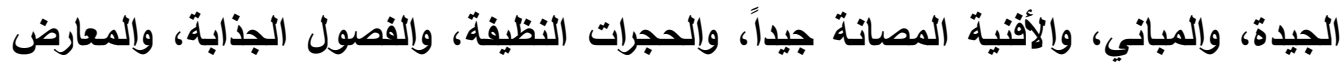
التي تعرض بها إنجازات الطلاب، وينبغي دعم البيئة المادية للددرسة أياً كانت قديمة. البرامج (Programs) : من البرامج العديدة التي تساعد على إيجاد المدارس الآمنة

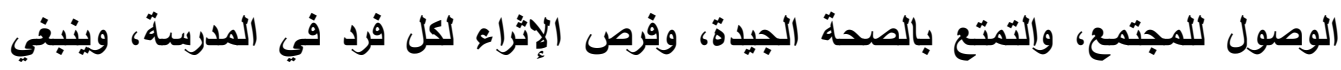

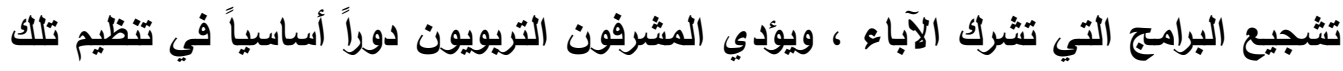

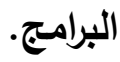

السياسات (Policies): ويتمثل ذلك في الحضور، وتنظيم الفصول والانتقال، Promotion

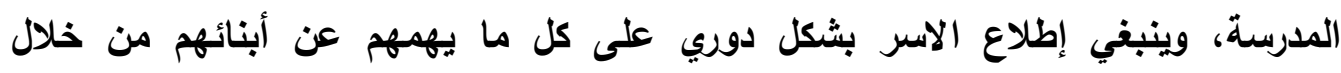

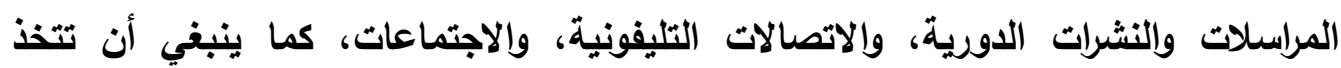

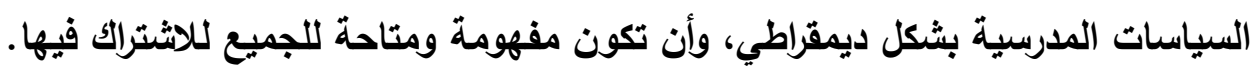
العمليات (Processes): العلمية هي الطريقة التي بها تؤدى الأثياء داخل المدرسة،

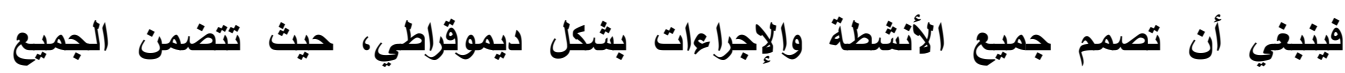
وتحترمهر، وإلمدرسة الجاذبة هي التي ترحب بكل الأفكار والمقترحات".

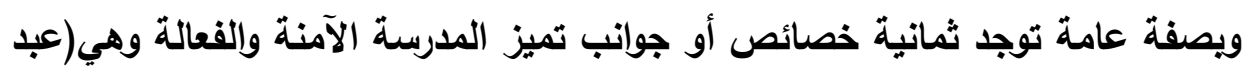

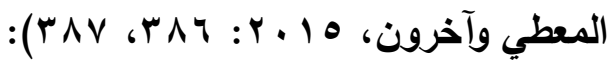


القيادة المهنية Professional Leadership : تبأ المدارس الآمنة بقادة المدرسة

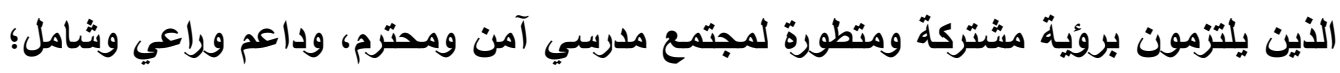

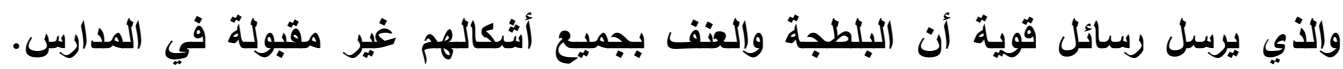

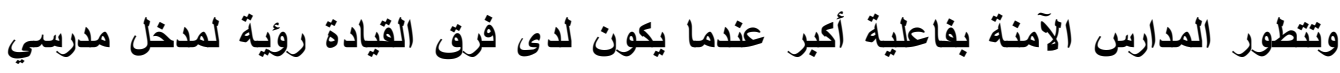
استراتيجي شامل تكون رفاهية الطالب ذات أولوية لايه، ويركز على منع العنف والوقاية منه

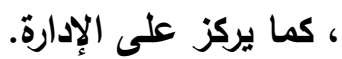

التركيز على التعليم والتعلم : Focusing on Teaching \& Learning : في التئ المدرسة الآمنة والفعالة يكون لاى المعلمين مدخلاً للوصول إلى فرص تعليم مهني ملائمة لتطوير وتحديث المهارات التي تمكنهم من العمل بتعاونية في إيجاد المدارس الآمنة الراعية

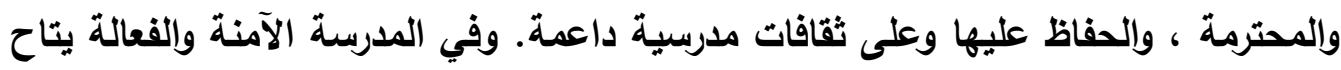
لعدد كبير من المعلمين الفرصة لتطوير المهارات نحو مناهج غير عقابية لمنع حوادث العنف والبلطجة في الدارس، وتقدم المدارس الآمنة والفعالة الفرص للهيئة العدرسية والطلبة للتعلم من البرامج المجتمعية خارج المنهج المدرسي المنتظم العادي لتحسين معرفتهم، وزيادة وعيهم، والتعرف على استراتيجيات التعامل مع العنف. الرؤية والأهداف الشتركة: Mutual Vision \& Objectives : تتحقق السيطرة على العنف والوقاية منه بسرعة أكثر في ثثافة المدرسة الآمنة الراعية المحترمة والداعمة ، والتئي تعزز العلاقات الإيجابية والقيم الاجتماعية. إن لاى المدرسة الآمنة والفعالة سياسة لمكافحة

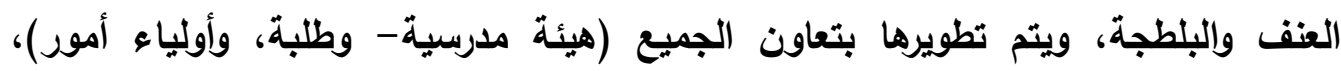
ويستغرق هذا بالضرورة وقتاً ، ومع ذلك فإن التعاون بعد مهماً بقدر أهمية وضع السياسة،

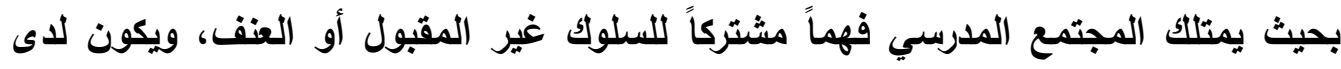
المدرسة توقعات محددة التعريف ومتفق عليها للأنواع المقبولة لسلوك الطلبة والهيئة التدريسية. وفي المدرسة الآمنة والفعالة يتلخل المعلمون بثبات وسرعة للسيطرة على أي الئي موقف عنف أو حادث بلطجة. وتعمل المدارس الآمنة والفعالة بالاشتراك مع الوالدين وأولياء

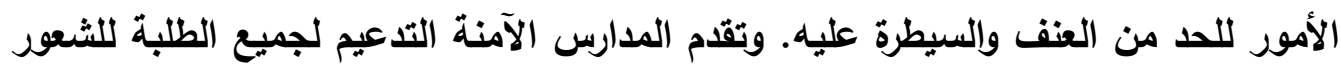
بالأمان ، وتؤكد على الدور المهم للمعلم في إدارة المواقف التي تحدث بها سلوكيات عنف. 
وتسهر الأنثطة اللاصفية مثل تدريس الأقران ، والتوجيه داخل المدرسة في تعزيز العلاقات

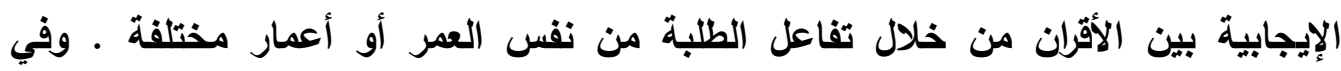
الددارس الآمنة والفعالة يعتنق الطلبة القيم الاجتماعية الإيجابية ويتصرفون بأسلوب محترم

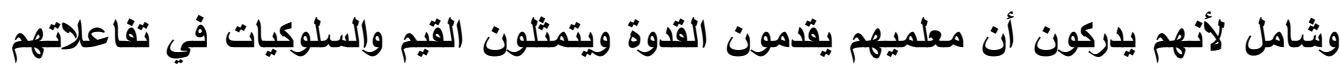

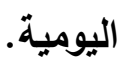

التدريس "التعليه" الهادف : Meaningful Teaching: توظف المدرسة الآمنة الفعالة العلاقات القائمة على المنهج التربوي مثل التطم التعاوني والتعلم القائم على حل المشكلات. وتسهم في تقام الطلبة والعلاقات الإيجابية بين الأقران. مجتمعات التعلم Learning Communities: في المدرسة الآمنة والفعالة تتعاون

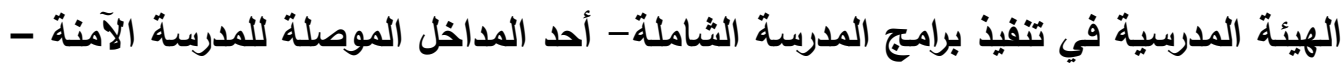
والإجراءات التي تقوي نوعية وجودة العلاقات بين الأفراد ، ويناء التعاطف والعمل بتعاونية.

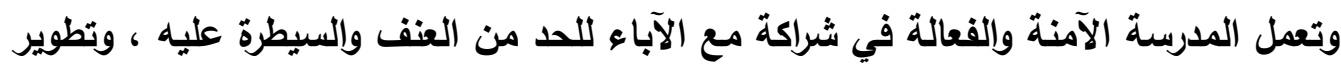

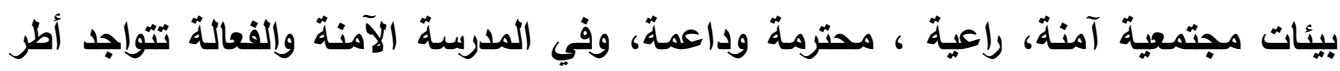
تستند إلى تدعيم الأقران والقيادة الطلابية الأصلية وملكية الطالب. كما تقدر العدرسة الآمنة

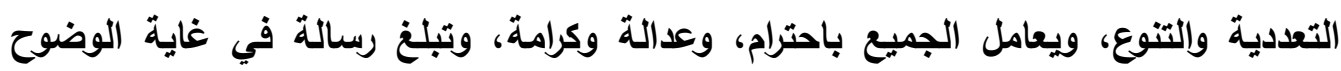

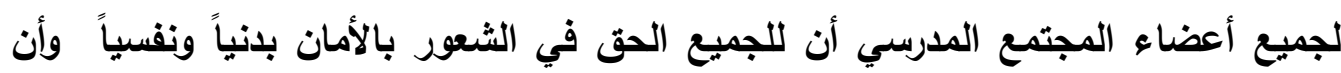
ضمان هذه السلامة مسؤولية الجميع. المحاسبة Accountability: تراقب المدرسة الآمنة والفعالة ذاتياً ويانتظام مستوى حدوث العنف والبلطجة في العدرسة، وتراجع وتنقح سياستها في مكافحة العنف والبلطجة ومبادراتها الددرسية الثاملة الإيجابية والمؤيدة للقيم الاجتماعية. كما أنها تراقب البيئة الددرسية على أساس يومي، ولايها تقنيات التفذية الراجعة لضمان فعالية السياسات والعمليات. وتقدم الدارس الآمنة والفعالة مجموعة متنوعة من الطرق التي يستطيع الطلبة

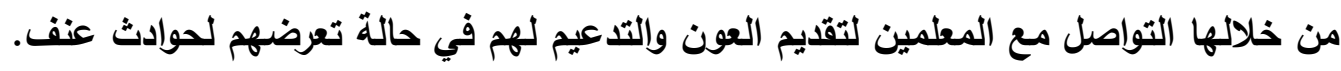
وتعمل المدارس الفعالة والآمنة بثكل نقدي على تقويم برامج إدارة والوقاية من العنف لضمان 
حيادها وموضوعيتها نظرياً، واستتادها إلى البرهان العلمي من حيث المحتوى، والمنهج التريوي وطريقة التوصيل، وأخذ ذلك بعين الاعتبار عند تنفيذ البرامج.

Motiving \& Securing Learning تحفيز وتأمين بيئات التعلم Environments فلسفة المدرسة. حيث توجد لايها برامج انتقالية قوية في المراحل المختلفة للعملية المدرسية ، لضمان تطوير جاهزية الطلبة للاخول إلى بيئات جديدة ، ولخفض القلق وزيادة المرونة". ثالثاً : أبعاد البيئة المدرسية الآمنة : أبمانه تتعدد أبعاد البيئة المدرسية الآمنة لتشمل الناحية النفسية والبذنية والفكرية والاجتماعية، وفيما يلي توضيح لتلك الجوانب: أ. البيئة الملدربية الآمنة نفسياً:

يعد الأمن النفسي أو الشخصي من المفاهيم الأساسية في علم الصحة النفسية ، ويرتبط الأمن النفسي والأمن الاجتماعي والصحة النفسية ارتباطاً موجباً.

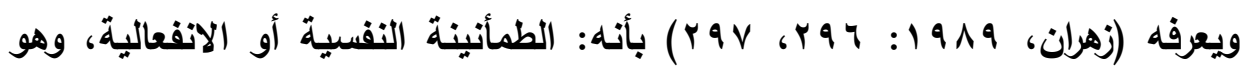
الأمن الثخصي أو أمن كل فرد على حدة ، وهو حالة يكون فيها إثباع الحاجات مضموناً وغير معرض للخطر، وهو محرك الفرد لتحقيق أمنه، وترتبط الحاجة إلى الأمن ارتباطاً وثيقاً بغريزة المحافظة على البقاء. وتهتم البيئة المدرسية الآمنة نفسياً بتكوين قوة الأنا لدى الأطفال، بحيث يعتمد الطقل على التقييم الذاتي أكثر من تقييم الآخرين، على أن يكون منفتحاً على التجرية ومتقبلاً

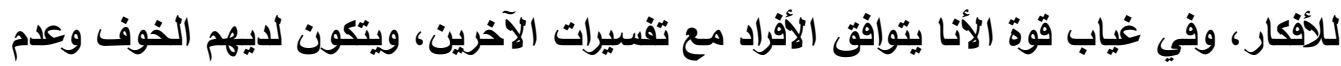
الثقة بأفكارهم الخاصة، وقوة الأنا مهمة بشكل خاص للمعلمين من حيث صلتها بالإبداع، ولأنهم يتمكنون من بنائها لدى الطلاب، بما يسمح لهم بالوقوف في وجه ضغط الأقران

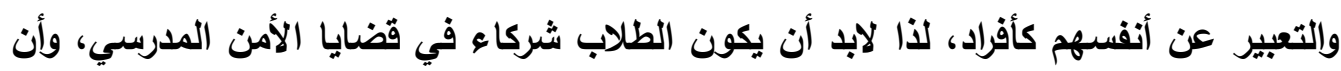

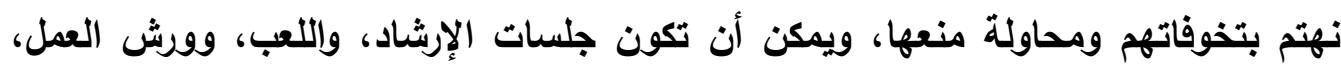
والتدريبات الافتراضية، والمسرح المدرسي وسائل فعالة لتنوير الطلاب والحد من مخاوفهر. 
ولتحقيق الأمن النفسي في الدرسة الآمنة ينبغي أن يرتقي دور المعلم من الوصاية على الطلاب إلى تنمية الثقة والاحترام بينه وبينهم) (Sindhi, 2013, 79).

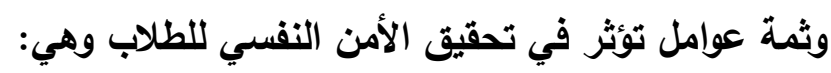
- عوامل نفسية: فتمثل البيئة أحد العوامل النفسية التي تؤثر في مثاعر الأمن والاطمئنان

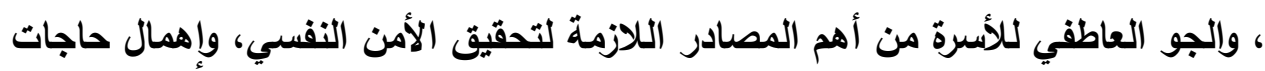
الطلاب وعدم إثباعها هو سبب الانحراف. - عوامل اجتماعية : يزداد شعور الفرد بالأمن النفسي عندما يكون قادراً على التكيف مع الآع

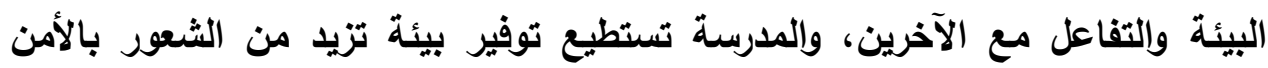
النفسي للطلاب، لأن الثخص القلق يجد الراحة أو الأمن بصدبة الآخرين.

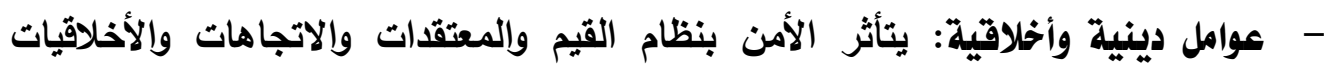

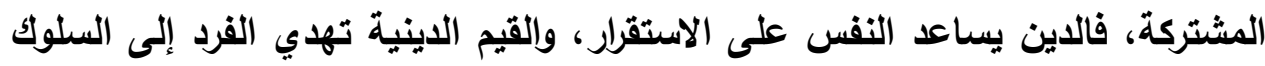

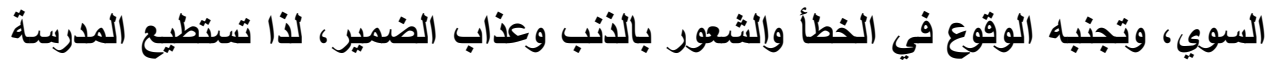
أن تغرس القيم لاى الطلاب من خلال المعاملات اليومية والسلوكيات المختلفة داخل

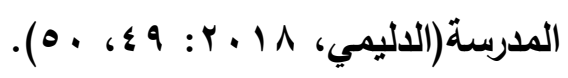

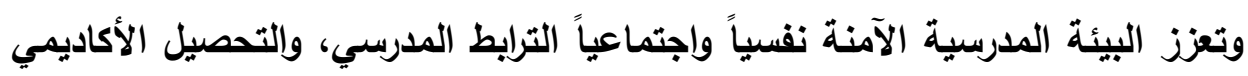

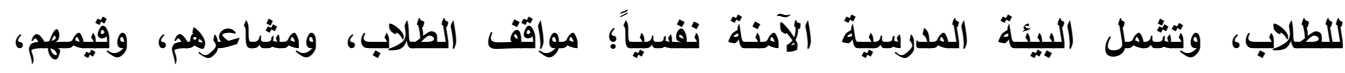
والاعتراف بنجاحاتهم واحتياجاتهم ودعم تعلمهم (Sindhi, 2013, 81).

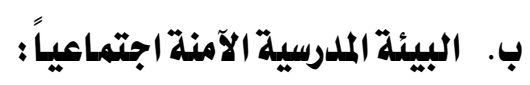
يعد التوافق الاجتماعي للطلاب أحد الجوانب الأساسية للبيئة المدرسية الآمنة، ومن

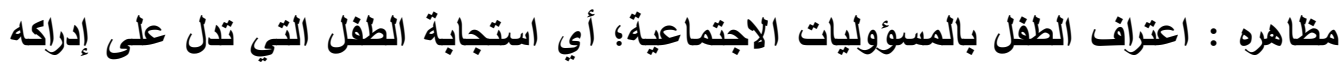

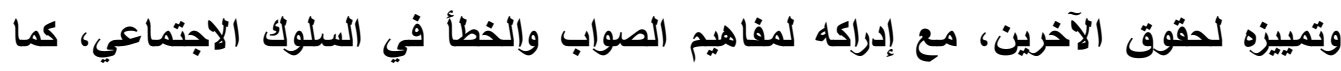
يكتسب الطفل المهارات الاجتماعية؛ أي أنه يبتعد عن الأنانية ، ويدرك العادية العات الاجتماعية

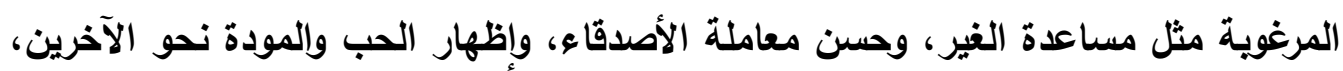

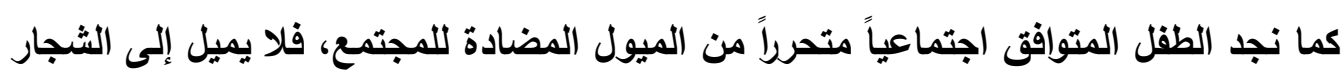

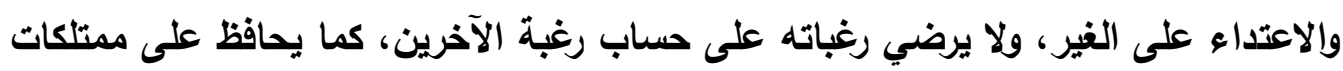


الغير ويطيع الأوامر ، ويشعر بأن أسرته تحبه وتعامله معاملة حنة تكفل له الأمن والاحترام،

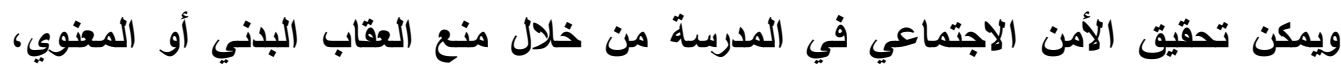
وتوفير المشاركة المجتمعية الفعالة من خلال تحسين وسائل الاتصال بين الأسرة والمدرسة، وإتاحة الفرصة للآباء للمشاركة التطوعية في الأنشطة المدرسية ومشاركة الآباء في اتخاذ

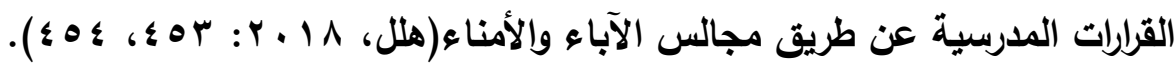

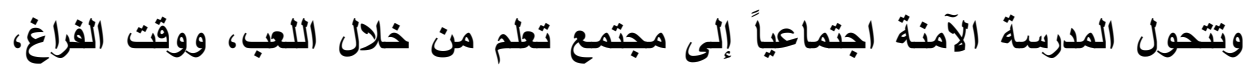

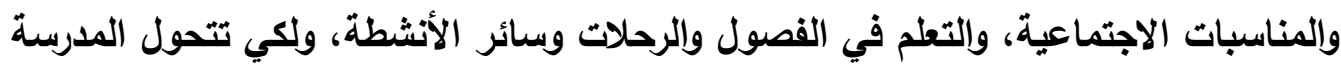
إلى مجتمع تعلم لابد أن يعمل المعلمون ومدير المدرسة على التخطيط وتتفيذ الإجراءات الروتينية المدرسية ، والامتحانات والتقويم، بحيث يتم تنظيم البيئة المدرسية والفصول الدراسية لدعم هذه التفاعلات وتعزيز عمليتي التعليم والتعلم(Sindhi, 2013, 81). ج. البيئة الملدرسية الآمنة مادياً: وتثمل ثلاث جوانب أساسية هي: الصحة الجسمية : ويقصد بها خلو البلن من المرض أو العاهة، ثم الصحة العقلية وهي: تنمية القدرات العقلية للطقل للقيام بعمليات التفكير والإدراك والتخيل، والصحة النفسية وهي: قرة الفرد على التكيف السليم مع نفسه ومع المجتمع المحيط، ولكي تؤدي المدرسة دورها في الجانب الصحي للطلاب لابد أن تراعي

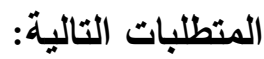

- الخدمات الوقائية : من خلال الكشف الطبي الدوري الشامل ، والتطعيمات، والنظافة ، وتقديم التوجيه والإرشاد والمعلومات لوقاية الطلاب من الممارسات

$$
\text { التي تضر بصحتهم. }
$$

- - الخدمات العلاجية: وهي الخدمات الطبية في المدرسة وصرف الأدوية اللازمة، بجانب إجراء فحوصات طبية دورية من خلال عيادات التأمين الصحي ، ويتم

$$
\text { تقديم العلاج مجاناً دون أي رسوم. }
$$

- الخدمات التأهيلية: وتثمل تزويد الأطفال ذوي الإعاقة بالأجهزة التعويضية

$$
\text { والمعينات الطبية لمن هم في حاجة إليها. }
$$

- - تقديم خدمات الإرشاد النفسي للطقل إزاء ما يتعرض لله من مشكلات(عطية،

$$
.(10: Y, \ldots \varepsilon
$$


وتثثمل البيئة المدرسية المادية مبنى المدرسة وجميع محتوياتها بما في ذلك الهياكل

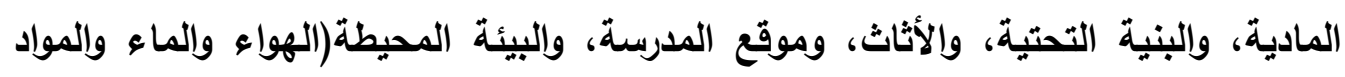

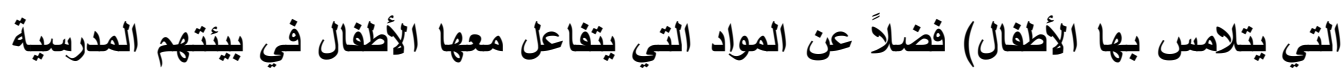

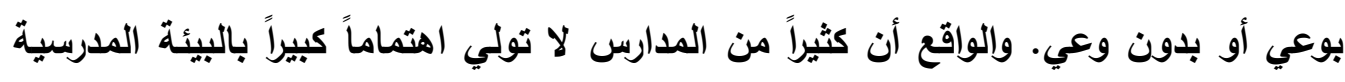

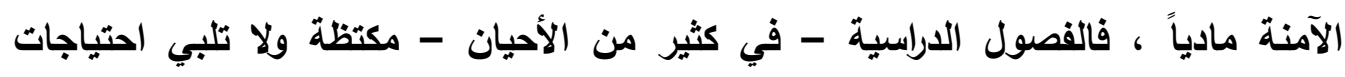

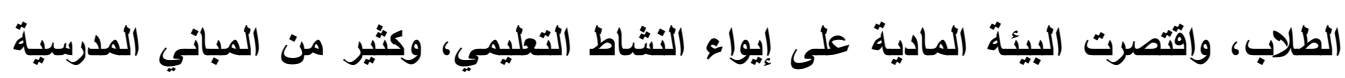

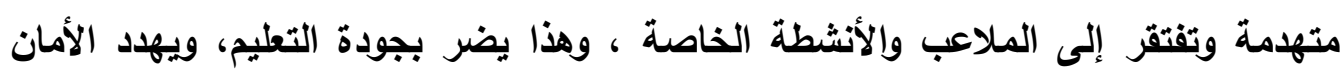
المادي للمدرسة (Sindhi, 2013, 80).

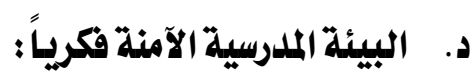

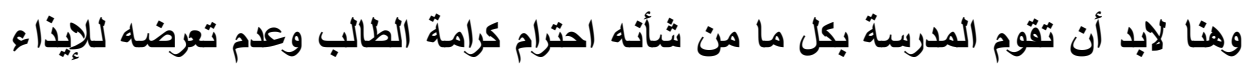

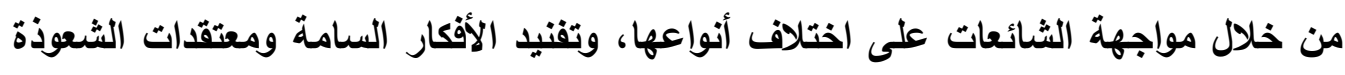

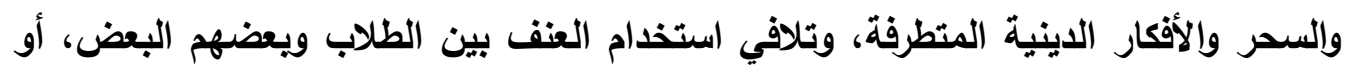

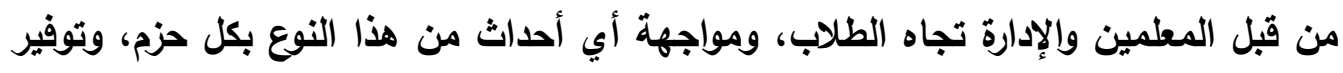

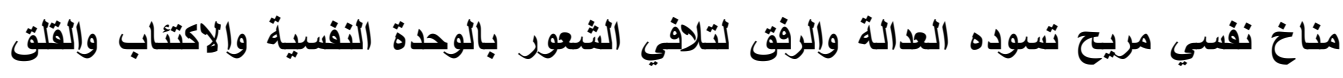

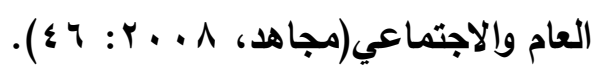


رابعاً : مقومات وعناصر البيئة الملدرسية الآمنة: ثمة مجموعة من المقومات لابد من توافرها لضمان بيئة مدرسية آمنة ومنها (أبو رياش، $:(1 \leq-1): Y \cdot 17$ المعلم: وهو أحد أهم هذه العناصر وأبعدها أثراً، وأكثرها ضرورة، ويكاد يكون القاسم المشترك لكل المقومات والمكونات الأخرى، فبقية المكونات تعتمد عليه في تفعيلها والقيام بدورها، لذا لابد أن يتحلى بجملة من الخصائص والسلوكيات في تعامله مع الطلاب أهمها:

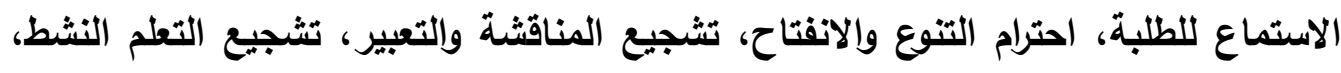
إعطاء وقت كاف للتفكير، تنمية ثقة الطلبة بأنفسهم، إعطاء تغذية راجعة إيجابية، تثمين

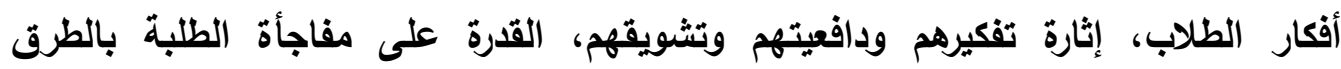
والأساليب والتنوع والتجديد، والإلمام بخلفيات الطلبة وظروفهم الأسرية والاقتصادية والعلمية.

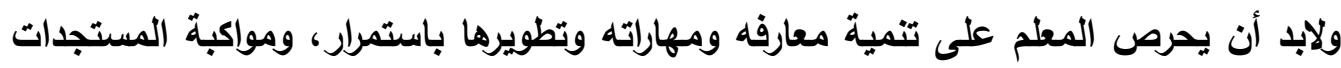
في تخصصه، والاطلاع على التجارب المماثلة في المدارس والدول الأخرى، وإثراء حصيلته الثقافية والحرص على تنوعها، والمعرفة الكافية بسير العلماء والمبدعين وظروفهم. ويقع على عاتق المدرسة والسلطة التريوية جملة من الأمور تتعلق بالمعلم منها: الحرص على لهى

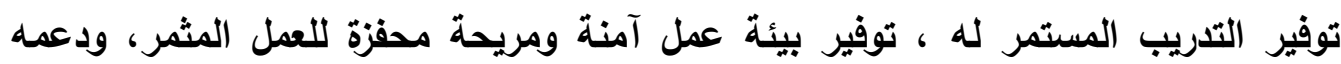
وتعزيزه، ومراعاة أن يكون نصابه من الحصص مناسباً للقيام بمهامه وواجباته على أكمل وتله وجه، وعدم إرهاقه أو إثغاله بمهمات إدارية قد تعطله عن القيام بعمله الأساسي، ويمكن أن أن يقوم بها غيره. الإدارة الملدرسية: يقع عليها عبء إدارة كل المكونات والعناصر لتحقيق الأهداف المرجوة، لذا يجب أن تتوافر فيها جملة من الخصائص والسمات ومنها : الخبرة والكفاءة، وأن تتميز بالمرونة والروح الديمقراطية والتفهم، وأن تتواصل مع جميع المعنيين داخل المدرسة وخارجها، وأن تدير الأزمات بكفاعة تحل المشكلات، وأن تتحمل الضغوطاته والته والعمل المتواصل، وأن تعزز الطلبة والعاملين، وأن تستطيع استقطاب الدعم من مؤسسات المجتمع المدني، وأن تقيم علاقات تعاون وثثة مع جميع الأطراف ، وأن تستجيب لداعي التطوير والتحديث، وأن توظف التكنولوجيا بفعالية، وتعممها على جميع العاملين كل حسب حاجته. 
المدرسة: وتتميز البيئة المدرسية الآمنة بمجموعة من الخصائص أهمها: ا. المبنى المدرسي المتكامل، المتسم بتوافر الخدمات الأساسية ، والبنية التحتية،

$$
\text { والسعة ، والمظهر الجمالي المريح. }
$$

r. الغرفة الصفية الواسعة، ذات التهوية الجيدة، المجهزة والمهيأة لعملية تعلم تعليم

$$
\text { على أعلى المستويات، وأفضل المواصفات. }
$$

r. المناخ المدرسي العام، المشبع بمبادئ المشاركة والعدالة والديمقراطية، المتمثل بتقبل إلمبل واحترام التتوع والاختلاف في الأفكار والاتجاهات، وتقبل النقد واحترام الرأي الآخر،

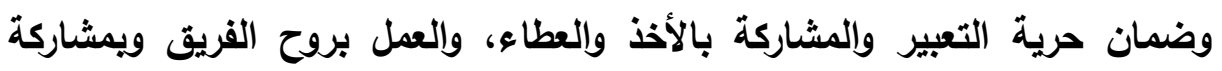
جميع الأطراف ذات العلاقة، وممارسة المواطنة في عدم التردد بطلب الحقوق مقابل القيام بالواجبات ، واحترام رأي الأغلبية والالتزام بما يترتب عليه.

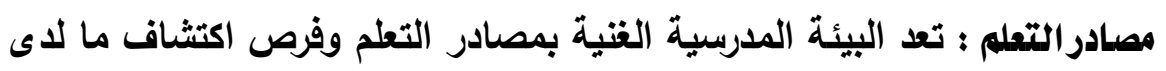

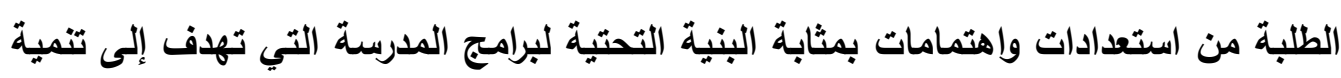
التفكير والإبداع؛ فالمدرسة الغتية بمصادرها التعليمية قادرة على توفير بيئة إيجابية لإثارة

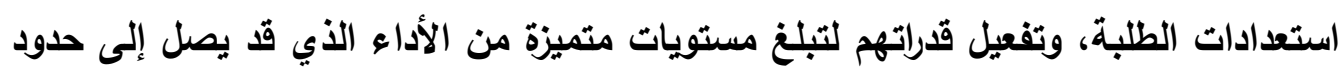

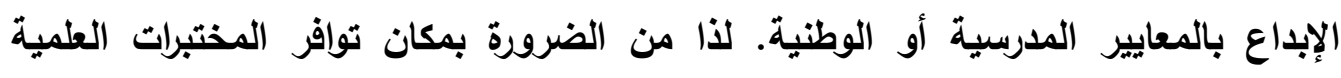
الكافية ، ومختبرات الحاسوب المتطورة، والمكتبة المدرسية الغتية المتجددة، والمرسم والمسرح

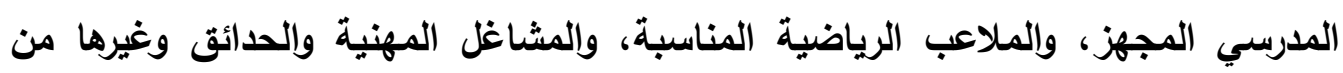
مصادر التعلم الضرورية. العلاقات الملدرسية : تشمل العلاقات المدرسية الإيجابية المعلمين والطلبة والإداريين، كما تثمل العلاقات مع أولياء الأمور والمجتمع المحلي، ويترتب على هذه المهيه

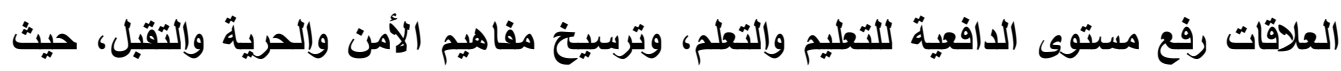
يسود الشعور بالرضا والثقة بالنفس والاستقلالية والرغبة في المشاركة. 
المنهاج المدرسي: ريما لا تستطيع المدرسة أن تغير المنهاج المدرسي لارتباطه

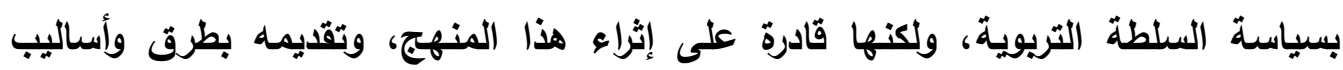

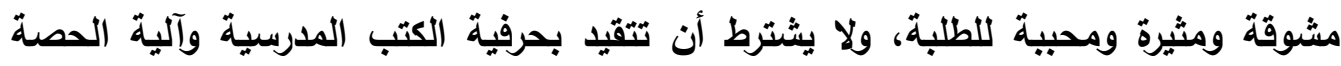
الصفية، بل بإمكانها أن تجعل الكتب المدرسية أساساً تبنى عليه الكثير من المهارات والتطبيقات والأنثطة ، بما يكفل تطلماً أفضل وأجمل وأكثر متعة وإنتاجية. توظيف تكنولوجيا الاتصالات والمعلومات: ينبغي أن تتوافر التقنية في المدرسة على أعلى المستويات حتى تستخدم بسهولة ويسر وفاعلية في جميع الجواتب التي يحتاجها

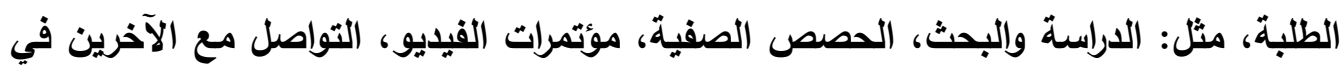

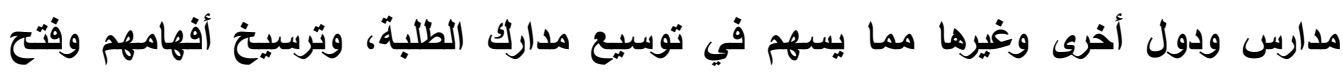
مجالات وآفاق عديدة أمامهر.

الأنشطة المدرسية : التي تعد نتاج مشاغل وورش تريوية تحقق نتاجات وأهداف مخطط لها، من تخطيط وإعداد وتنفيذ الطلبة، وتعبر في العادة عن مستوى أداء الطلبة،

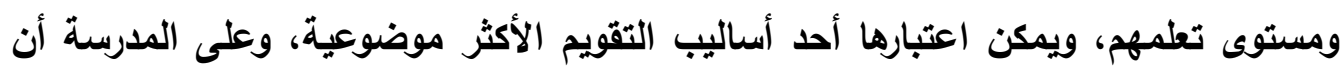

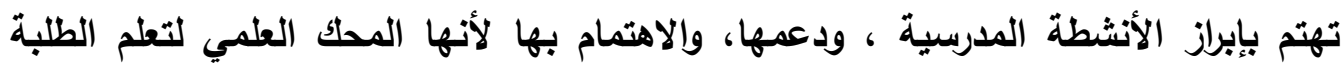
وأبرز أدوات تميزهم وإظهار إبداعهم.

السلطة التربوية: ويقصد بها الجهة المسؤولة عن المدرسة، والتي بيدها تعيين المعلمين، وتزويد المدرسة بما تحتاجه، وهي الجهة المشرفة إدارياً وفنياً على المدرسة.

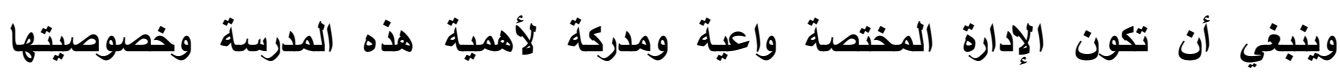

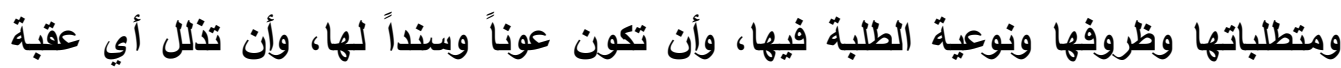
يمكن أن تقف في طريقها ضمن صلاحيتها ومسؤوليتها. أساليب التقويم: ينبغي استخدام أساليب جديدة لتقييم مستوى تقام الطلبة وإنجازاتهم، مثل تقييم المحكمين وتقييم الرفاق، والتقييم الذاتي، والبطاقة التراكمية وغيرها". 
خامساً : مبررات تحول مدارس اللدمج إلى بيئة مدرسية آمنة: يعرف الدمج بأنه : طريقة تسعى إلى التعامل مع حاجات التعلم لكل الأطفال والثثباب والبالغين والكبار، بتركيز خاص على من هم عرضة للتهميش والإقصاء. ويعني التعليم الدامج

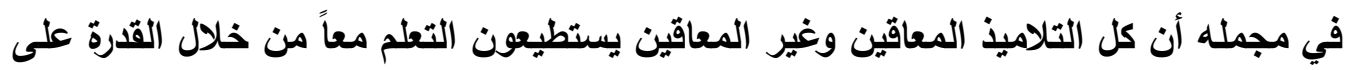
الوصول إلى إمكانيات التعليم أو رعاية الطفولة المبكرة، أو الالتحاق بالمدارس وأماكن التعليم

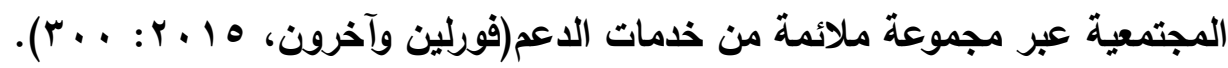
وقد ظهر مصطحان في الأدب التريوي الحديث وهما:(Integration) و و (mainstreaming)، ويشيران إلى تعليم الطلاب ذوي الإعاقة ضمن برامج التربية والتعليم

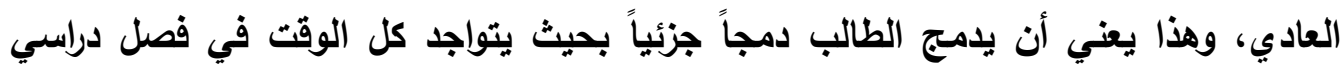

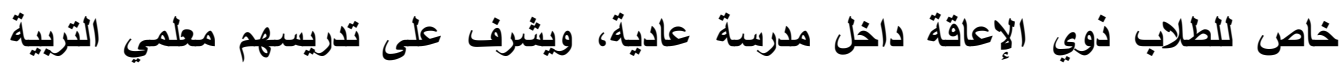
الخاصة، ولكنه يشارك الطلاب العاديين بكل الأنثطة التي تقيمها المدرسة خارج فصلهد

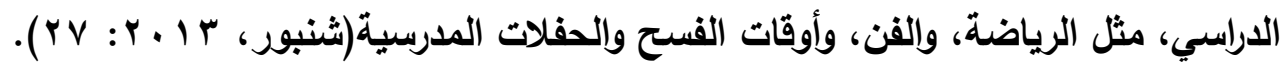
أما الدمج الثامل (Inclusion) فهو: نظام يتيح للأطفال ذوي الاحتياجات الخاصة الثانة

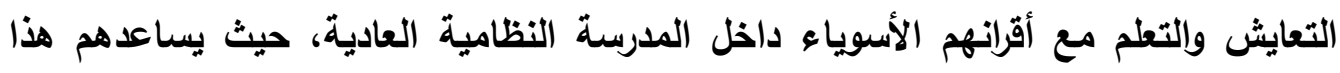
النظام على زيادة ثقتهم بأنفسهم واعتمادهم عليها قدر طاقاتهم وما يتوافر لايهم من إمكانات

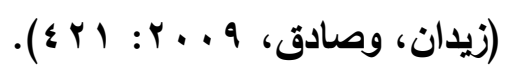

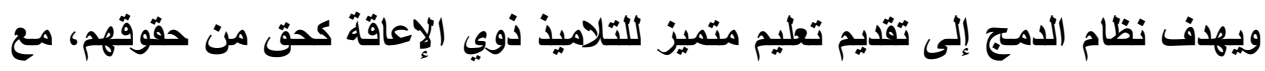

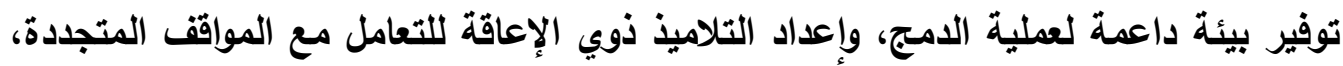
ومتابعة التطورات المتلاحقة، بما يتناسب مع احتياجاتهم وظروفهم ، إذ يهاف دمئ داعج الأطفال

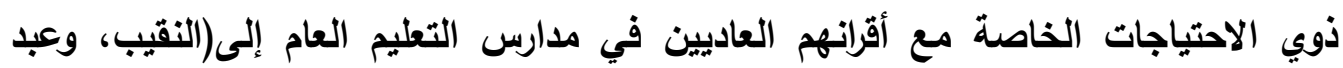

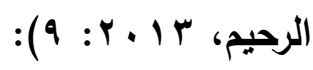

1- أهدف تعليمية: تتضمن توفير بيئة تعليمية تتيح لذوي الاحتياجات الخاصة ممارسة

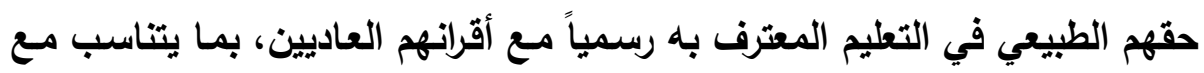

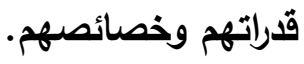


ץ - أهدف اجتماعيـة: تتضـح في تيسير عمليـة التنشئة الاجتماعيـة بين الأطفـال ذوي

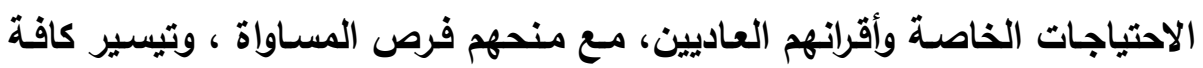

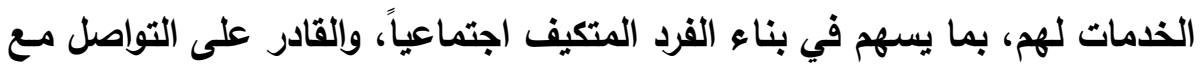
الآخرين، وعلى جانب آخر، تكوين اتجاهـات إيجابية لـى الأطفال العـاديين تجاه أقرانهم من ذوي الاحتياجات الخاصة، والتعرف على جوانب شخصيتهم واستعداداتهم للتعليم. r- أهـداف نقسية: تكمن في تنميـة شـور الأطفـال ذوي الاحتياجـات الخاصـة بـالأمن والطمأنينة في التعامل مع الآخرين، والثثة بالذات من خلال التعليم والمشاركة في الأنثطة المختلفة والحياة جنباً إلى جنب مع العاديين".

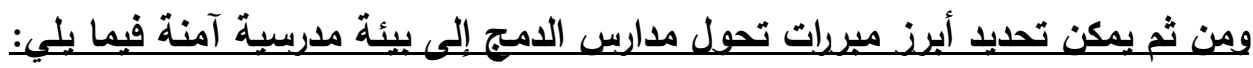

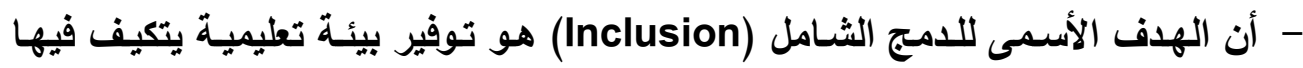

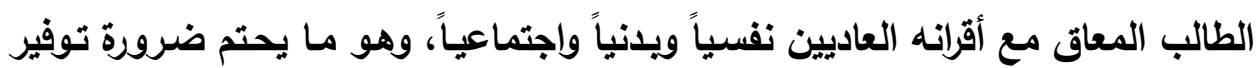
بيئة مدرسية آمنـة ترعى هذا التنوع وتنسـهـ في إطار قيمي أخلاقي حتى لا تتحول المدرسة إلى مسرح للتنمر وساحة لممارسة العنف ضد الطلاب المعاقين أو العاديين. - "أن الطلاب ذوي الاحتياجـات الخاصـة يحملـون الصسويات المصـاحبة لإعـاقتهم، فمـثلاً يحتاج عدد من التلاميذ إلى مساعد شخصي، أو مساعد تعليمي للأنشطة الرئيسية مثل التحرك داخل المدرسة، وحاجتهم إلى وقت إضافي سواءً للوصول إلى الصف أو إتمام

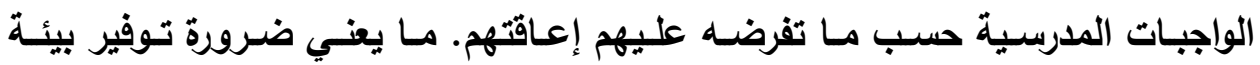
مدرسية مجهزة لمناسبة احتياجات الطلاب ذوي الإعاقة.

- عدم توفر الإمكانيات والوسائل التعليمية المناسبة لخدمة جميع الطلاب دون تمييز. - عدم وجود سياسات وتشريعات واضحة تضمن حقوق الطلاب ذوي الاحتياجات الخاصة داخل الصفوف العاديـة، وتـدني التعاون بين معلمـي التربيـة الخاصـة ومعلمـي التربيـة

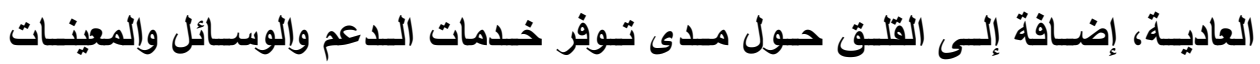

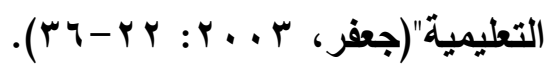


- تخوف الطالب ذو الإعاقة ، فهو غير مهيأ لعملية اللامج، وقد يكون لديه خوف من زملائه أو من المعلمين الجدد أو من إدارة المدرسة.

- قد يكون للامج أثر سلبي في زيادة الهوة بين الطلاب ذوي الإعاقة وياقي الطلاب في

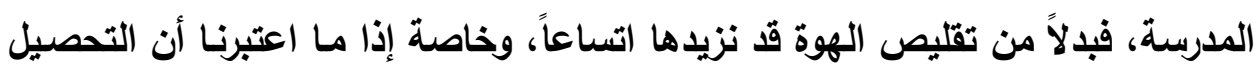

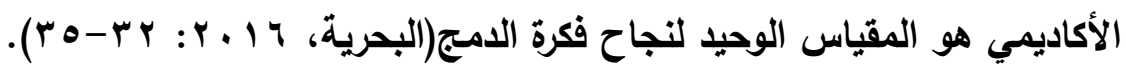
- إذا كان الطالب السوي يواجه الكثير من المشكلات في حياته، فالطالب ذو الإعاقة أيضاً يعـاني مـن مشـكلات عديـدة ومنهـا: مشـكلات مرتبطـة بالسـلوك العـدواني والتقلبـات

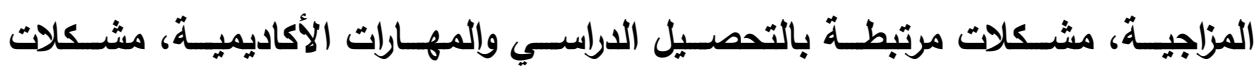

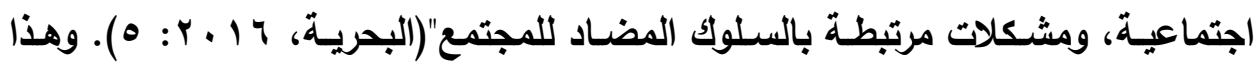
يتطلب تـوفير بيئة مدرسية آمنـة تعمل على حل هذه المشكلات أو الحــ منهـا قدر

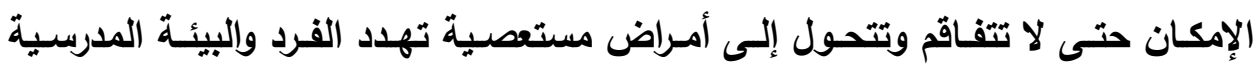
والمجتمع. - أن عدم الثـعور بـالأمن داخل المدرسـة يعد مصدراً لكثير من المشكلات النفسية التي يعاني منها الطالب، كالثعور بالنقص، وضـف الثقة بالنفس، وعدم القدرة على إقامـة

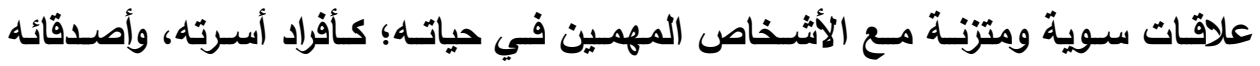

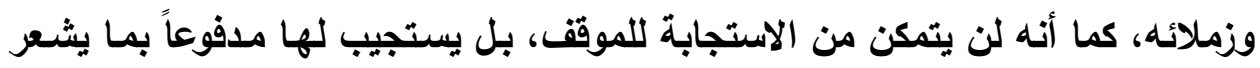

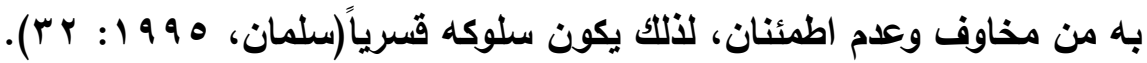
- تعد المدرسـة الآمنـة من المداخل العديثة التي تعمل على إيجاد بيئة مدرسية يسودها

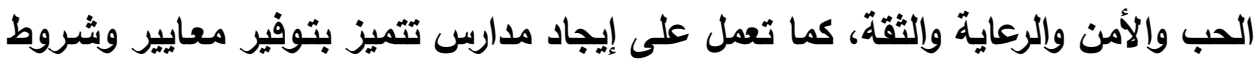
محفزة للتعليم وتطوير تفكير الطالب وإثراء خبراته، وتثـيع التفكير الإبـاعي وحريـة التعبير وقبول التنوع واحترام الرأي الآخر والعمل بروح الفريق، كما توفر المدرسـة الآمنة

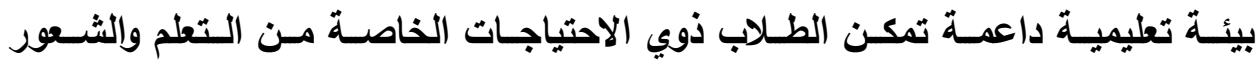

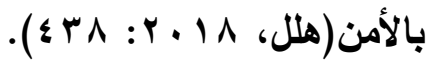




\section{ويناءً على ما تقدم بمكن استخلاص ما يليـ}

1 - يهرف دمج ذوي الاحتياجات الخاصـة مـع أقرانهم العاديين إلى تكافؤ الفرص التعليمية،

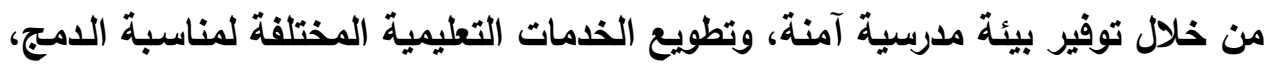

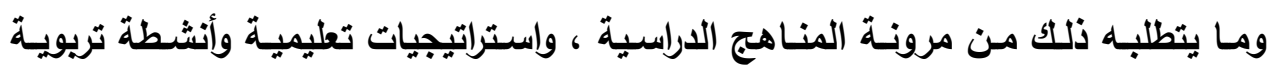
تراعي القدرات المتباينة للطلاب في ظل نظام الدمج، وذلتك لتمكين الطلاب ذوي الإعاقة من التفاعل الإيجابي وتكوين مفاهيم إيجابيـة نحو الذات، وتحقيق التكيف الاجتمـاعي

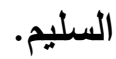

Y - أن مجرد دمـج التلاميذ ذوي الاحتياجـات الخاصـة مـع أقرانهم العـاديين لا يضـمن لهم التكيف والتعايش معهم دون توفير بيئة مدرسية آمنة نفسياً، واجتماعياً، ويدنياً وفكرياً.

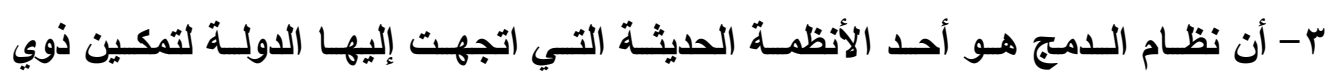

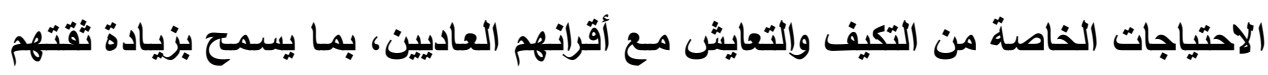

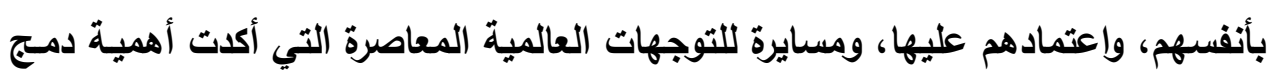
ذوي الاحتياجات الخاصة وخطورة عزلهم في أماكن مخصصـة بعيداً عن الحياة الطبيعية مع أقرانهم العاديين. ع - أن الدمج سلاح ذو حدين: فهو آلية لبناء الثقة لدى التلاميذ ذوي الإعاقة إذا مـا توفرت

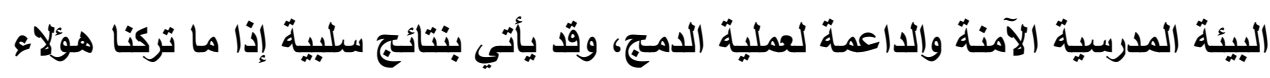
التلاميذ عرضة للسخرية أو التهكم والتنمر والعنف دونما إرشاد أو توجيه. ه - أن تهيئة البيئة الملائمة للامج هو بمثابة عنصر أسـاس لنجاح نظام الدمج، من خلال

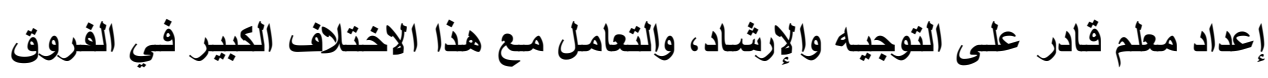

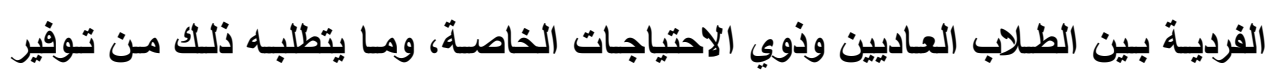

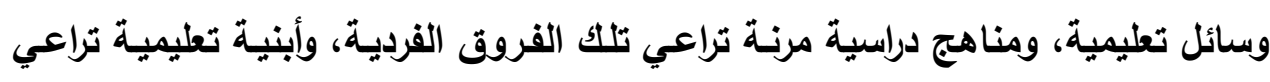

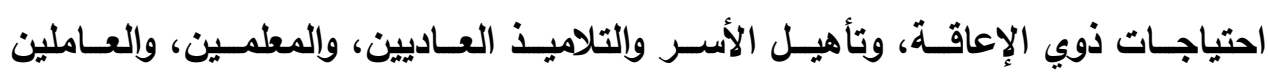

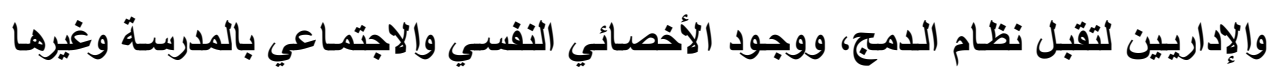
من المتطلبات. ويتضح مما سبق أن الطلاب والمعلمين في مدارس الامج بحاجة ماسة إلى بيئة

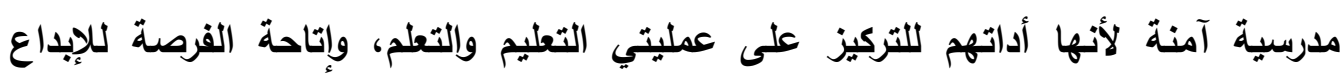


والتميز، وهي البيئة المناسبة لاستيعاب الطلاب في مدارس الامج، حيث التنوع في خصائص

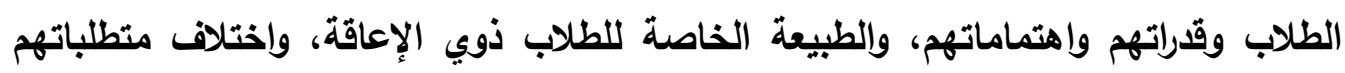

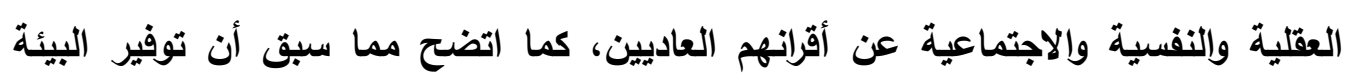

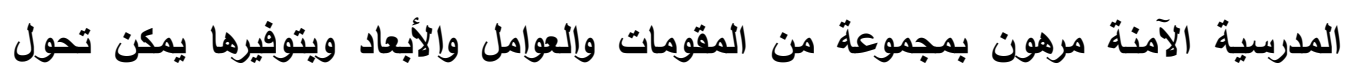

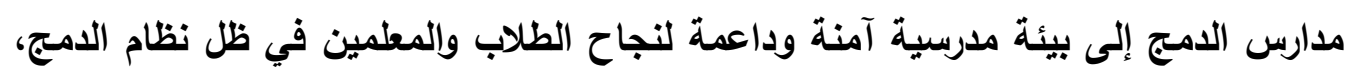

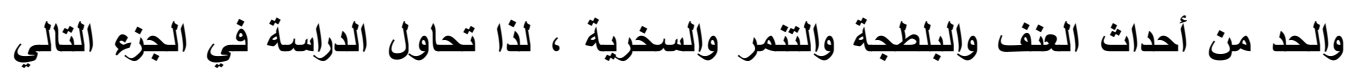
الوقوف على واقع أبعاد تحول مدارس الدمج إلى بيئة مدرسية آمنة. الدراسة الميلانية ونتائجها

يتناول هذا الجزء عرضًا منهجيًا للاراسة الميدانية وإجراءاتها ونتائجها، وذلك على النحو

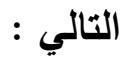

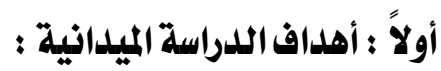

هدفت الاراسة الميدانية إلى التعرف على أبعاد تحول مدارس الامج إلى بيئة مدرسية

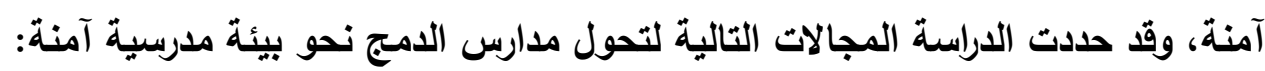
- الروئة والأهداف. • - الترابط والثقة والتواصل الفعال. • - القيادة المهنية. - التركيز على التعليم الهادف. • المجتمعات المهنية وبيئات التعلم.

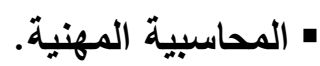


كما تستهدف الدراسة أيضاً التعرف على الفروق بين استجابات أفراد عينة الدراسة بحسب:

$$
\text { 1- التخصص (علمي - أدبي). }
$$

r- سنوات الخبرة (أقل من خمس سنوات ) (ه- • 1 سنوات) (أكثر من عشر سنوات).

$$
\text { r- النوع (ذكر - أنثى). }
$$

ثانياً : خطوات الدراسة الميدانية :

لتحقيق أهداف الدراسة الميدانية تناولت الاراسة الخطوات التالية:

$$
\text { 1 - - إعداد أداة الدراسة. }
$$

r - ت بديل مجتمع الدراسة وأفراد العينة.

r- تطبيق أداة الاراسة على أفراد العينة.

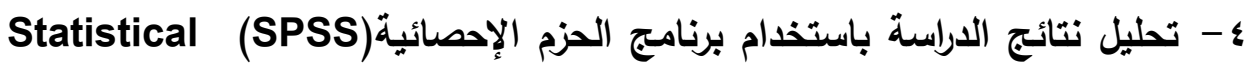
Package for Social Sciences

ثالثاً: منهج البحث:

هدف البحث الحالي إلى تقديم تصور مقترح لتحول مدارس الدمج إلى بيئة مدرسية

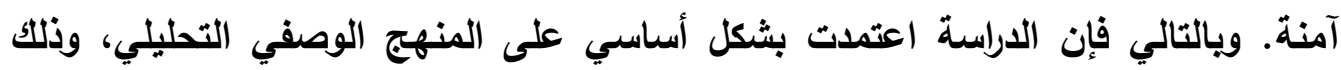
لملائمته لطبيعتها ومناسبته لتحقيق أهدافها.

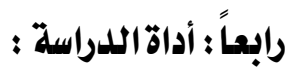
من خلال الرجوع إلى أدبيات البحث التربوي بالإضافة إلى الدراسات السابقة المرتبطة بمجال البيئة المدرسية الآمنة والامج والإطار النظري للاراسة الحالية تم إعداد الاستبانة كأداة لها، ثم عرضت الاستبانة على السادة المحكمين، الذين أبدوا ملاحظاتهم حول ملاعمة كل

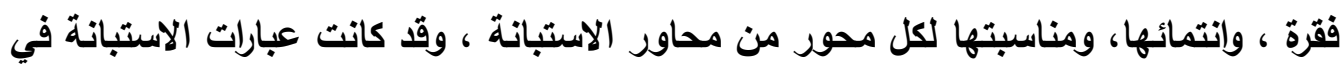
صورتها الأولية (19) عبارة ، وفي ضوء اقتراحات المحكمين وملاحظاتهم ، تم تعديل

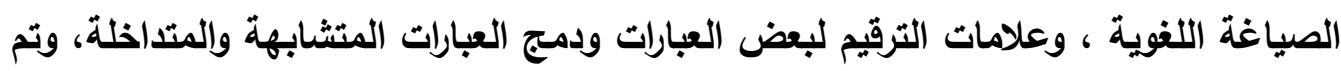

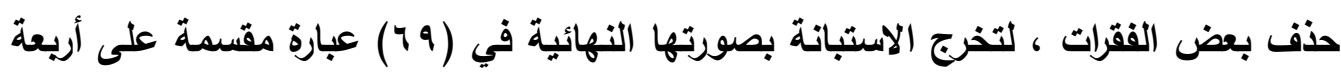
محاور تهدف بمجملها إلى التعرف على أبعاد تحول مدارس الدمج إلى بيئة مدرسية آمنة ، ويذلك تأكد الباحثان من صدق المحتوى. 
خامساً: مجتمع وعينة الدراسة :

يتمثل مجتمع الدراسة الحالية في جميع معلمي ومعلمات مدارس الامج في جمهورية

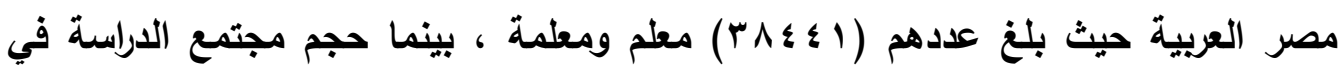

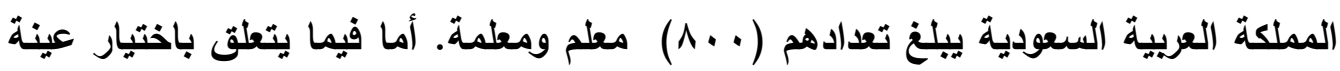
الاراسة، فقد تم اختيار عينة عشوائية طبقية احتمالية من مجتمع الدراسة من خلال تطبيق معادلة مورجان و كريشي ( • ( I ) التالية:

$$
\mathbf{s}=\frac{X^{2} N P(1-P)}{d^{2}(N-1)+X^{2} P(1-P)}
$$

S

= X $X^{2}$ N = N = تثير إلى نسبة مجتمع البحث الأي يوفر أعلى حجم للعينة حيث تبلغ النسبة (ه ه . ).

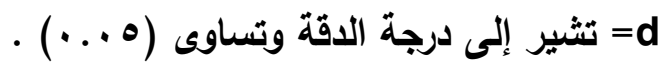

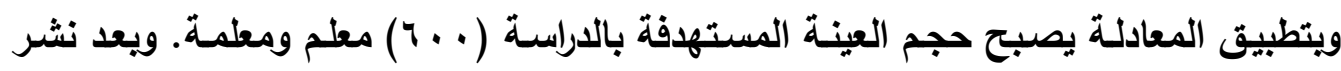

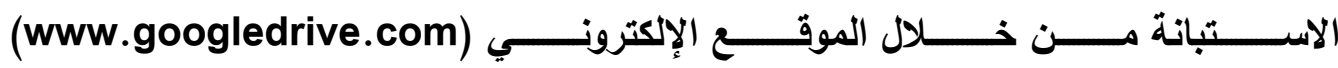
Http://www.googledrive.com/

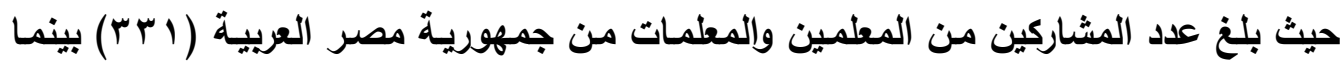

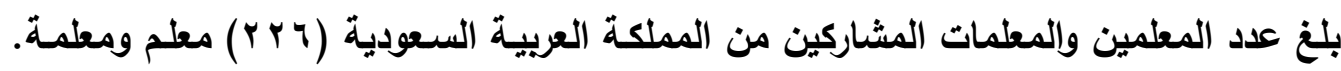
والجدول التالي يوضح التفاصيل أعلاه :

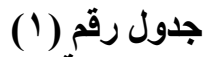

مجتمع وعينة البحث

\begin{tabular}{|c|c|c|c|}
\hline العينة المستردة & العينـة المستثهفة & مجتمع البحث & 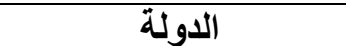 \\
\hline rrI & $r \wedge$. & $r \wedge \varepsilon \leqslant 1$ & جمهوريـة مصر العربية \\
\hline YYT & r.. & A.. & المملكة العربية الستودية \\
\hline$\Delta 0 \mathrm{~V}$ & $7 \leqslant$. & $r q r \leqslant 1$ & الإجمالى \\
\hline
\end{tabular}


وفيما يلي توصيف عينة البحث بحسب الخصائص الايمغرفية والوظيفية وتشمل (النوع،

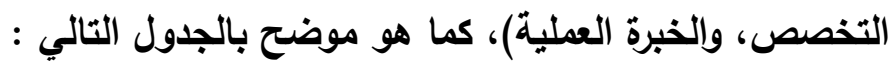

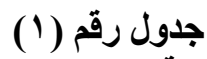

توصيف عينة الدراسة بحسب الخصائص الايمغرافية

\begin{tabular}{|c|c|c|}
\hline النسبة المئوية & العدد & 1. النوع \\
\hline $70 . Y$ & Mqr & ذكر \\
\hline$r \leqslant . \wedge$ & $19 \leq$ & أنثى \\
\hline & & r. التخصص \\
\hline$\theta \wedge . Y$ & TY & علمي \\
\hline$\$ 1 . \wedge$ & TrT & أدبي \\
\hline & & rا ب. سنوات الخبرة \\
\hline Y.Y & Ir & اقل من • سنوات \\
\hline$r \cdot .1$ & 171 & 0ـ إلى • 1 \\
\hline TV.V & rVV & أكثر من · 1 سنوات \\
\hline
\end{tabular}

يتضح من الجدول رقم (1) أن غالبية أفراد العينة المشاركين في الاراسة الحالية من الأكور حيث يشكلون نسبة ץ.0 ٪\% من إجمالي المعلمين والمعلمات المشاركين في الاراسة،

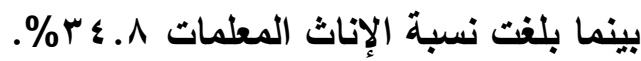
كما بينت النتائج بالجدول رقم (1) أن غالبية أفراد العينة وينسبة ؟. به\% تخصصهم علمي، بينما ^. \؛ \% تخصصهم أدبي. وفيما يتعلق بتوصيف عينة الدراسة حسب سنوات

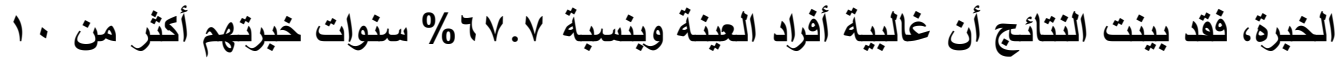

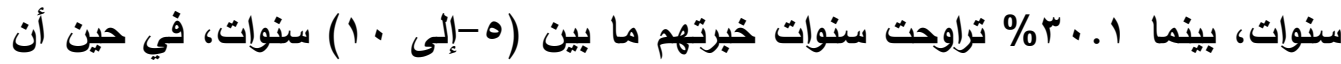

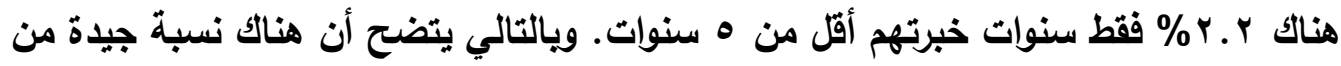
الخبرات بين المعلمين والمعلمات المشاركين في الدراسة، مما يساهم في إثراء نتائج الدراسة. 
سادساً : تقنين أدوات الدراسة ؛

للحصول على البيانات التي تساهم في تحقيق أهداف الدراسة، قام الباحثان بإعداد استمارة استبيان تكونت من ستة محاور رئيسية، كما شملت الخصائص الايمغرافية لأفراد العينة. وللتحقق من ثبات وصدق أداة جمع البيانات الأولية في الدراسة الحالية، تم إجراء دراسية استطلاعية وذلك بتوزيع الاستبانة في صورتها الأولية على عينة محدودة من مجتمع الاراسة بلغ حجمها (OV) وذلك للتحقق من مدى مناسبة الأداة لجمع البيانات المطلوية.

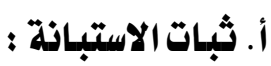
تم التحقق من ثبات الاستبانة بطريقتين، حيث تم استخدام معامل ألفا كرونباخ وذلك لقياس الثبات الكلي للاستبانة ومحاورها، كما تم كذلك استخدام أسلوب التجزئة النصفية لقياس الثبات بحساب معامل سبيرمان براون وكذلك معامل جتمان للتجزئة التصفية.

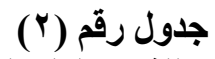

معاملات الفا كرونباخ للثبات الكلي للاستبانة ومحاور ها

\begin{tabular}{|c|c|c|}
\hline معاملات ألفا كرونباخ & عدد البنود & محاور الاراسة \\
\hline$\cdot .9 \cdot 9$ & 1 & المحور الأول: الروئية والأهداف \\
\hline$\because 90 Y$ & IT & المحور الثاني: الترابط والثقة والتواصل الفعال \\
\hline$\because 9 r \wedge$ & $1 \varepsilon$ & المحور الثالث: القيادة المهنية \\
\hline$\because 9 r \cdot$ & 11 & المحور الرابع : التركيز على التعليم الهادف \\
\hline$\cdot .949$ & 1. & التعلم المـور الخـامس: المجتمعـات المهنيـة ويئــات \\
\hline$\because .90 r$ & 11 & المحور السادس: المحاسبية المهنية \\
\hline$\because .9 \wedge \mathrm{V}$ & 79 & التبات الكلي للاستبانة \\
\hline
\end{tabular}

بينت النتائج بالجدول رقم (r) أن قيمة معامل ألفا كرونباخ للثبات الكلي للاستبانة

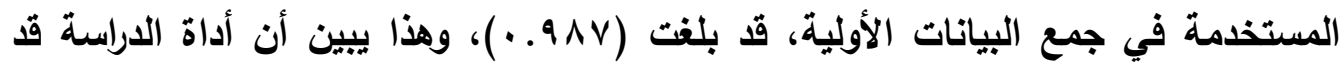

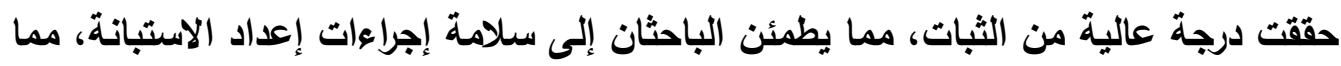
يعني أنه يمكن الاعتماد على هذه البيانات في تحقيق أهداف الدراسة. 
كما جاءت قيم الثبات عن طريق التجزئة النصفية كما هو مبين بالجدول رقم (广)

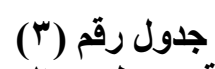

ثبات الاستبانة عن طريق التجزئة النصفية

\begin{tabular}{|c|c|c|c|}
\hline قيمة معامل & قيمة ألفا كرونباخ & عدد البنود & \\
\hline & $. .9 \vee \leq$ & ro & النصف الأول: \\
\hline & $\cdot .9 V V$ & $r \varepsilon$ & النصف الثاني: \\
\hline .900 & & & معامل سبيرمان براون \\
\hline $.90 \leqslant$ & & & معامل جتمان للتجزئة النصفية \\
\hline
\end{tabular}

ونستتتج من الجدول رقم (r) أنه على الرغم من تجزئة الاستبانة إلى نصفين، إلا

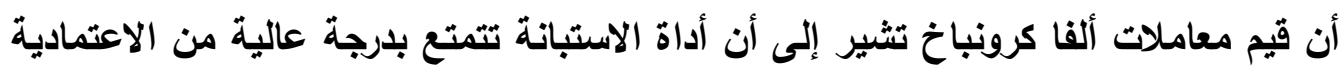

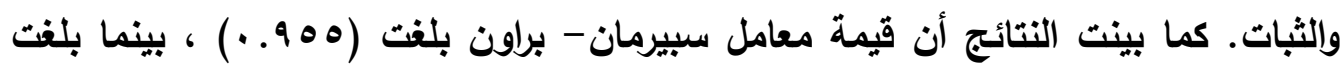

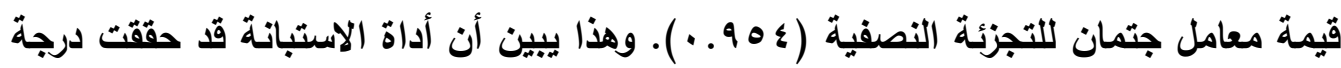
عالية من الثبات.

ب. مؤشرات صدق أداة الاستبانة : كما قام الباحثان بالتحقق من صدق أداة الاراسة من خلال قياس درجة ارتباط كل فقرة أو عبارة مع الارجة الكلية للمحور الذي تنتمي إليه وجاهت التئ النتائج كما هو مبين

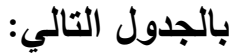


تصور مقترح لتحول مدارس الدمج إلى بيئة مدرسية آمنة . جدول رقم (ع ) التالي:

درجة ارتباط كل فقرة مع الارجة الكلية للمحور الأي تتثي إليه

\begin{tabular}{|c|c|c|c|c|c|}
\hline \multicolumn{2}{|c|}{ المحور الثالث: القيادة } & \multicolumn{2}{|c|}{ المحور الثاني: التزابط والثقة } & \multicolumn{2}{|c|}{ المحور الأول: الرؤية والأهداف } \\
\hline معامل الارتباط & رقم & معامل الارتباط & رقم & معامل الارتباط & رقم \\
\hline$\cdot . \Lambda \cdot \vee * *$ & $Y \varepsilon$ &.$\wedge \mu \wedge * *$ & 11 & $.7 \cdot V * *$ & 1 \\
\hline$\bullet \wedge r \wedge * *$ & ro & $\cdot \wedge \mid \vee * *$ & Ir & $.077 * *$ & $r$ \\
\hline.$\wedge 70 * *$ & ry &.$V \odot V * *$ & 14 & $.09 V * *$ & $r$ \\
\hline.$\wedge 19 * *$ & $r V$ &.$\wedge \neg \wedge * *$ & $1 \varepsilon$ &.$\wedge \cdot \Lambda * *$ & $\varepsilon$ \\
\hline.$\vee 70 * *$ & $r \Lambda$ &.$V I Y * *$ & 10 &..$V Y Y * *$ & 0 \\
\hline $.0 \leqslant 1 * *$ & rq & $\bullet \wedge \vee \Delta * *$ & 17 & $\cdot \Delta \bullet V * *$ & 7 \\
\hline.$\wedge Y \neg * *$ & r. &.$\wedge 07 * *$ & 18 &..$\vee \wedge \neg * *$ & V \\
\hline $.7 V \cdot * *$ & $M$ &. $.119 * *$ & 11 & $\cdot . \wedge 1 \cdot * *$ & $\Lambda$ \\
\hline$. V \bullet \leqslant * *$ & rr &.$\wedge 0 \cdot * *$ & 19 &.$\Lambda \cdot 1 * *$ & 9 \\
\hline.$V 19 * *$ & $r$ &.$\wedge 7 \vee * *$ & $r$. &.$\vee \vee 9 \vee * *$ & 1 . \\
\hline.$\Delta \mu 1 * *$ & $r \varepsilon$ &.$V 7 \% * *$ & YI & & \\
\hline$\because V \cdot 9 * *$ & ro & $\cdot . \Lambda \cdot r * *$ & Yr & & \\
\hline.$V \vee T * *$ & rq & .0TH** & $r r$ & & \\
\hline.$\Lambda \cdot Y * *$ & rV & & & & \\
\hline \multicolumn{2}{|c|}{ المحاسبية السادس: المهنية } & \multicolumn{2}{|c|}{ المهورية الخامسئات التعلم المجتمعات } & \multicolumn{2}{|c|}{ التعليم الهور الرابع: التركيز على } \\
\hline..$\wedge r q * *$ & 09 & $\because V \cdot \varepsilon * *$ & $\varepsilon 9$ & $.0 \vee 9 * *$ & $\mu \wedge$ \\
\hline.$\wedge V \Delta * *$ & 7. &.$\wedge 7 \vee * *$ & 0 . &.$V 01 * *$ & rq \\
\hline$\cdot \wedge \bullet \wedge * *$ & 71 & $\cdot \wedge 9 \cdot * *$ & 01 & $.7 \leqslant 1 * *$ & $\varepsilon$. \\
\hline . & $7 r$ &.$\wedge \neg \wedge * *$ & $\Delta r$ &. $.871 * *$ & $\& 1$ \\
\hline$. \vee V 7 \leq * *$ & 74 &.$\wedge \vee \wedge * *$ & or & . VฯF** & $\varepsilon r$ \\
\hline$\because \wedge \vee \wedge * *$ & $7 \varepsilon$ &. $.117 * *$ & $0 \leq$ &. $.119 * *$ & $\varepsilon r$ \\
\hline$. \wedge \leqslant Y * *$ & 70 & $.711 * *$ & 00 &.$\wedge \backslash \wedge * *$ & $\varepsilon \varepsilon$ \\
\hline$\cdot V \cdot V * *$ & 77 & $\because V 0 \leq * *$ & 07 &.$\vee \wedge 1 * *$ & $\leqslant 0$ \\
\hline$\because \wedge \leqslant 0 * *$ & $7 V$ & $\because \vee \diamond \wedge * *$ & $\Delta V$ &.$\vee \vee \vee \wedge * *$ & $\varepsilon 7$ \\
\hline.$\wedge 79 * *$ & 71 & $. \wedge \mid r * *$ & $0 \wedge$ &.$\vee \vee \wedge \mu * *$ & $\varepsilon V$ \\
\hline. $.7 \vee 9 * *$ & 79 & & &.$V T V * *$ & $\varepsilon \Lambda$ \\
\hline
\end{tabular}

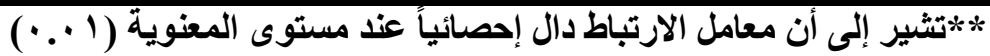


يتضح من النتائج بالجدول رقم (؛) أعلاه أن كل فقرة من فقرات الاستبانة ترتبط

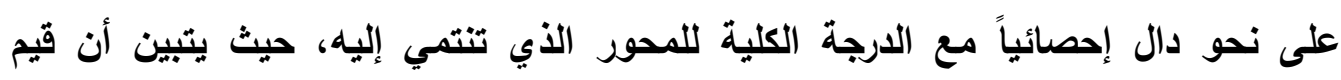

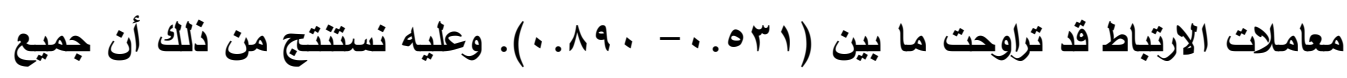

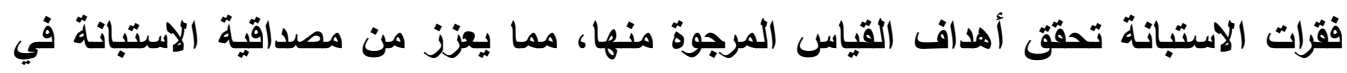
الحصول على البيانات والمعلومات التي تساهم في تحقيق أهداف الدارية.

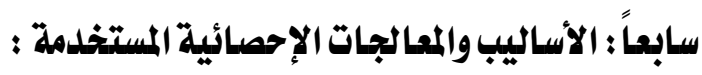
لتحليل بيانات الدراسة وتفسير نتائجها بشكل علمي يحقق أهدافها، تم استخدام

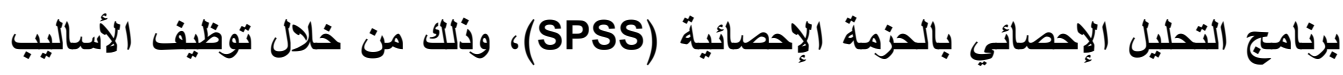

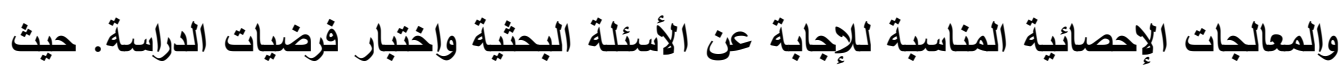

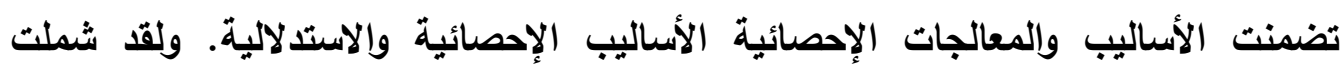

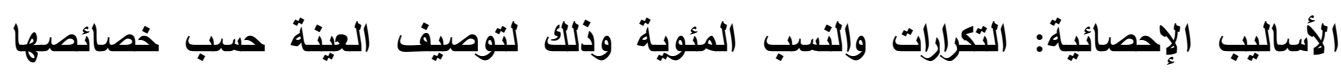

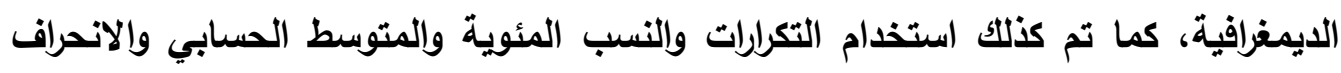

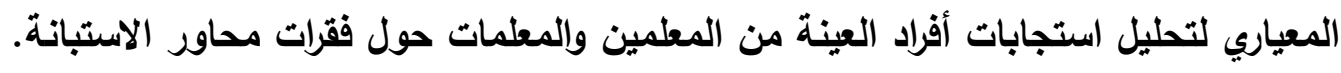

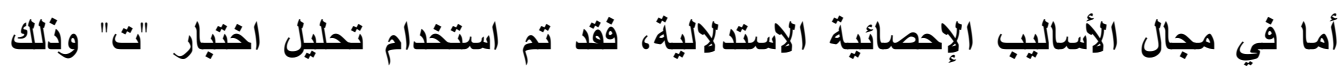
لاختبار دلالة الفروق بين استجابات أفراد العينة حول محاور الدراسة تعزى لاختلاف متفير الإلية

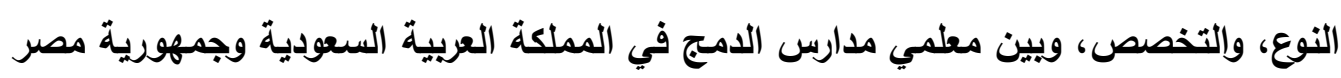

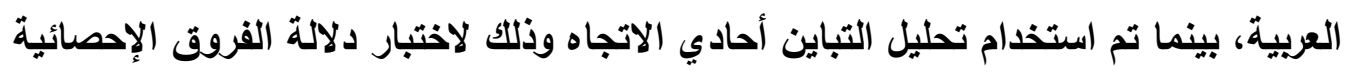
باختلاف سنوات الخبرة. بالإضافة إلى ذلك فقد تضمنت الأساليب الإحصائية استخام معامل

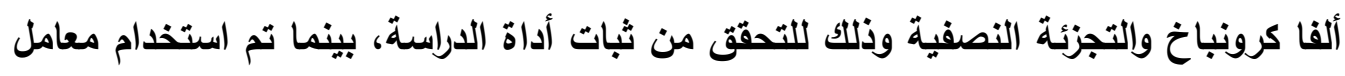

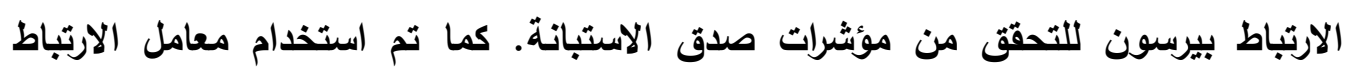
بيرسون لاختبار فرضيات الدراسة. 


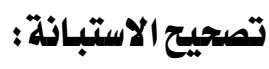

تعطى الاستجابة(دائماً)(الدرجة (ץ)، والاستجابة (أحيانـاً)تعطي الارجـة (ץ)، والاستجابة

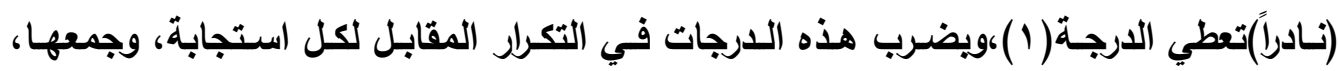
وقسمتها على إجمالي أفراد العينة، يعطي ما يسمى بـ(الوسط المرجح)، الذي يعبر عن الوزن الذابن النسبي لكل عبارة على حدة كما يلي:

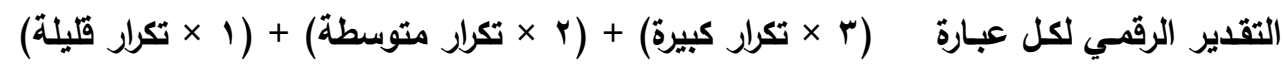
عدد أفراد العينة منوميطه

وقد تحدد مستوى الأهمية لاى عينة الدراسة (تقدير طول الفترة التي يمكن من خلالها

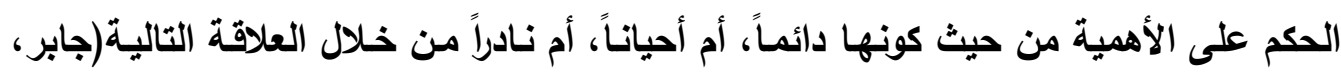

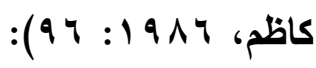

$$
\frac{1-\dot{0}}{\dot{0}}=\frac{1}{\text { مستوى }}
$$

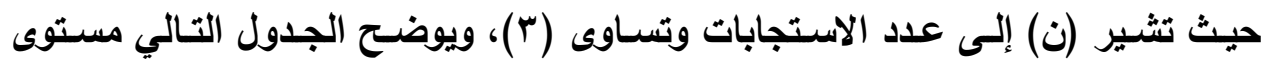
ومدى أهمية العبارة لاى عينة الدراسة لكل استجابة من استجابات الاستبانة:

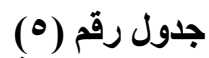
تدرج المقياس الثلاثي لتقييم قيمة المتوسط الحسابي

\begin{tabular}{|c|c|}
\hline 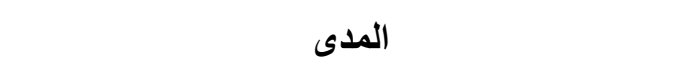 & 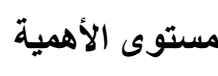 \\
\hline من اوحتى (1 + 7 7. ·) أي 74.1 تقريباً & نادراً \\
\hline 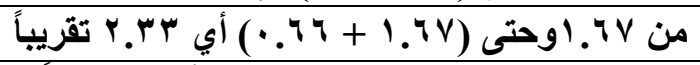 & أحياناً \\
\hline 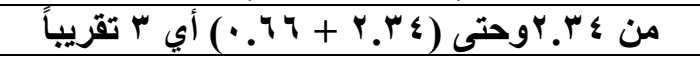 & نادراً \\
\hline
\end{tabular}

ثامناً: نتائج اللدراسة الميلدانية وتفسيرها

تناول الباحثان في هذا الجزء من تحليل آراء أفراد العينة حول فقرات محاور الدراسة والتي ترتبط بشكل مباشر بالإجابة عن السؤال الرئيس للاراسة والذي يتمثل في :

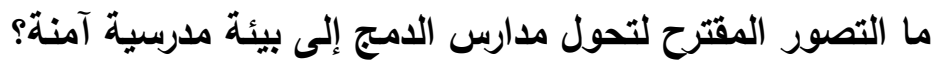
ويمكن الإجابة عن السؤال الرئيس من خلال استعراض نتائج استجابات أفراد العينة حول محاور الدراسة الستة والتي تم عرض نتائجها كما بالجداول التالية: 
أ. النتائج الخاصة بترتيب عبارات المحور الأول الخاص باستجابات أفراد العينة حول

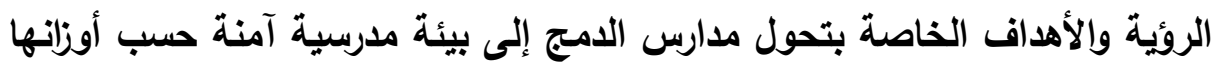

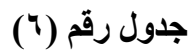

التكرارات والنسب المئوية والمتوسطات الحسابية والانحرافات المعيارية لاستجابات

أفر اد العينة حول الروئية والأهداف الخاصة بتحول مدارس الدمج إلى بيئة مدرسية آلمنة المبنة

\begin{tabular}{|c|c|c|c|c|c|c|c|c|}
\hline \multirow{2}{*}{ 覃: } & \multirow{2}{*}{$\begin{array}{l}\bar{y} \\
\bar{y} \\
\bar{y} \\
\overline{3} \\
y\end{array}$} & \multirow{2}{*}{$\begin{array}{l}\overline{3} \\
\overline{3} \\
\overline{3} \\
\overline{3} \\
3 \\
3\end{array}$} & \multicolumn{3}{|c|}{ خيارات الإجابة } & & & \\
\hline & & & 咨 & $\overline{7}$ & $\frac{7}{3}$ & & & - \\
\hline \multirow{2}{*}{1} & \multirow{2}{*}{$\because v r$} & \multirow{2}{*}{$r . . \cdot$} & $1 \leqslant 1$ & Y71 & $1 \leqslant 1$ & $ت$ & \multirow{2}{*}{ 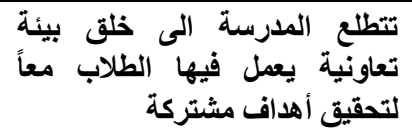 } & \multirow{2}{*}{1} \\
\hline & & & r.. & $\leq 7.9$ & $r 7.7$ & \%ं & & \\
\hline \multirow[t]{2}{*}{ r } & \multirow[t]{2}{*}{$\because v 1$} & \multirow[t]{2}{*}{1.91} & $1 \leq \varepsilon$ & $r \wedge$. & Irr & $ت$ & \multirow{2}{*}{ 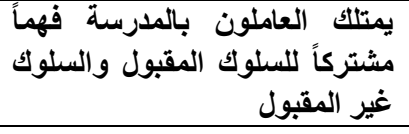 } & \multirow[t]{2}{*}{$r$} \\
\hline & & & ro. 9 & $0 . . r$ & $r r . q$ & \%ं & & \\
\hline \multirow{2}{*}{0} & \multirow{2}{*}{.71} & \multirow{2}{*}{1.91} & $10 \mathrm{~V}$ & Yq & 1.7 & ت & \multirow{2}{*}{ للتعريف إدارة المدرسة مطبو الانضباط في في } & \multirow{2}{*}{$r$} \\
\hline & & & $r \wedge . r$ & or.A & 19. & \%ن & & \\
\hline \multirow[t]{2}{*}{$r$} & \multirow[t]{2}{*}{$\because v}$. & \multirow[t]{2}{*}{1.97} & $1 \leq 9$ & rAr & $1 \times 4$ & ت & \multirow{2}{*}{ 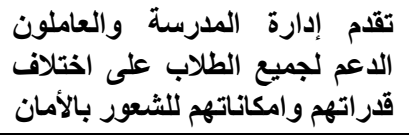 } & \multirow[t]{2}{*}{$\varepsilon$} \\
\hline & & & rצ.1 & $0 . .7$ & YY.T & \%ं & & \\
\hline \multirow{2}{*}{ v } & \multirow{2}{*}{$\because \wedge 1$} & \multirow{2}{*}{1.10} & rri & 187 & 10. & $ت$ & \multirow{2}{*}{ 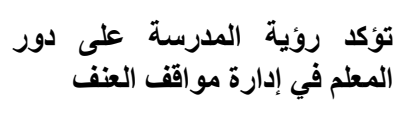 } & \multirow{2}{*}{ - } \\
\hline & & & $\approx 1.0$ & 4.7 & $r 7.9$ & \%ن் & & \\
\hline \multirow{2}{*}{7} & \multirow{2}{*}{$\because \wedge r$} & \multirow{2}{*}{1.14} & $r r \varepsilon$ & 171 & 100 & $ت$ & \multirow{2}{*}{ في الثُعور بالأمان بدنياً ونفيعياً ألنق } & 7 \\
\hline & & & $\varepsilon Y_{.}$ & $r \cdot . r$ & $r V . \Lambda$ & \%ن் & & \\
\hline & & & Y41 & $1 Y 1$ & 180 & $ت$ & تؤكد المدرسة على أن ضمان & \\
\hline$\wedge$ & $\because \wedge \vee$ & 1.10 & $\leq 7.9$ & r..V & 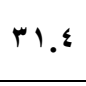 & \%ن் & 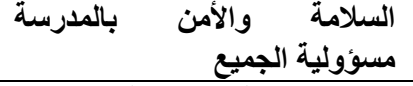 & $v$ \\
\hline 9 & $v_{1} y_{7}$ & $v^{2 r}$ & rqA & IVT & 117 & $ت$ & تتضمن روئة المدرسة استخدام & $\hat{A}$ \\
\hline 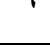 & $\because$ & .8 & $\varepsilon \wedge .1$ & $r 1.1$ & $r \cdot . \wedge$ & \%ن் & بدائل تربوية للعنف والتخويف & $n$ \\
\hline & & & MIV & 147 & $11 \leq$ & ت & تتضمن روئة المدرسة الوصول & \\
\hline 1. & $\because \wedge$. & $1.7 \varepsilon$ & 07.9 & rY. & $r \cdot .0$ & \%ن & والطلاب الأمن والانضباط بين العاملين & 9 \\
\hline$\varepsilon$ &.$V_{7}$ & 190 & 180 & rrV & $1 \leqslant 0$ & $ت$ & تنشر المدرسة ثقافة الأمن والأمان & 1. \\
\hline 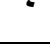 & . & .0 & $r 1 . \varepsilon$ & $\leqslant Y .7$ & $r q . \cdot$ & \%ं & بين جميع العاملين و الطلاب & 10 \\
\hline & .77 & $1 . \wedge \mathrm{V}$ & & & 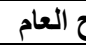 & عسابي الا & | المتوسط ال & \\
\hline
\end{tabular}


يتضح من الجدول رقم (؟) أن استجابات أفراد العينة من معلمي ومعلمات مدارس

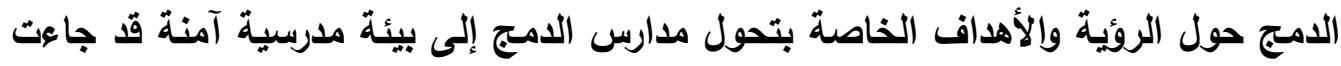

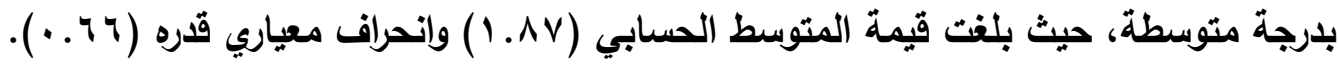
ويالتالي نستتتج مما سبق أن استجابات أفراد العينة تثبير إلى توفر الروئية والأهداف الخاصة بالتحول إلى بيئة مدرسية آمنة بدرجة متوسطة. وريما تعزى هذه النتيجة إلى تركيز الروئية والأهداف على الأبعاد التعليمية الروتينية، وضعف اهتمامها بتوفير بيئة هدرسية آمنة ، نظراً

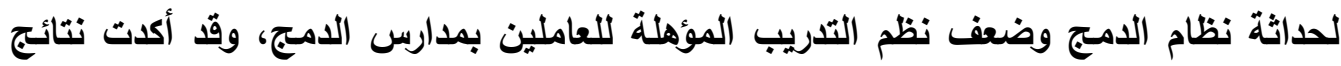
دراسة (المكاوي، 9 1.ب) أن درجة الاحتياجات التدريبية لمطلمي مدارس الدمج في مصر

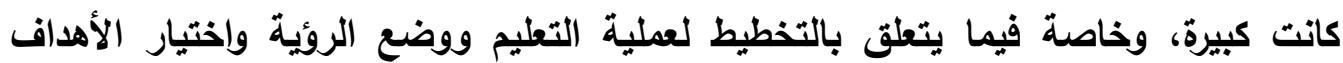

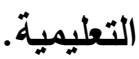
وفيما يلي يتناول الباحثان أبرز المؤثرات المتعقة بالروئية والأهداف المتعلقة بتحول

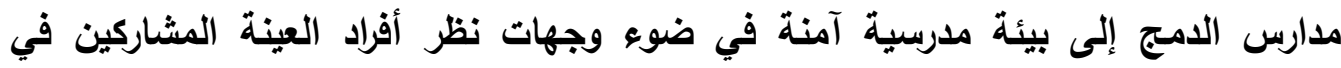

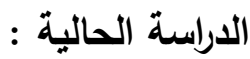

أظهرت النتائج بالجدول رقم (7) أن العبارة رقم (1) والتي تثثير إلى" تتطلع المدرسة

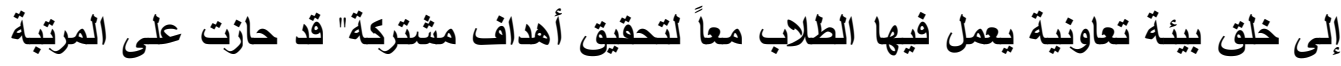

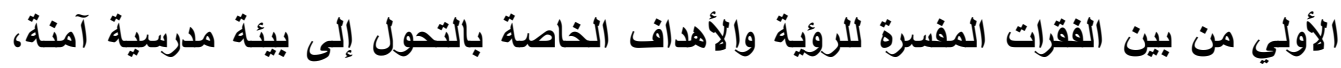
ويعز ذلك قيمة المتوسط الحسابي لاستجابات أفراد العينة من المعلمين والمعلمات حيث الماهي

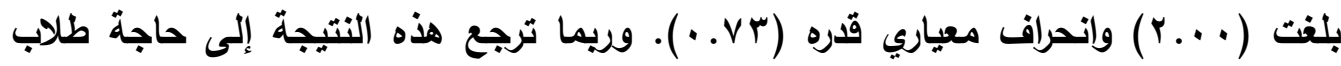
الدمج إلى بيئة تعاونية لوجود طلاب من ذوي الاحتياجات الذاصة وهم بحاجة ماستة إلى بيئة

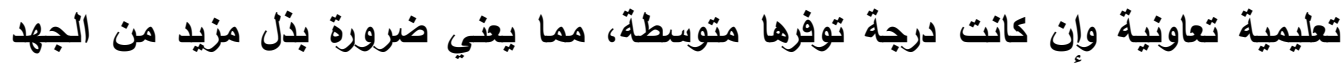
لتحقيق بيئة تعاونية تدعم تحول مدارس الدمج إلى بيئة مدرسية آنذة لأنه بمثابة البنية

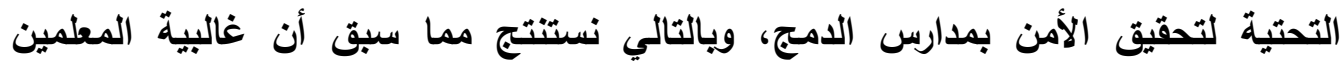

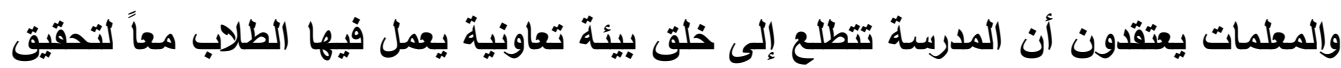
أهداف مشتركة بدرجة متوسطة. كما كثفت النتائج بالجدول رقم (†) أن العبارة رقم (ץ) " يمتلك العاملون بالمدرسة

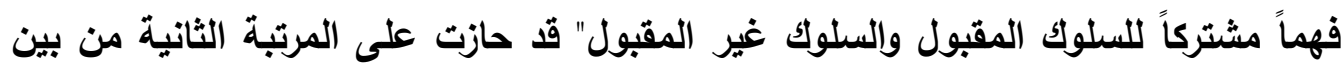


الفقرات المفسرة للروئية والأهداف الخاصة بالتحول إلى بيئة مدرسية آمنة، ويعزز ذلك قيمة المتوسط الحسابي لاستجابات أفراد العينة من المعلمين والمعلمات حيث بلغت (1 (1 1) وإنحراف معياري قدره ( V V . ). ويالتالي نستنتج مما سبق أن غالبية المعلمين والمعلمات في مدارس الدمج يعتقدون أنهم يمتلكون فهما مشتركاً للسلوك المقبول والسلوك غير المقبول بدرجة متوسطة. وقد أكلت نتائج دراسة (جاب الله، 10 ـ ب) عدم تفهم المعلمين لاحتياجات الطلاب ذوي الاحتياجات الخاصة.

كما كشفت النتائج بالجدول رقم (†) أن العبارة رقم (؛ ) والتي نصت على" تقدم إدارة

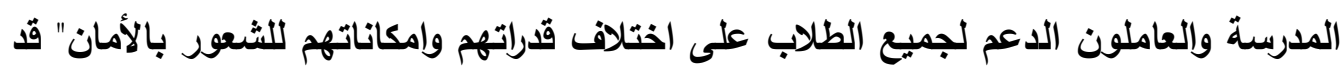
نالت المرتبة الثالثة من بين الفقرات المفسرة للروئية والأهداف الخاصة بالتحول إلى بيئة مدرسية آمنة، ويعزز ذلك قيمة المتوسط الحسابي لاستجابات أفراد العينة من المعلمين

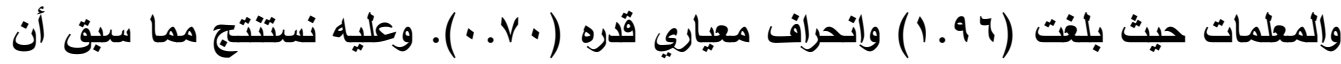
غالبية المعلمين والمعلمات يعتقدون أن إدارة المدرسة والعاملون يقدمون الدعم لجميع الطلاب على اختلاف قدراتهم وإمكاناتهم للشعور بالأمان بدرجة متوسطة ويدعم ذلك النسبة الموزونة لاستجابات أفراد العينة حيث بلغت ( .^^؛\%). وهو ما يتفق مع ما توصلت إليه نتائج دراسة (قطامي، و ، . r) من أن مدركات الطلبة لبيئة التعلم الآمنة كاتت متوسطة. وفي ذات السياق، فقد أظهرت النتائج بالجدول رقم (؟) أن العبارة رقم (^) والتي

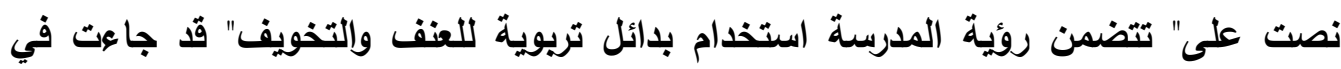
المرتبة قبل الأخيرة من بين الفقرات المفسرة للروئة والأهداف الخاصة بالتحول إلى بيئة مدرسية آمنة، ويعزز ذلك قيمة المتوسط الحسابي لاستجابات أفراد العينة من المعلمين لين لهن

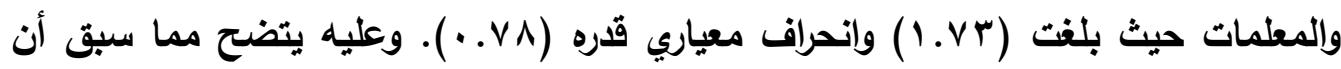

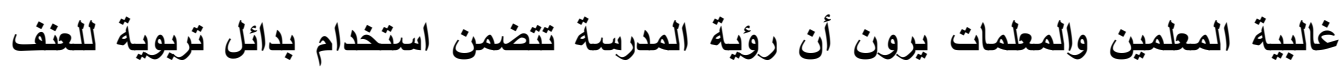
والتخويف بلرجة متوسطة. كما بينت النتائج بالجدول رقم (؟) أن العبارة رقم (9) والتي نصت على" تتضمن روئية المدرسة الوصول إلى الأمن والانضباط بين العاملين والطلاب بشكل تدريجي ومنظم." قد جاءت في المرتبة الأخيرة من بين الفقرات المفسرة للروئية والأهداف الخاصة بالتحول إلى بيئة مدرسية آمنة، ويعزز ذلك قيمة المتوسط الحسابي لاستجابات أفراد العينة من المعلمين 
والمعلمات حيث بلفت (ع ؟. 1) وانحراف معياري قدره (•^. •). ويالتالي يتبين أن غالبية

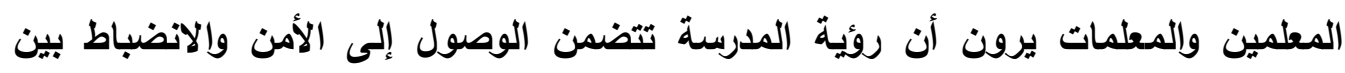
العاملين والطلاب بشكل تدريجي ومنظم بدرجة ضعيفة ويدعم ذلك النسبة الموزونة

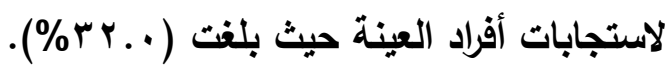

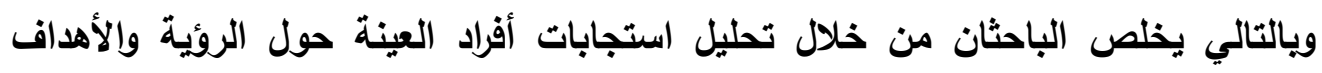

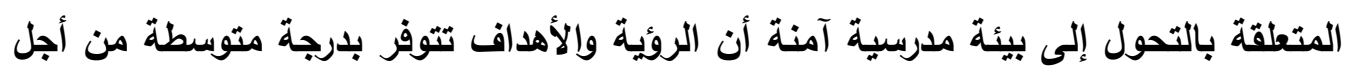

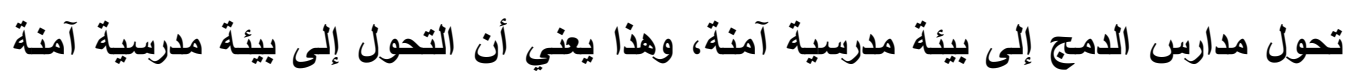

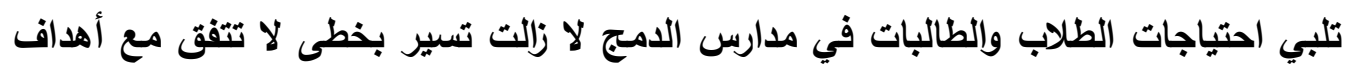

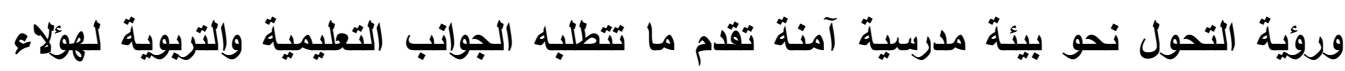

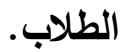

ب. النتائج الخاصة بترتيب عبارات المحور الثاني الخاص باستجابات أفراد العينة حول

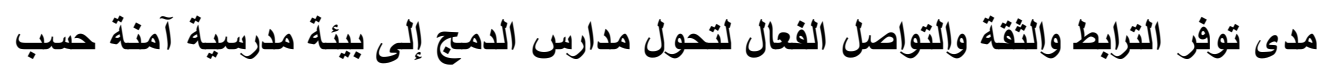

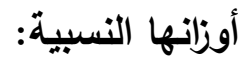




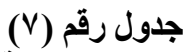

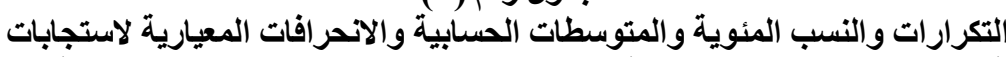

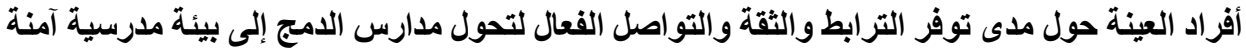

\begin{tabular}{|c|c|c|c|c|c|c|c|c|}
\hline \multirow{2}{*}{ 深: } & \multirow{2}{*}{ 蛹事: } & \multirow{2}{*}{$\bar{s}$} & \multicolumn{3}{|c|}{ خيارات الإجابة } & & & \multirow{2}{*}{$\begin{array}{l}\text { ब, } \\
\text { 司 } \\
\text { :0 }\end{array}$} \\
\hline & & & $\stackrel{-3}{3}$ & $\bar{y}$ & $\frac{2}{3}$ & & & \\
\hline \multirow{2}{*}{1} & \multirow{2}{*}{.04} & \multirow{2}{*}{ T.Mr } & rA & rTO & $r \cdot \varepsilon$ & $ت$ & \multirow{2}{*}{ شعتور الطالب بأهميته كعضو في } & \multirow{2}{*}{11} \\
\hline & & & $\bullet$. & $\bullet \wedge . \varepsilon$ & r.. & \% & & \\
\hline \multirow[b]{2}{*}{$r$} & \multirow[b]{2}{*}{.79} & \multirow[b]{2}{*}{ r.IV } & A. & $r \cdot r$ & ivo & ت & \multirow{2}{*}{ 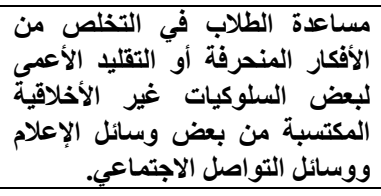 } & \multirow[b]{2}{*}{ ir } \\
\hline & & & $1 \leqslant . \varepsilon$ & $0 \leqslant . Y$ & $r .4$ & \%ن & & \\
\hline \multirow{2}{*}{$\wedge$} & \multirow{2}{*}{.79} & \multirow{2}{*}{1.99} & $1 \% 0$ & rqs & $1 \% \Lambda$ & $ت$ & \multirow{2}{*}{ عراعاة المرونة في تطبيق القانون } & \multirow{2}{*}{ ir } \\
\hline & & & $r \varepsilon . r$ & or.^ & $r r . \cdot$ & \% ن & & \\
\hline \multirow{2}{*}{9} & \multirow{2}{*}{$\because \leqslant V$} & \multirow{2}{*}{ r.lะ } & YY & $\varepsilon r_{0}$ & 1.7 & $ت$ & \multirow{2}{*}{ التواصل الفلاب و والعاملين مهارات } & \multirow{2}{*}{$1 \leqslant$} \\
\hline & & & $\xi . V$ & 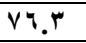 & 19.9 & $\%$ & & \\
\hline \multirow[t]{2}{*}{ r } & \multirow[t]{2}{*}{$\because .0 Y$} & \multirow[t]{2}{*}{$r .11$} & ro & rAᄉ & ع & 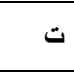 & \multirow{2}{*}{ الطابتابة أو الاحتقار فئة التعاملة مع عن } & \multirow[t]{2}{*}{10} \\
\hline & & & $7 . r$ & 79.7 & $r \leqslant .1$ & $\%$ & & \\
\hline$\&$ & $0 \leqslant 9$ & $r 10$ & $r$ & $\$ 1$. & 117 & $ت$ & المبادرة إلى اكتشاف أسباب العنف & 19 \\
\hline 2 & $\because .8$ & .10 & 0.7 & Vr. & $r \cdot . \Lambda$ & \%ن & بين الطلاب وبعضهم البعض. & 16 \\
\hline & & & Vo & Trt & 107 & $ت$ & تحفيز الطلاب على التواصل مع & \\
\hline - & ? & Y.10 & 17.0 & 09.0 & r^.• & \% & تعرض الطعالب للعنف أو التنمر في حال & IV \\
\hline & & & $r .9$ & 111 & 1T. & $ت$ & استثمار الأنثطة الطلابية في تعزيز & \\
\hline ir & $\cdot \wedge r$ & 1.71 & 00.0 & r..$r$ & $r$ r.r & \%ن & بين الطوة والتسامح والتعاون والأمن & 11 \\
\hline & & & $r .9$ & 111 & $1 \%$. & $ت$ & تعريف الطلاب بالتصرف الصحيح & \\
\hline ir & $\cdot \wedge r$ & 1.71 & 00.0 & r..$r$ & $r r . r$ & \% & داخل المدرسئة أو خار تعرضها للعنف & 19 \\
\hline & & & 1.1 & rrt & $1 \% \varepsilon$ & $ت$ & توطيا العلاقة بين المعلمين والطلاب & \\
\hline $\mathrm{v}$ & .70 & r. .7 & $1 \wedge .1$ & $\bullet \vee . \wedge$ & $r \leqslant .1$ & \% ن & ألثنتاء ممارسة الأثطة المدرسية & r. \\
\hline 11 & $.7 r$ & $1 . \wedge 1$ & $1 \leqslant 9$ & rro & $\wedge$. & $ت$ & 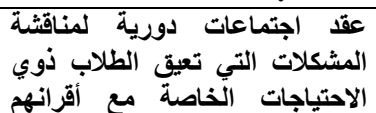 & r \\
\hline & & & ห..^ & $\bullet \wedge . \wedge$ & $1 \varepsilon . \varepsilon$ & \% & العاديين. & \\
\hline & & & $1 T$. & $r \leqslant 1$ & $\Lambda 4$ & $ت$ & تثقيف الأسرة وأفراد ـ المجتمع & \\
\hline 9 & $\cdot .7 r$ & 1.94 & $r$ r.r & $7 . r$ & 10.4 & \% & 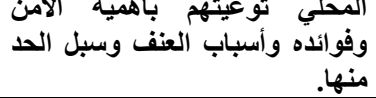 & rr \\
\hline & & & 197 & rTI & $1 \%$. & $ت$ & قيام المعلم بدوره الإرشادي تجاه & \\
\hline 1. &. .14 & $1 . \wedge 1$ & ro.r & $\leqslant 1.0$ & $r r . r$ & \%ن & الخاصة. العاديين وذوي الاحتياجات & $r r$ \\
\hline & $\because . \leqslant 1$ & $r .+1$ & & & 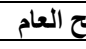 & 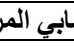 & المتوسط الح الح المت & \\
\hline
\end{tabular}


بينت النتائج بالجدول رقم (V) أن استجابات أفراد العينة من معلمي ومعلمات مدارس الامج حول مدى توفر الترابط والثقة وإلتواصل الفعال والمتعلقة بتحول مدارس الامج إلى بيئة

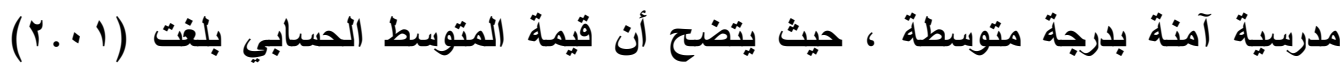

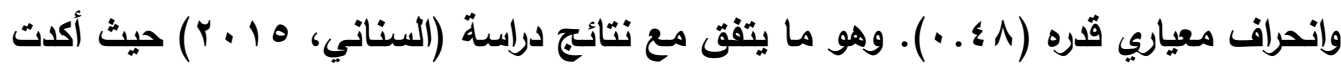

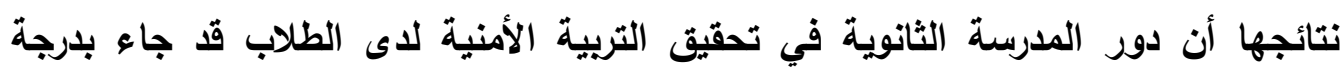

متوسطة.

وفيما يلي يتناول الباحثان أبرز المؤشرات المتعلقة بالترابط والثقة والتواصل الفعال

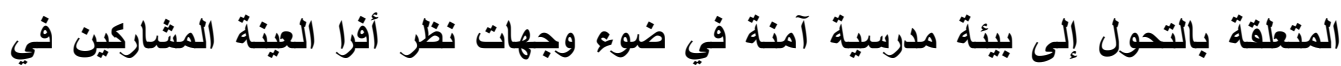

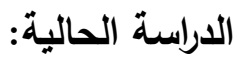

أظهرت النتائج بالجدول رقم (V) أن العبارة رقم (1 (I) والتي نصت على "ثعور الطالب بأهميته كعضو في المجتمع المدرسي" قد حازت على المرتبة الأولي من بين الفقرات

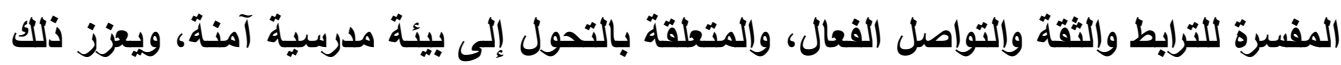

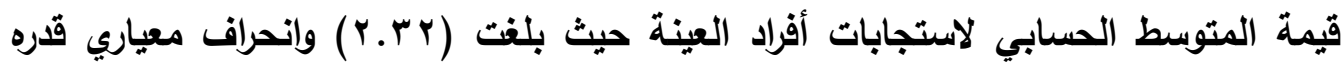

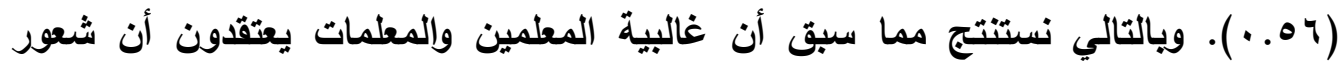
الطالب بأهميته كعضو في المجتمع المدرسي يتوفر بلرجة متوسطة. وقد أكلات دراسة (خليل

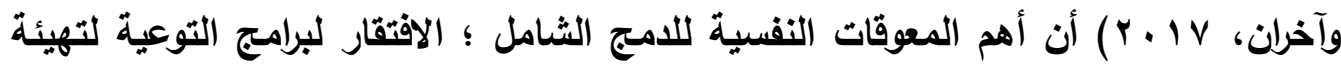
العاملين بالمدرسة لاستقبال التلاميذ ذوي الإعاقة.

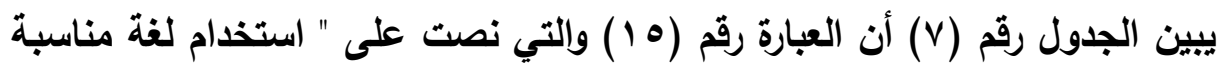
ويعيدة عن الإهانة أو الاحتقار في التعامل مع الطلاب" قد حازت على المرتبة الثانية من بين الفقرات المفسرة للترابط والثقة والتواصل الفعال والمتعلقة بالتحول إلى بيئة تعليمية آمنة،

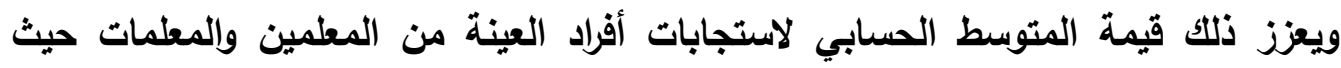

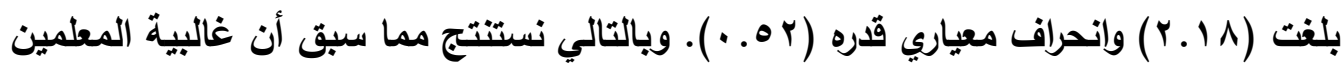

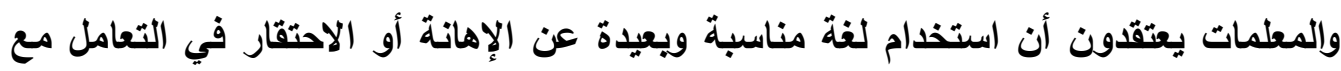
الطالب يتوفر بلرجة متوسطة. كما يتضح من الجدول رقم (V) أن العبارة رقم (Y Y ) والتي نصت على " مساعدة الطلاب في التخلص من الأفكار المنحرفة أو التقليد الأعمى لبعض السلوكيات غير التير الأخلاقية 
المكتسبة من بعض وسائل الإعلام ووسائل التواصل الاجتماعي" قد حازت على المرتبة الثالثة من بين الفقرات المفسرة للترابط والثثة والتواصل الفعال، والمتعقة بالتحول إلى بيئة مدرسية آمنة، ويعزز ذلك قيمة المتوسط الحسابي لاستجابات أفراد العينة من المعلمين والمعلمات

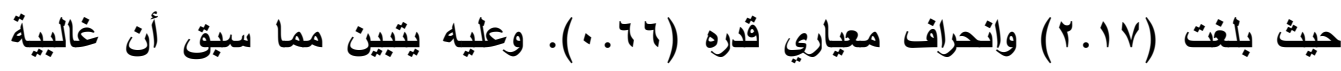
المطمين والمعلمات يعتقدون أن مساعدة الطلاب في التخلص من الأفكار المنحرفة أو التقليد الأعمى لبعض السلوكيات غير الأخلاقية المكتسبة من بعض وسائل الإعلام ووسائل التواصل الاجتماعي يتحقق بدرجة متوسطة.

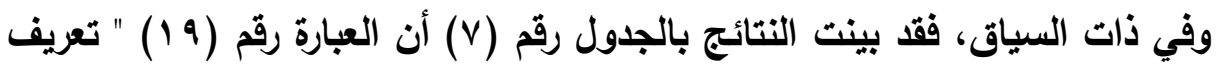
الطلاب بالتصرف الصحيح والمقبول في حال تعرضهم للعنف داخل المدرسة أو خارجها " قد لـ حازت على المرتبة قبل الأخيرة من بين الفقرات المفسرة للترابط والثقة والتواصل الفعال، والمتعلقة بالتحول إلى بيئة مدرسية آمنة، ويعزز ذلك قيمة المتوسط الحسابي لاستجابات

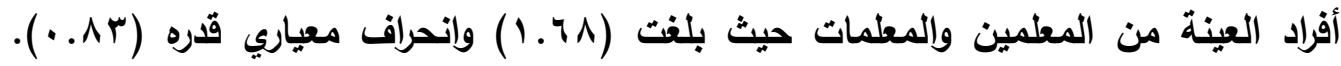
ويالتالي نستنتج أن غالبية المطلمين والمعلمات يرون أن عملية تعريف الطلاب بالتصرف الصحيح والمقبول في حال تعرضهم للعنف داخل المدرسة وخارجها يتحقق بدرجة متوسطة.

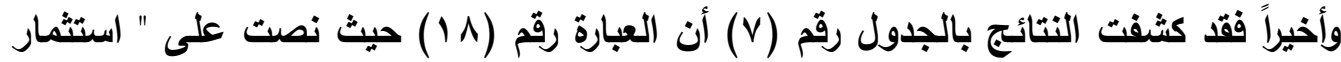
الأنثطة الطلابية في تعزيز الأخوة والتسامح والتعاون والأمن بين الطلاب " قد حازت على الته

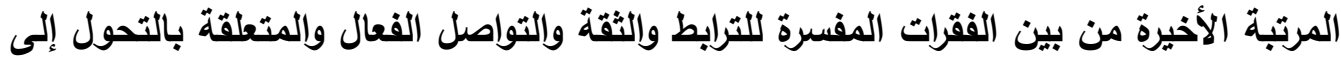
بيئة مدرسية آمنة، ويغزن ذلك قيمة المتوسط الحسابي لاستجابات أفراد العينة من المطلمين

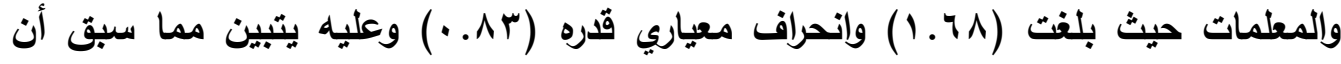
غالبية أفراد العينة يؤكدون أن استثمار الأنشطة الطلابية في تعزيز الأخوة والتسامح والتعاون

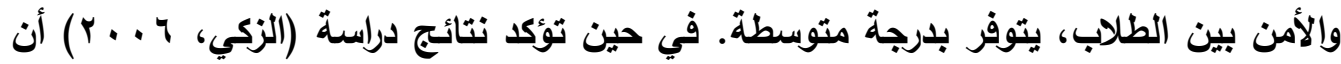

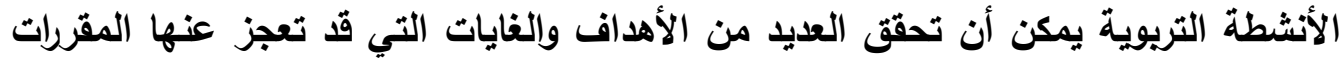
والمناهج النظامية، وأنها تنمي الوعي الأمني وتجعل البيئة المدرسية أكثر أمناً.

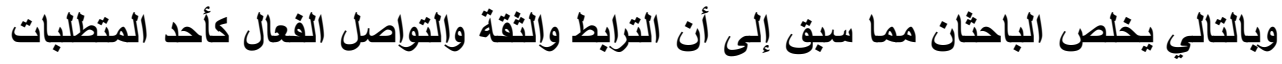

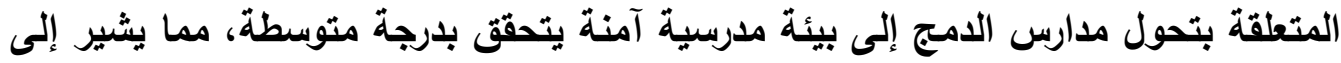


ضرورة الاهتمام بتعزيز عملية الترابط والثقة والتواصل الفعال بين كافة الأطراف المهتمة لضمان تحول مدارس الدمج إلى بيئة مدرسية آمنة.

ج. النتائج الخاصة بترتيب عبارات المحور الثالث الخاص باستجابات أفراد العينة حول مدى توفر القيادة المهنية لتحول مدارس الامج إلى بيئة مدرسية آمنة حسب أوزانها

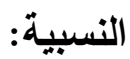




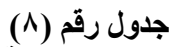

التكرارات و النسب المئوية و المتوسطات الحسابية والانحرافات المعيارية لاستجابات

أفراد العينة حول مدى توفر القبادة المهنية لتحول مدارس الدمج إلى بيئة مدرسية آمنة

\begin{tabular}{|c|c|c|c|c|c|c|c|c|}
\hline \multirow{2}{*}{ 雪: } & \multirow{2}{*}{ 高沀: } & \multirow{2}{*}{ 事市 } & \multicolumn{3}{|c|}{ خيارات الإجابة } & & & \multirow{2}{*}{ : 量 } \\
\hline & & & -23 & $\overline{3}$ & $\frac{7}{3}$ & & & \\
\hline \multirow{2}{*}{ r } & \multirow[b]{2}{*}{. $\mathrm{TV}$} & \multirow{2}{*}{$r . \cdot r$} & $11 \mathrm{~V}$ & $r \cdot \Lambda$ & ITY & 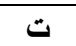 & \multirow{2}{*}{ 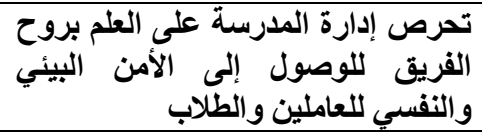 } & \multirow[b]{2}{*}{ r } \\
\hline & & & r.. & $00 .{ }^{r}$ & $r r . v$ & \% & & \\
\hline \multirow{2}{*}{$\wedge$} & \multirow{2}{*}{$\cdot . \vee \varepsilon$} & \multirow{2}{*}{1.94} & IVV & $r \leqslant \Lambda$ & ITr & 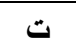 & \multirow{2}{*}{ تشكلات إلطارة المدرسة المبادرات لحل } & \multirow{2}{*}{ ro } \\
\hline & & & $r 1 . \wedge$ & $\leqslant \leqslant .0$ & YY.V & $\%$ & & \\
\hline \multirow{2}{*}{$\varepsilon$} & \multirow{2}{*}{. .79} & \multirow{2}{*}{$1.9 \mathrm{~V}$} & $1 \leqslant$. & rqo & TYY & $ت$ & \multirow{2}{*}{ 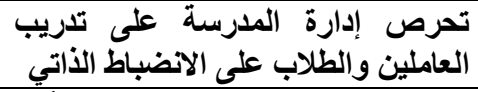 } & \multirow{2}{*}{ r } \\
\hline & & & Yo.1 & 00. & $Y 1.9$ & \% & & \\
\hline \multirow{2}{*}{$r$} & \multirow{2}{*}{$\cdot{ }^{v} \cdot$} & \multirow{2}{*}{$1.9 \mathrm{~V}$} & $1 \leqslant r$ & YAT & Trk & $ت$ & \multirow{2}{*}{ الأمان اللعناخلخ المدرسي والطلاب تحقيق الأمن } & \multirow{2}{*}{ rV } \\
\hline & & & YO.V & 01.5 & rT. & \%ن & & \\
\hline \multirow{2}{*}{1} & \multirow{2}{*}{$\cdot .71$} & \multirow{2}{*}{ r.17 } & 91 & $Y \wedge \varepsilon$ & IAY & $ت$ & \multirow{2}{*}{ القانونم الطلاب في المدرسة احترام } & $r \Delta$ \\
\hline & & & 19.5 & 01. & TY.V & $\%$ & & 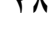 \\
\hline 0 & 79 & 197 & $1 \leqslant 0$ & rq. & ITY & $ت$ & توجد لاتحة للانضباط المدرسي واضحة & ra \\
\hline & . & 1.1 & rq." & O. . 1 & r. 1.9 & \% & ومعلنة & \\
\hline & & & YYI & TY. & 117 & $ت$ & تقوم إدارة المدرسة بتوعية الطلاب & \\
\hline 11 & .074 & $1 . \wedge 1$ & rq.v & $r q . \diamond$ & $r \cdot . \wedge$ & \% & بالمداجبات $\quad$ و والاتظمة & r. \\
\hline 9 & 79 & 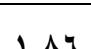 & $1 \vee \Lambda$ & rVq & $1 \ldots$ & 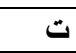 & تتاح الفرصة للطلاب والعاملين للتعبير & $w_{1}$ \\
\hline 1 & .17 & .01 & rY.. & $0 . .1$ & $1 \Lambda_{.} \cdot$ & \% ن & عن أفكار هم بحية وفق ضوابط المدرسة & \\
\hline 7 & $V_{Y Y}$ & ra & 171 & Y90 & $1 \times 9$ & ت & تطبيق لائحة الانضباط المدرسي بعدالة & $\mu r$ \\
\hline 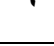 &. &.. & $r 9.1$ & $\varepsilon \vee .7$ & YY.T & $\%$ & على جميع العاملين والطلاب & \\
\hline 15 & $y_{1}$ & 107 & mo & IVY & $v \cdot$ & $ت$ & تدعو إدارة المدرسة أولياء الأمور إلى & $\mu$ \\
\hline & r. & & 09.7 & $r \cdot .9$ & $1 Y .7$ & $\%$ & المشاركة في الأنشطة المدرسية & \\
\hline$y$ & 79 & r & 100 & 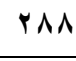 & $11 \varepsilon$ & $ت$ & تتعامل إدارة المدرسة والعاملين مع & 4 \\
\hline$r$ & . &.. & $r V . \Lambda$ & $01 . \mathrm{V}$ & $r \cdot .0$ & \%ن & 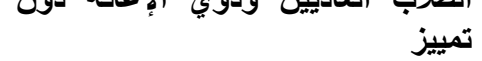 & 16 \\
\hline & & & rMA & $1+9$ & A. & 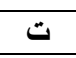 & تدعو إدارة المدرسة أعضاء المجتمع & \\
\hline it & $\cdot . \mathrm{Vr}$ & $1.0 \leqslant$ & $7 . .7$ & ro. & $1 \leqslant .4$ & $\%$ & 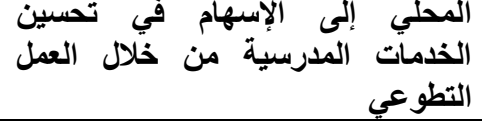 & ro \\
\hline & & & 184 & YAO & 99 & ت & تعمل إدارة الددرسة بالتنسيق مي الجهات & \\
\hline 1. &. .71 & $1 . \wedge 4$ & -1.7 & 01.5 & IV.Y & $\%$ & 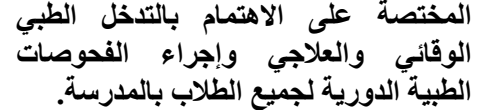 & r \\
\hline $1 \leqslant$ & $\cdot . v 1$ & 1.29 & roy & ira & Vr & 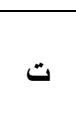 & 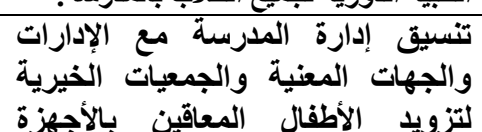 & $r v$ \\
\hline & & & 74.9 & RT.T & 14.9 & \% & التعويضية والمعينات الطبية اللازمة & \\
\hline &. .07 & 1.14 & & & لعام & 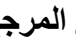 & المتوسط الحساب & \\
\hline
\end{tabular}


بينت النتائج بالجدول رقم (^) أن استجابات أفراد العينة من معلمي ومعلمات مدارس الدمج حول مدى توفر القيادة المهنية المتعلقة بتحول مدارس الامج إلى بيئة مدرسية آمنة

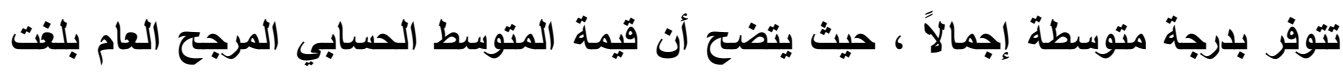

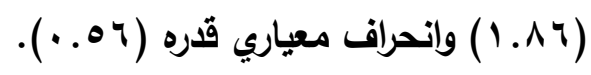
وفيما يلي يتناول الباحثان أبرز المؤثرات المتعلقة بالقيادة المهنية المتعلقة للتحول

إلى بيئة مدرسية آمنة في ضوء وجهات نظر أفراد العينة المشاركين في الدراسة الحالية:

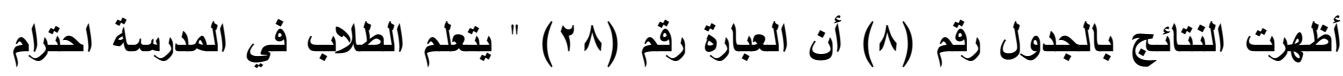
القانون " قد حازت على المرتبة الأولي من بين الفقرات المفسرة للقيادة المهنية كأحد المتطلبات الهامة للتحول إلى بيئة تعليمية آمنة، ويعزز ذلك قيمة الكاولية المتوسط الحسابي

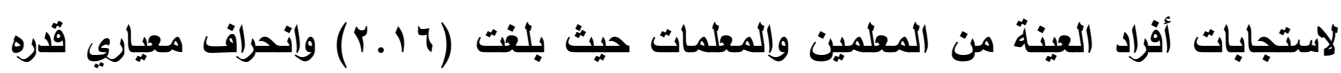

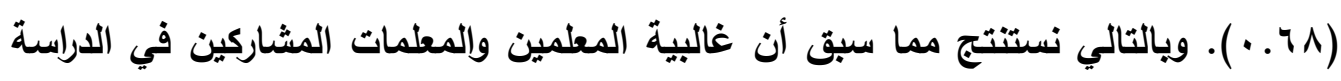
الحالية يعتقدون أن موضوع تعلم الطلاب في المدرسة احترام القانون يتوفر بدرجة متوسطة.

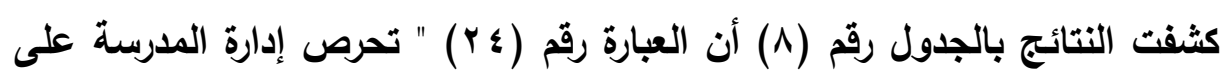
العمل بروح الفريق للوصول إلى الأمن البيئي والنفسي للعاملين والطلاب " قد حازت على الى الثارة

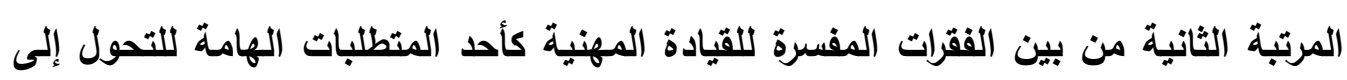
بيئة مدرسية آمنة، ويدعم ذلك قيمة المتوسط الحسابي لاستجابات أفراد العينة من المعلمين

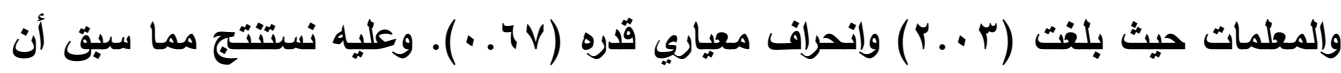

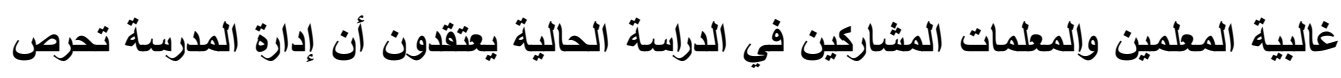
على العمل بروح الفريق للوصول إلى الأمن البيئي والنفسي للعاملين والطلاب يتوفر بدرجة متوبطة. 


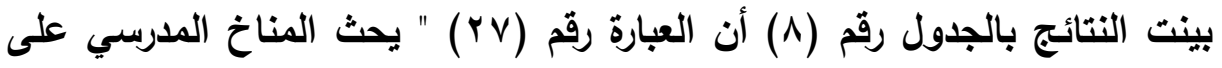

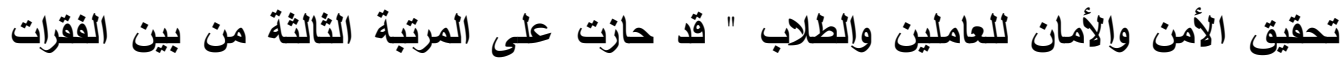

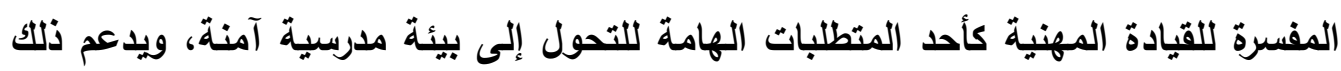

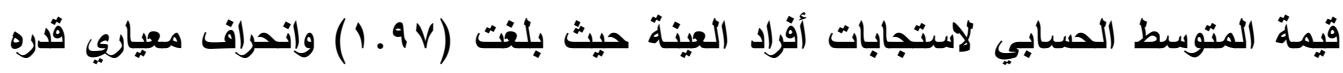

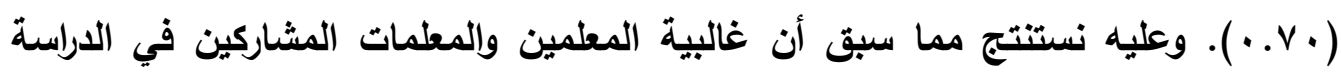

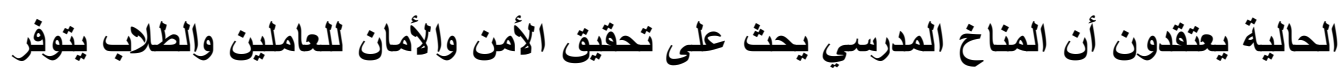

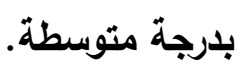

كما كثفت النتائج بالجدول رقم (^) أن العبارة رقم (هاب) " تحرص إدارة العدرسة

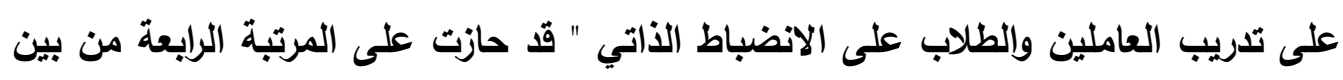

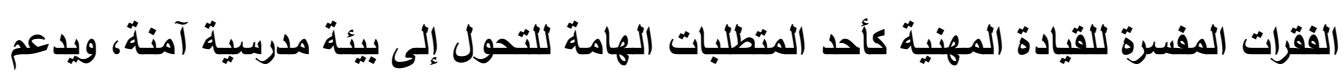

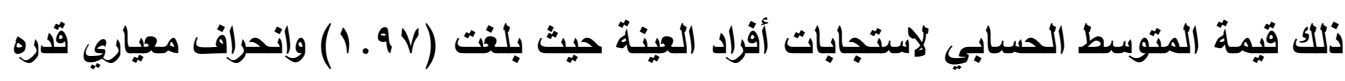

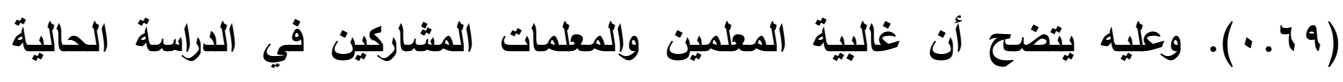
يعتقدن أن إدارة المدرسة تحرص على تدريب العاملين والطلاب على الانضباط الذاتي بدرجة الدئة

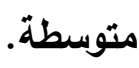

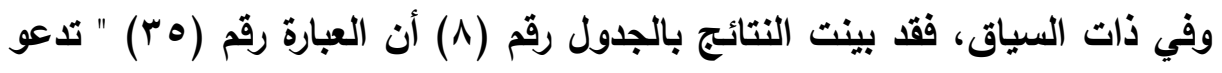

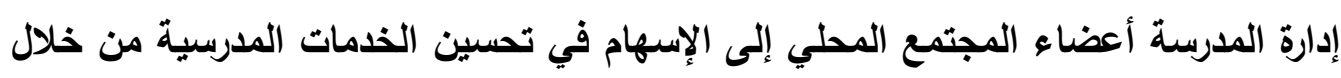

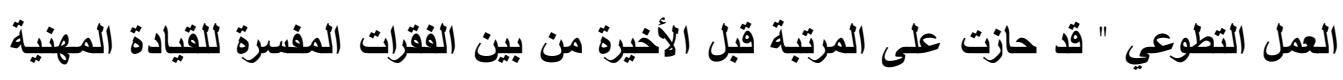

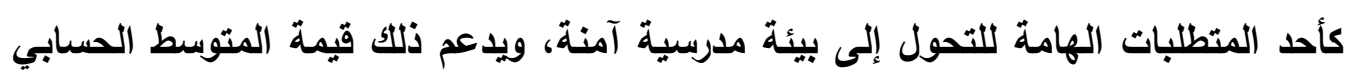

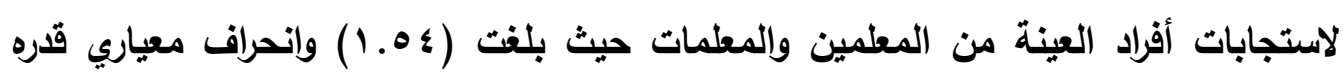

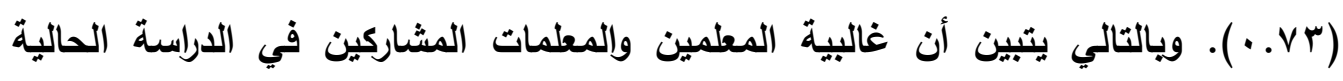

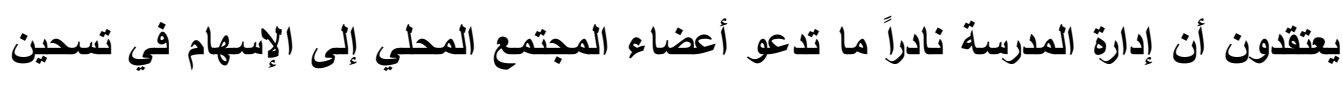

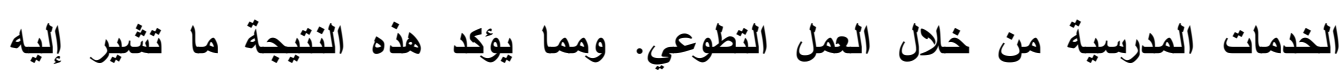

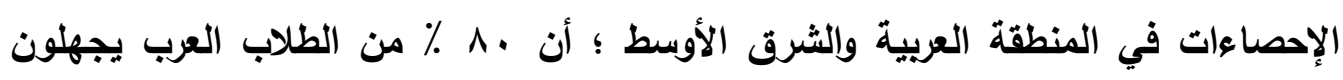

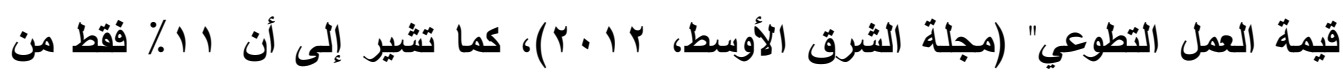

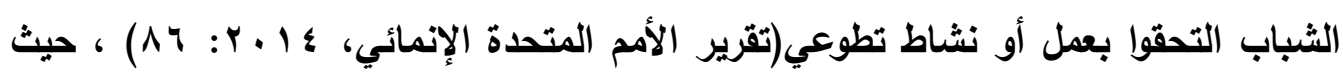

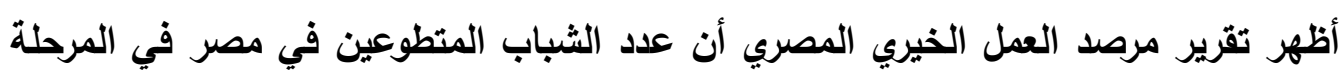




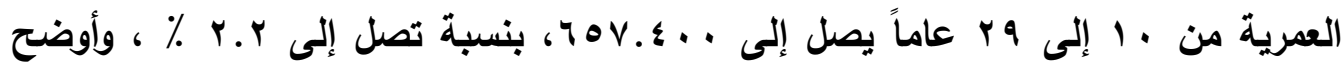

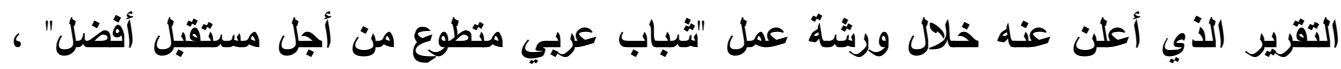

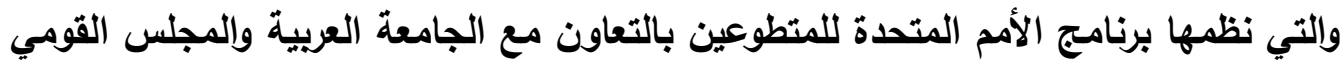

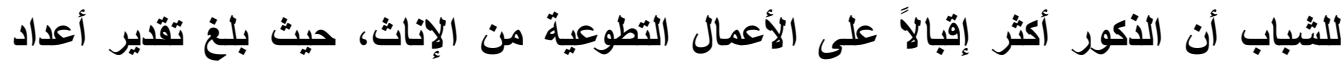

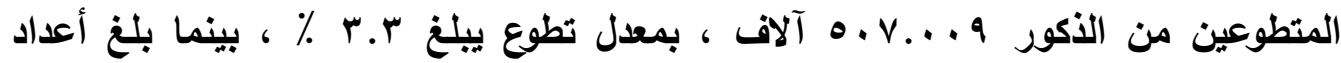

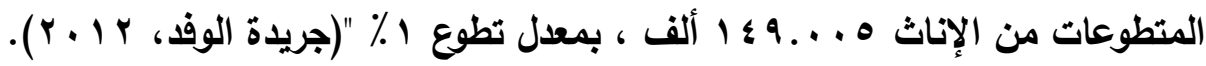

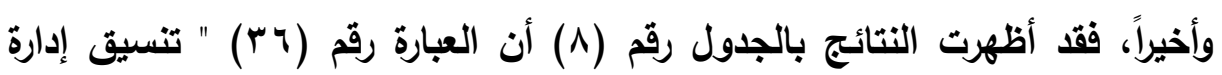

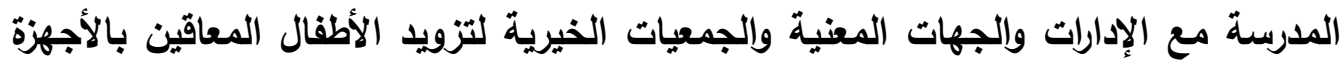

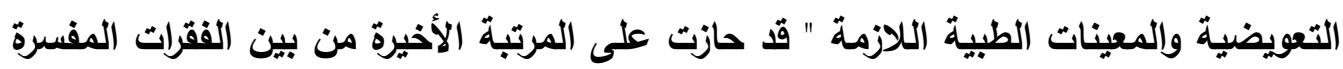

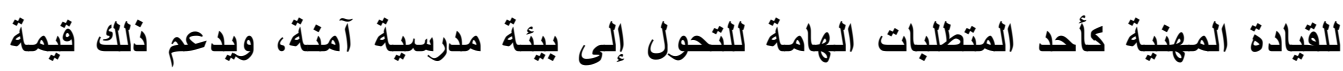

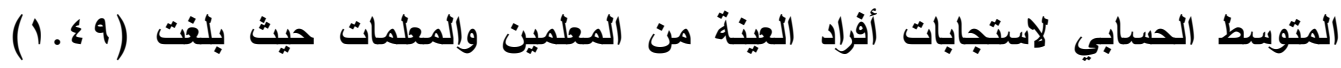

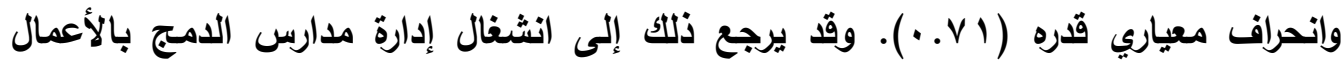
الروتينية وتنفيذ الجدول الدراسي ، وضعف التنسيق بين الجمعيات الخيرية والمؤسسات

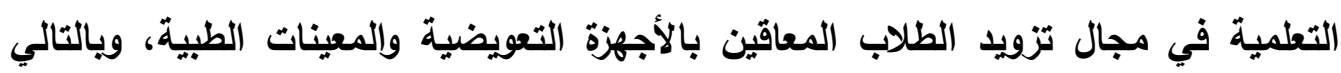

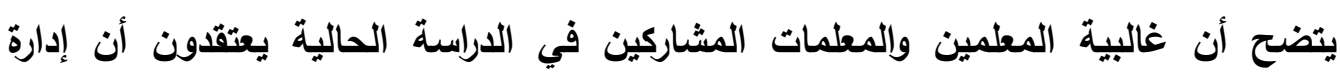
المدرسة ناداً ما تتسق مع الإدارات والجهات المعنية والجمعيات الخيرية لتزويد الأطفال المعاقين بالأجهزة التعويضية والمعينات الطبية اللازمة.

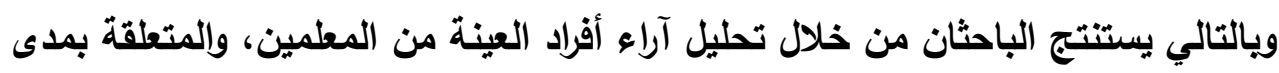

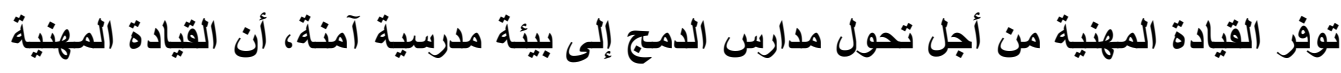

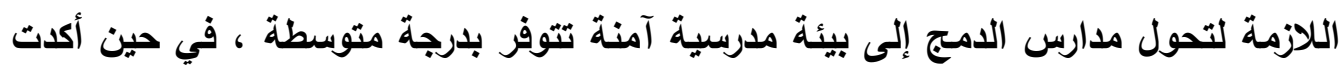

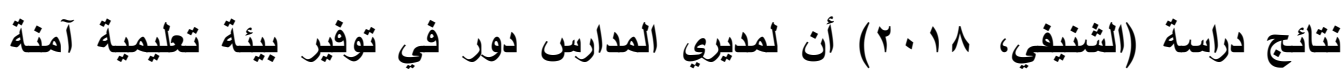

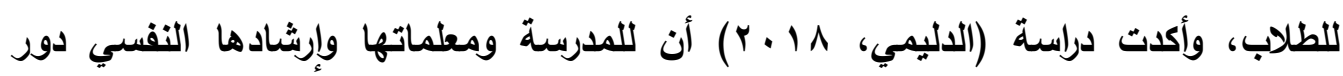

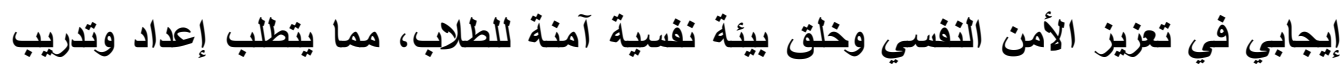

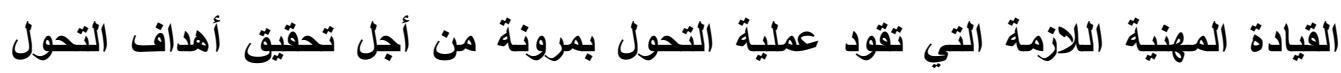
التعليمية والتزبوية. 
د. النتائج الخاصة بترتيب عبارات المحور الرابع الخاص باستجابات أفراد العينة حول

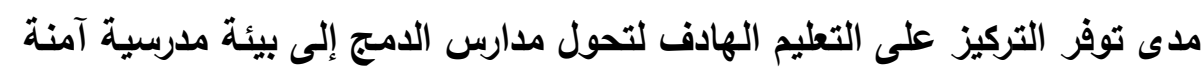

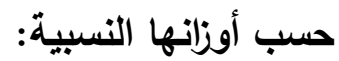

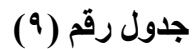

التكرارات والنسب المئوية والمتوسطات الحسابية والانحر افات المعيارية لاستجابات

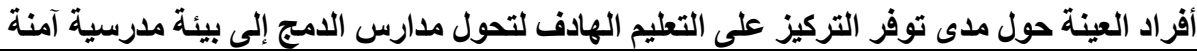

\begin{tabular}{|c|c|c|c|c|c|c|c|c|}
\hline \multirow{2}{*}{ 牙: } & \multirow{2}{*}{ 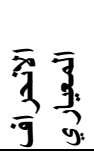 } & \multirow{2}{*}{ 牙 } & \multicolumn{3}{|c|}{ خيارات الإجابة } & & & \multirow{2}{*}{ 高 } \\
\hline & & & $\stackrel{2}{3}$ & $\bar{y}:$ & $\frac{7}{3}$ & & & \\
\hline \multirow{2}{*}{$r$} & \multirow{2}{*}{.7} & \multirow{2}{*}{$r . \leqslant V$} & 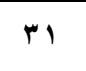 & $r r \varepsilon$ & rqr & 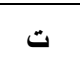 & \multirow{2}{*}{ 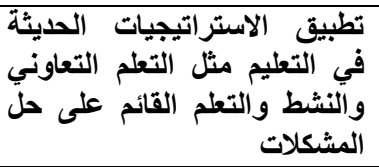 } & \multirow{2}{*}{$r \wedge$} \\
\hline & & & 0.7 & $\varepsilon r_{.} \cdot$ & or.s & \%ं & & \\
\hline \multirow{2}{*}{0} & \multirow{2}{*}{.04} & \multirow{2}{*}{ r.rq } & $r_{1}$ & $r r \varepsilon$ & 194 & ت & \multirow{2}{*}{ الإدارة الصتف ب استراتيجيات عن العنف حديثة } & \multirow{2}{*}{ rq } \\
\hline & & & 0.7 & $9 \cdot$. & $r \leqslant . \varepsilon$ & $\%$ & & \\
\hline \multirow{2}{*}{$r$} & \multirow{2}{*}{$\because v r$} & \multirow{2}{*}{ r.rq } & $\wedge 1$ & $I V \wedge$ & YqA & $ت$ & \multirow{2}{*}{ 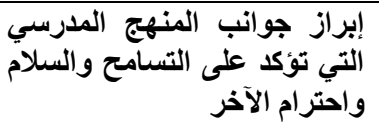 } & \multirow[b]{2}{*}{$\varepsilon$. } \\
\hline & & & $1 \leqslant .0$ & rr." & or.o & \%ن & & \\
\hline \multirow[b]{2}{*}{$\varepsilon$} & \multirow[b]{2}{*}{$\because 70$} & \multirow[b]{2}{*}{ r.ru } & 07 & r99 & TrY & $ت$ & \multirow{2}{*}{ 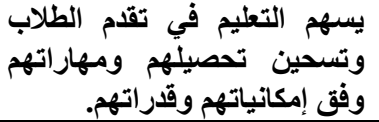 } & \multirow[b]{2}{*}{$\leqslant 1$} \\
\hline & & & $1 \cdot .1$ & $\leq \wedge . r$ & $\leqslant 1.7$ & \%ं & & \\
\hline \multirow{2}{*}{1} & \multirow{2}{*}{$\because \diamond \mathrm{V}$} & \multirow{2}{*}{ Y. $\leqslant V$} & $Y 1$ & YOY & $r \wedge \leq$ & $ت$ & \multirow{2}{*}{ بين الطلاب وبعضيم العلاقات الإيجابية } & \multirow{2}{*}{$\leqslant r$} \\
\hline & & & $r . \wedge$ & $\varepsilon 0 . Y$ & $01 . \cdot$ & $\% \dot{0}$ & & \\
\hline \multirow[b]{2}{*}{9} & \multirow[b]{2}{*}{$\because \vee 9$} & & $1 \leq V$ & $r \cdot r$ & $r \cdot \Lambda$ & $ت$ & ينك تقايم الخدمات الإرشادية & \\
\hline & & Y.11 & r.. & r..r & $r v . r$ & \%ن & 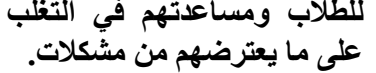 & $\leqslant r$ \\
\hline & & & Irr & YIS & Y. & ت & تستخدم الأساليب الوقائية والعلاجية & \\
\hline$\wedge$ & $\because V V$ & r.lı & rr.q & r^.๕ & $r v . v$ & $\%$ & لتيقاع العقوبة علئه الطلاب المخالفين قبل & $\varepsilon \varepsilon$ \\
\hline 1. & - $\lambda_{1}$ & $r . r$ & 180 & 119 & 194 & $ت$ & تحتوي الأنشطة الطلابية على برامج & $\leqslant 0$ \\
\hline & ו & & $r 1 . \varepsilon$ & $r r .9$ & $r \varepsilon . \wedge$ & $\%$ & تستوعب التلاميذ ذوي الإعاقة & \\
\hline V &.$V r$ & r IV & 1.1 & $r \leq V$ & $r \cdot r$ & $ت$ & إثراء الموقف التعليمي بالأنشطة & $\leqslant 7$ \\
\hline & $\because$ & & 19.5 & \&ะ.r & $r \bar{r}$ & $\%$ & التربوية للحد من الشغب والعنف & 27 \\
\hline 7 & .79 & Y Y r & $\wedge 7$ & r4r & $r \cdot \Lambda$ & $ت$ & الإشراف على تنفيذ البرنامج & $\leqslant y$ \\
\hline & & & 10.5 & $\varepsilon V . Y$ & $r V . r$ & $\%$ & الدراسي بالمدرسة & $2 v$ \\
\hline 11 & $\because \vee \leqslant$ & 1.11 & Y10 & $r r \leq$ & 1.1 & ت & التعليمية لتناسب جميع الوسائل والمصادر & $\leqslant \wedge$ \\
\hline & & & $r \wedge .7$ & $\varepsilon Y_{.}$ & 19.5 & \%ن & & \\
\hline & $.0 Y$ & Y.YY & & & 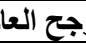 & حسابي & المتوسط & \\
\hline
\end{tabular}


بينت النتائج بالجدول رقم (9) أن استجابات أفراد العينة من معلمي ومعلمات مدارس الامج حول مدى توفر التركيز على التعليم الهادف لتحول مدارس الدمج إلى بيئة مدرسية آمنة يتوفز بلرجة متوسطة ، حيث يتضح أن قيمة المتوسط الحسابي المرجح العام بلفت

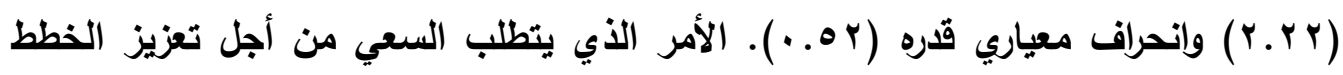

$$
\text { التي تدعم التركيز على التعليم الهادف. }
$$

وفيما يلي يتناول الباحثان أبرز المؤثرات المتعلقة بالتركيز على التعليم الهادف

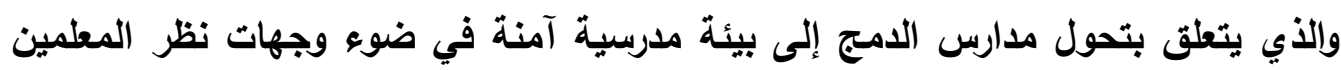
والمعلمات عينة الدراسة الحالية:

أظهرت النتائج بالجدول رقم (9) أن العبارة رقم (Y \&) " يدعم التعليم العلاقات الإيجابية بين الطلاب ويعضهم البعض " قد حازت على المرتبة الأولي من بين الفقرات

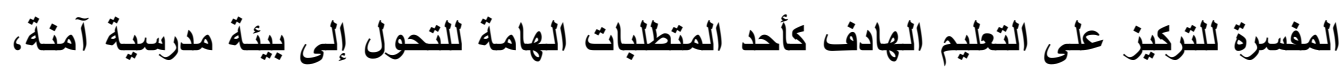

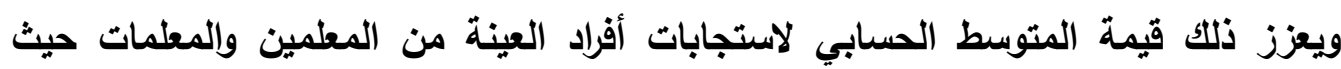

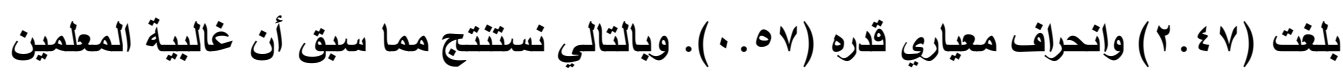

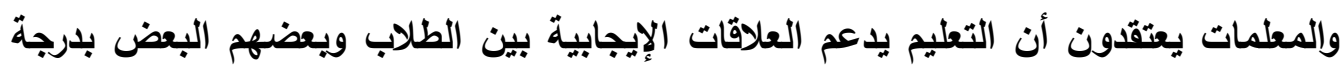
متوسطة.

كما بينت النتائج بالجدول رقم (q) أن العبارة رقم (r^) حيث نصت على" تطبيق الاستراتيجيات الحديثة في التعليم مثل التعلم التعاوني والنشط والتعلم القائم على حل الجل المشكلات " قد حازت على المرتبة الثانية من بين الفقرات المتعلقة بالتركيز على التعليم

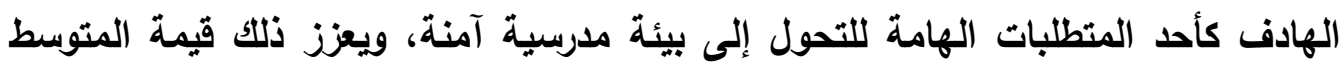

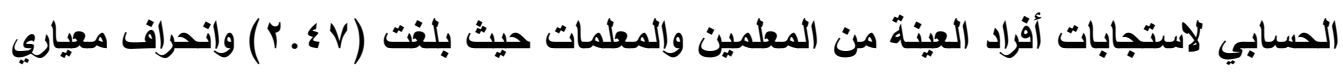

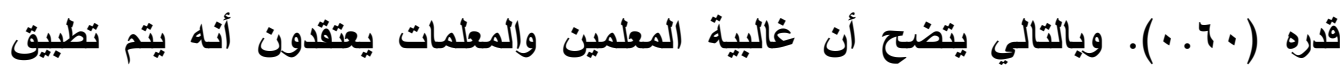

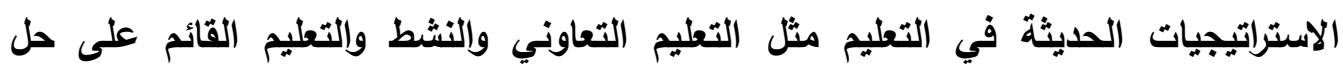
المشكلات من أجل التحول إلى بيئة مدرسية آمنة. 
وفي ذات السياق، فق أظهرث النتائج بالجدول رقم (9) أن العبارة رقم ( • ؛) والتي

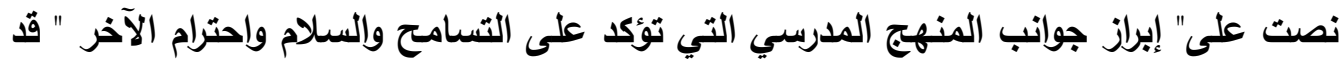

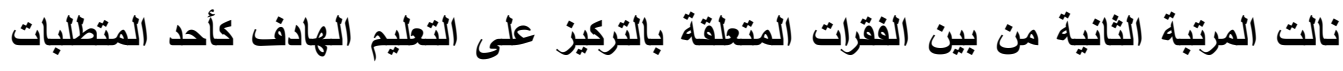

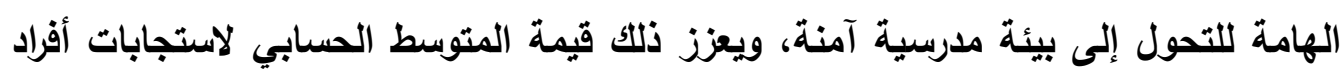

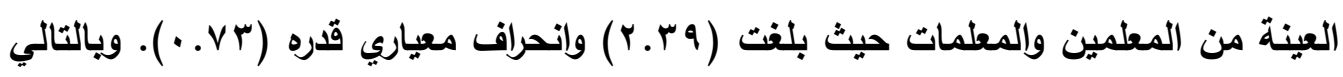

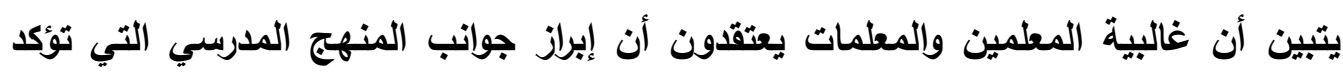

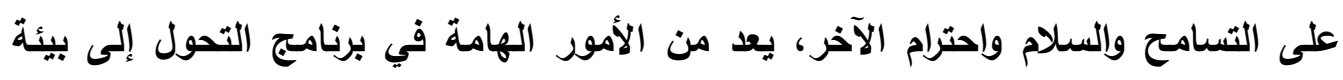
تعليمية آمنة تعنى بشئون طلاب الامجه.

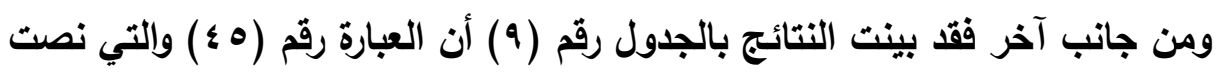

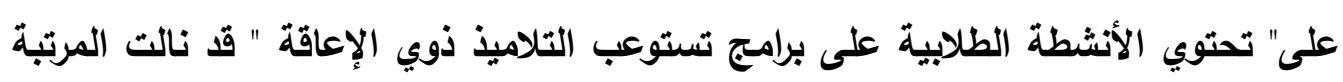

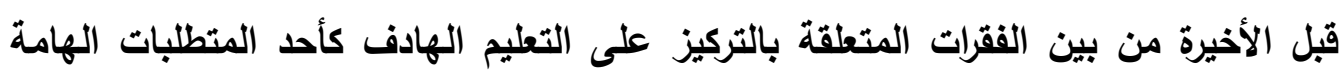

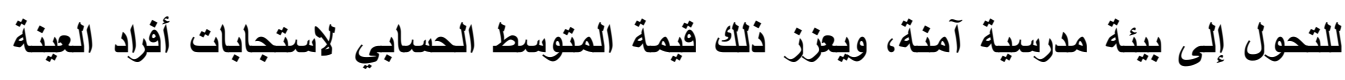

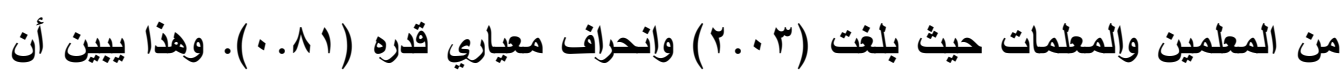

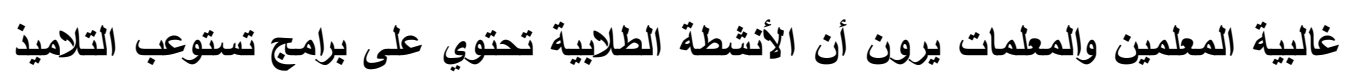

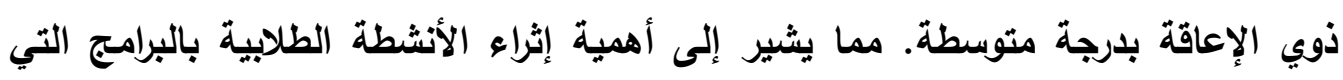
تستوعب التلاميذ ذوي الاحتياجات الخاصة وتلبي رغباتهر.

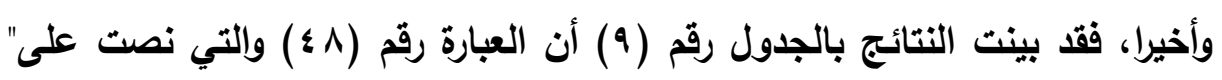

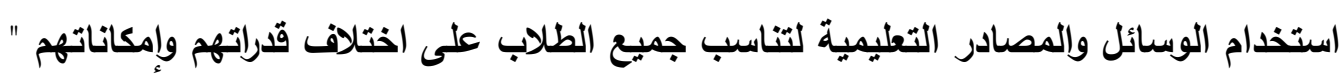

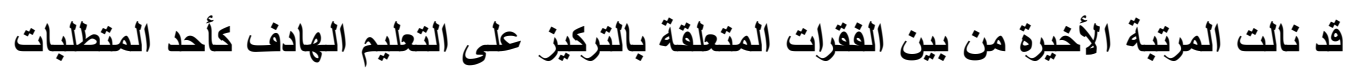

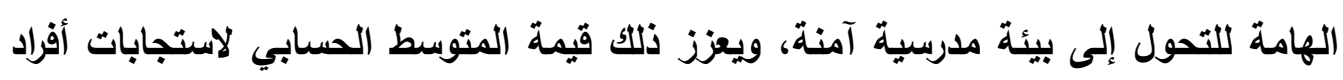

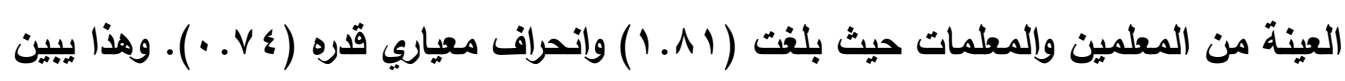

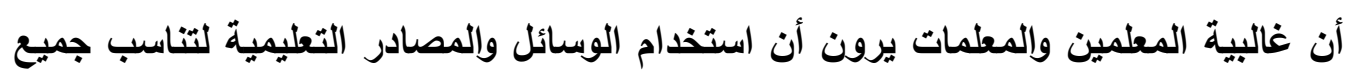

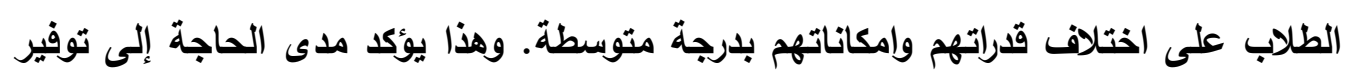
الوسائل والمصادر التطليمية التي تتناسب مع قدرات التلاميذ وقداتهم وإمكاناتهم الفردية. 


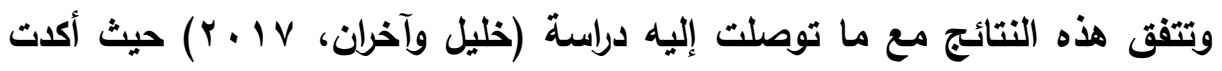

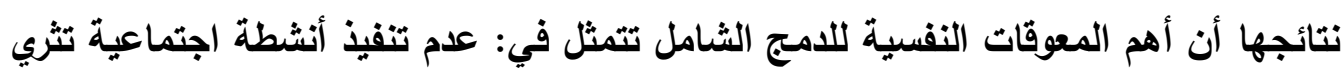
العلاقة بين التلاميذ ذوي الإعاقة وأقرانهم العاديين، وقصور في إثباع رغبات وميول التلاميذ

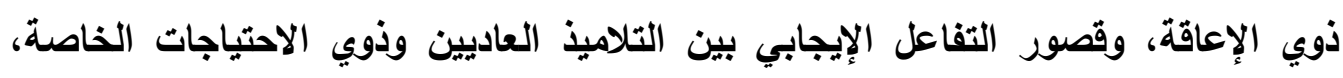

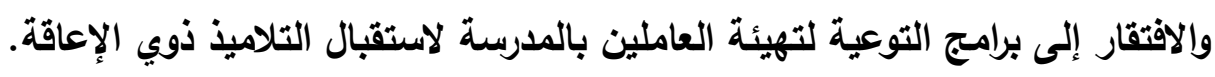

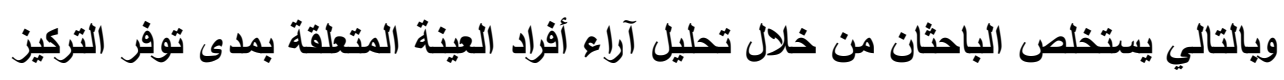

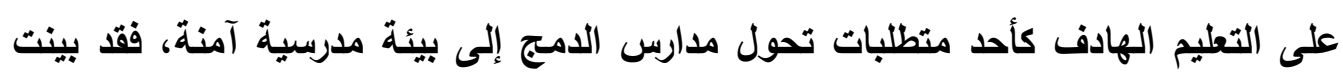

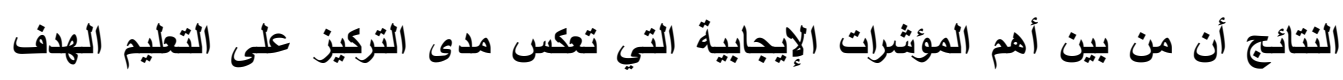

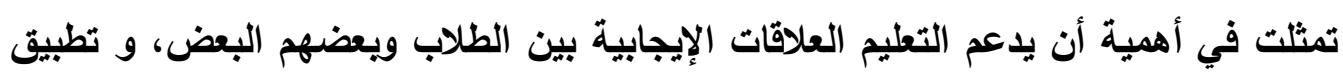

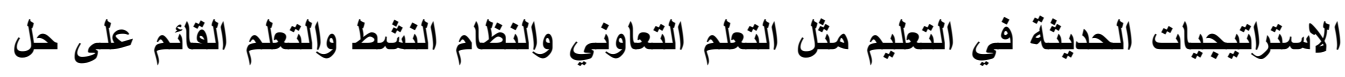

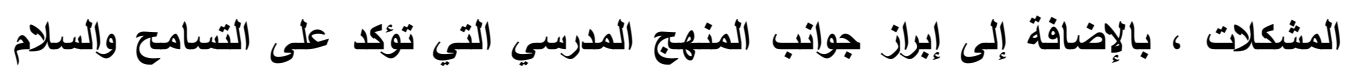

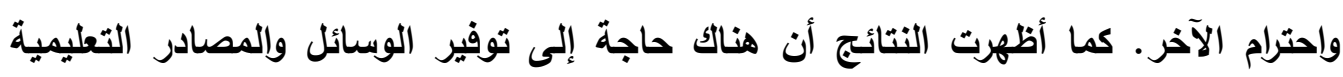

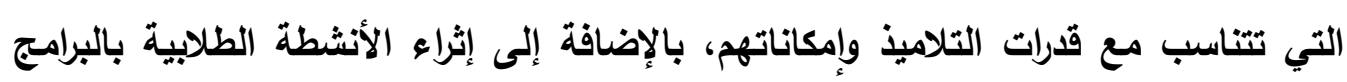

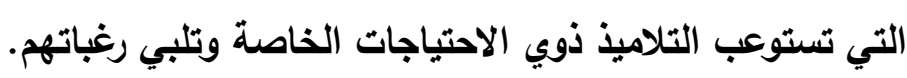

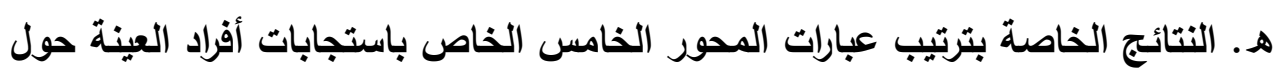

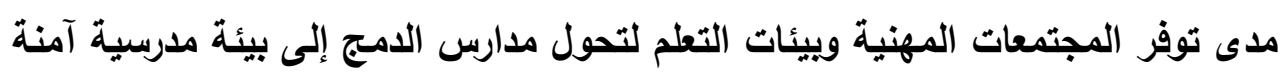

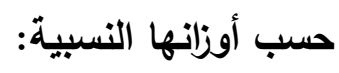


تصور مقترح لتحول مدارس الدمج إلى بيئة مدرسية آمنة .

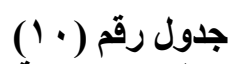

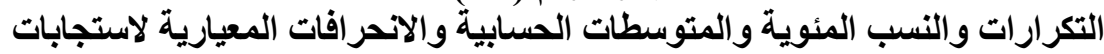

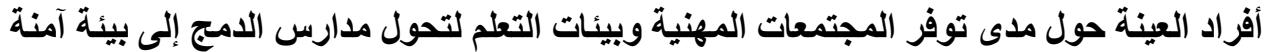

\begin{tabular}{|c|c|c|c|c|c|c|c|c|}
\hline \multirow{2}{*}{ 可: } & \multirow{2}{*}{ 高 } & \multirow{2}{*}{ 孚 } & \multicolumn{3}{|c|}{ 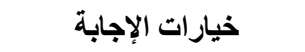 } & & & $: \mathcal{2}$ \\
\hline & & & $\stackrel{-3}{3}$ & $\overline{1}:$ & ${ }_{13}^{\frac{7}{3}}$ & & & 10 \\
\hline \multirow[t]{2}{*}{1} & \multirow{2}{*}{$\because \leqslant 0$} & \multirow{2}{*}{$r . r r$} & $\Lambda$ & $\varepsilon \mid \Lambda$ & $|r|$ & ت & \multirow{2}{*}{ 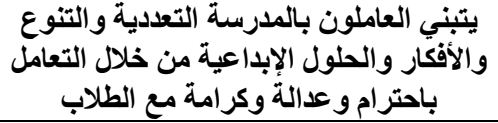 } & \multirow{2}{*}{$\varepsilon q$} \\
\hline & & & $1 . \varepsilon$ & $\vee \bullet$. & $r r .0$ & \% & & \\
\hline \multirow{2}{*}{$r$} & \multirow{2}{*}{. .70} & \multirow{2}{*}{ 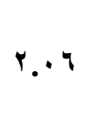 } & 1.1 & $p 1 q$ & IrV & ت & \multirow{2}{*}{ 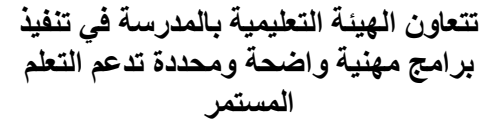 } & \multirow{2}{*}{0 . } \\
\hline & & & 11 & ov.r & $r \varepsilon .7$ & $\%$ & & \\
\hline \multirow{2}{*}{$\varepsilon$} & \multirow{2}{*}{$\because \vee 7$} & \multirow{2}{*}{ I.Ar } & $Y 17$ & YrY & 119 & ت & \multirow{2}{*}{ توجد خطة للارتقاء بنوعية وجودة العلاقات } & \multirow{2}{*}{01} \\
\hline & & & $\stackrel{\mu}{\Lambda}$ & rq.^ & Y $1 . \varepsilon$ & \%ं & & \\
\hline \multirow{2}{*}{0} & \multirow{2}{*}{$\because V V$} & \multirow{2}{*}{$1 . \wedge}$. & rrI & $r \cdot \varepsilon$ & IYY & ت & \multirow{2}{*}{ يتم تلعيم الشراكة مع أولياء الأمور للحد السيطرة عليه } & \multirow{2}{*}{$\Delta r$} \\
\hline & & & \&1. & rq. & Y 1.9 & ن & & \\
\hline \multirow[b]{2}{*}{ V } & \multirow{2}{*}{.$V V$} & \multirow[b]{2}{*}{$1 . V \varepsilon$} & Yos & 194 & 11. & ت & \multirow{2}{*}{ تعزليز المعلمون والقيادات المدربة الطية على وملكية الطالب } & \multirow[b]{2}{*}{ or } \\
\hline & & & $\varepsilon 0$. & $r \varepsilon . V$ & 19.8 & $\%$ & & \\
\hline \multirow{2}{*}{9} & \multirow{2}{*}{$\bullet . \wedge \mu$} & \multirow{2}{*}{1.20} & $r \wedge I$ & Iro & $1 \leq 1$ & ت & \multirow{2}{*}{ 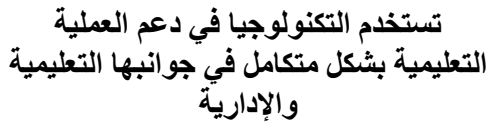 } & \\
\hline & & & 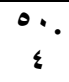 & $r \varepsilon . Y$ & $r \bullet . r$ & ن & & $0\}$ \\
\hline & & & 194 & 194 & IVY & ت & يراعي المعلم الفروق الفردية بين الطلاب & \\
\hline$r$ & $\bullet \wedge 1$ & 1.97 & $\stackrel{r \varepsilon}{0}$ & $r \varepsilon .7$ & $r \cdot .9$ & $\%$ & إمكانياته في دراسته وفق & 00 \\
\hline & & & $m \cdot 1$ & 149 & $11 \mathrm{~V}$ & ت & & \\
\hline$\Lambda$ &.$\wedge \cdot$ & $1.7 \mathrm{~V}$ & $0 \leq$. & ro.. & r.. & $\%$ & (المكتبة_المع & 07 \\
\hline & & & Mr & IYV & 1.9 & ت & تهتم المدرسة بالرحلات والحفلات المدرسية & \\
\hline 9 & $\because \vee q$ & $1.7 r$ & $\frac{0 V}{1}$ & rY.A & 19.7 & $\%$ & بطة الفنية والرياضية والاجتماعية & $\Delta V$ \\
\hline & & & rrt & IYV & 99 & ت & & \\
\hline $1 \cdot$ &. $\mathrm{VV}$ & 1.01 & 89. & rY.A & $1 \mathrm{~V} .1$ & $\%$ & 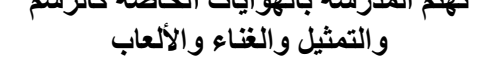 & $\bullet \wedge$ \\
\hline & .94 & $1 . \wedge r$ & & & & رجح & المتوسط الحسابي & \\
\hline
\end{tabular}


بينت النتائج بالجدول رقم (· (1) أن استجابات أفراد العينة من معلمي ومعلمات

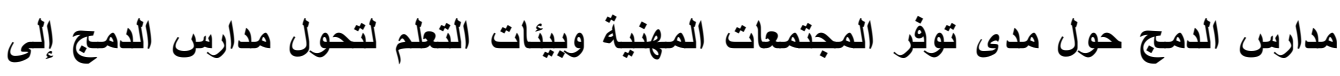
بيئة مدرسية آمنة يتوفر بلرجة متوسطة، حيث يتضح أن قيمة المتوسط الحسابي بلغت

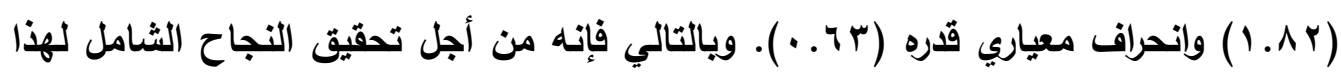

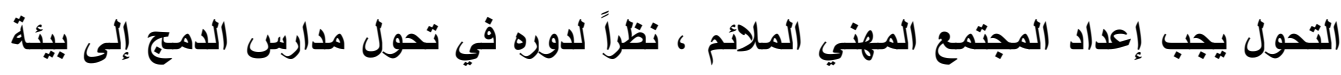
مدرسبة آمنة.

وفيما يلي يتتاول الباحثان أبرز المؤشرات المتعلقة بأهمية توفر المجتمعات المهنية

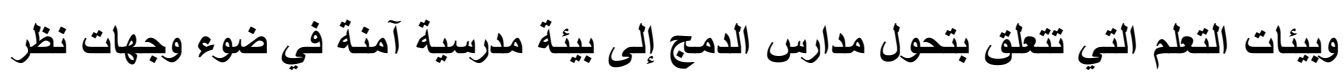
المعلمين والمعلمات عينة الدراسة الحالية: كثفت النتائج بالجدول رقم (• 1) أن العبارة رقم (9 ؛ ) " يتبني العاملون بالمدرسة

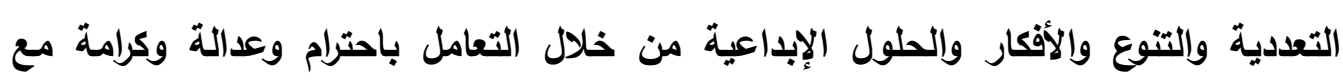
الطلاب " قد حازت على المرتبة الأولي من بين الفقرات المتعلقة بمدى توفر المجتمعات

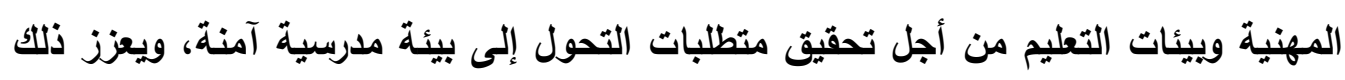

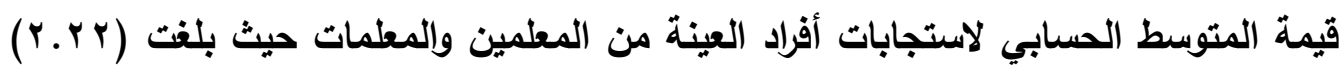
وانحراف معياري قدره (0 ـ . ). ويالتالي يتبين مما سبق أن غالبية المعلمين والمعلمات

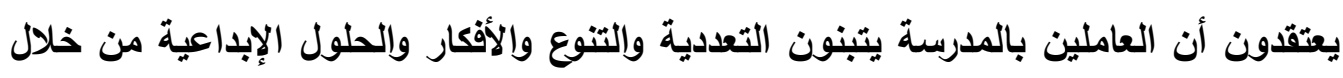

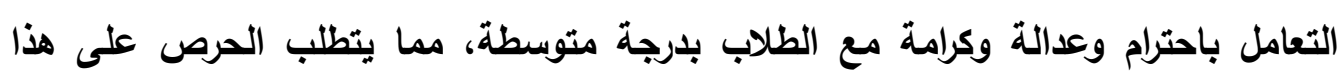
الجاتب لأنه يعد من الركائز الهامة لتحقيق أهداف عملية التحويل إلى بيئة مدرسية آمنة.

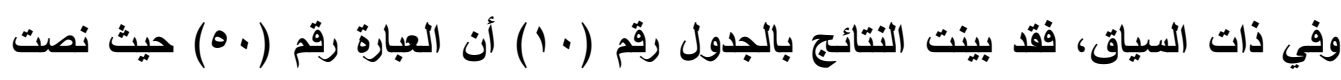
على" تتعاون الهيئة التعليمية بالمدرسة في تنفيذ برامج مهنية واضحة ومحددة تدعم التعلم

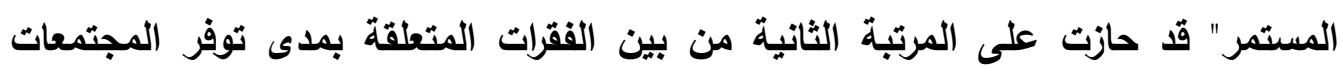

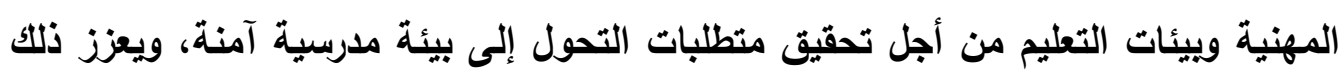

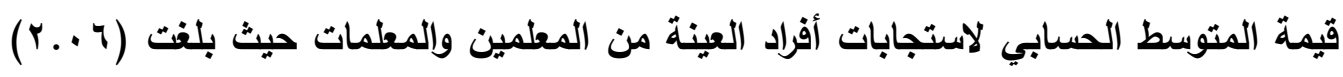
وإنحراف معياري قدره (0 ج . ) ). وعليه نستتتج من ذلك أن غالبية المعلمين والمعلمات يرون أن الهيئة التعليمية بالمدرسة تتعاون في تنفيذ برامج مهنية واضحة ومحددة تدعم التعلم

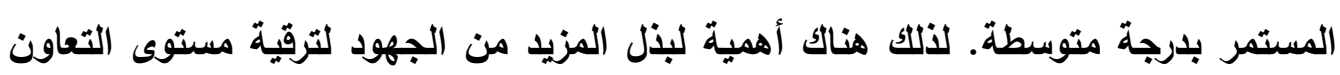


في تنفيذ البرامج المهنية المطلوية لتحقيق أهداف التحول. وقد أكلت نتائج دراسة (المكاوي،

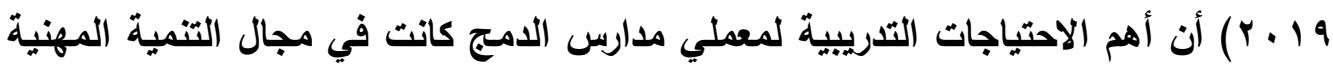

للمعلم.

كما بينت النتائج بالجدول رقم (· (1) أن العبارة رقم (ه०) " يراعي المعلم الفروق الفردية بين الطلاب بحيث يسير كل طالب في دراسته وفق إمكانياته " قد حازت على المرتبة الثالثة من بين الفقرات المتعلقة بمدى توفر المجتمعات المهنية وييئات التعليم من أجل تحقيق متطلبات التحول إلى بيئة مدرسية آمنة، ويدعم ذلك قيمة المتوسط الحسابي

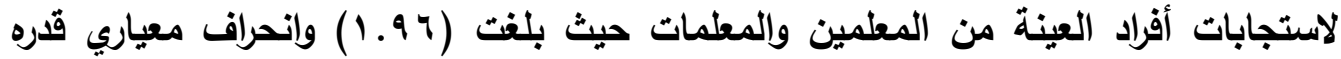
( (1. • ). ويالتالي نستنتج من ذللك أن غالبية المعلمين والمعلمات يعتقدون أن المعلم يراعي الفروق الفردية بين الطلاب بحيث يسير كل طالب في دارسته وفق إمكانياته بدرجة متوسطة. وفي دراسة (Geitz \& Mclnosh, 2014) جاء مجال علاقة المعلم بالطلاب في المرتبة الخامسة والأخيرة ضمن مستويات إدراك الطلاب لبيئة التعلم الآمنة. كما أثنارت النتائج بالجدول رقم ( • 1) أن العبارة رقم (هV) " تهنم المدرسة بالرحلات والحفلات المدرسية والأنشطة الفنية والرياضية والاجتماعية والمسرح المدرسي" قد جاعت في المرتبة قبل الأخيرة من بين الفقرات المتعلقة بمدى توفر المجتمعات المهنية وبيئات التعليم من أجل تحقيق متطلبات التحول إلى بيئة مدرسية آمنة، ويدعم ذلك قيمة المتوسط الحسابي

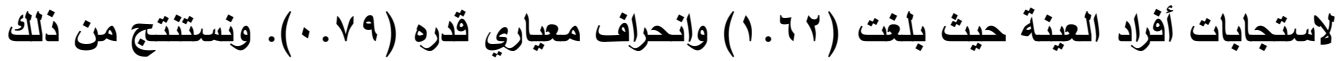
أن غالبية المعلمين والمعلمات المشاركين في الدراسة الحالية يعتقدون أن هناك اهتمام من جانب المدرسة بالرحلات والحفلات المدرسية والأنشطة القنية والرياضية والاجتماعية والمسرح المدرسي بلرجة غير مناسبة، حيث أظهرت النتائج أن و.

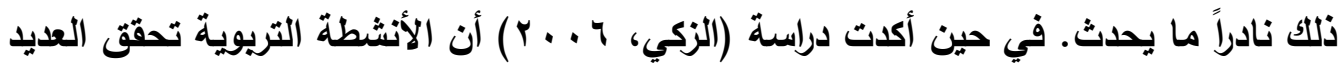
من الأهداف والغايات التي قد تعجز عنها المقررات والمناهج النظامية، وتنمي الوعي الأمني بين الطلاب، وتجعل المدرسة أكثر أماناً. 
بينما أظهرت النتائج بالجدول رقم (· 1) أن العبارة رقم (1ه) حيث نصت على" تهتم

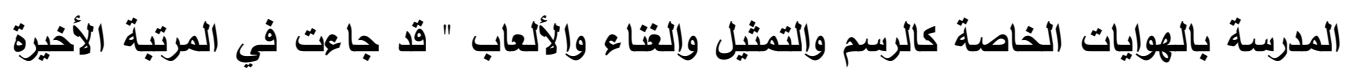

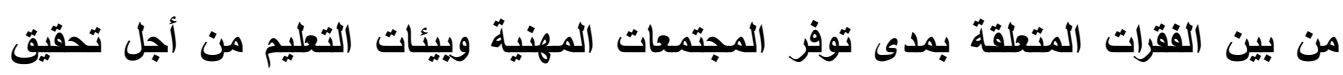

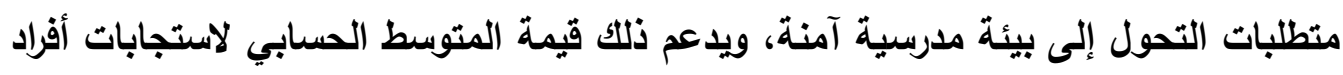

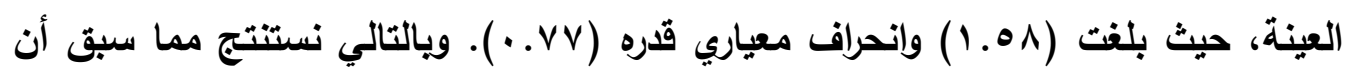

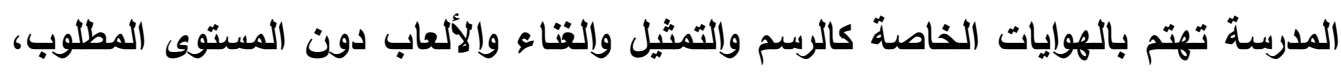

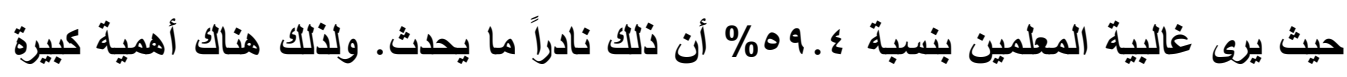

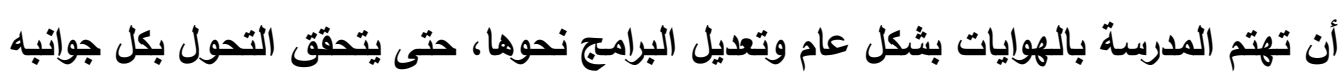
التعليمية والأنثطة المصاحبة.

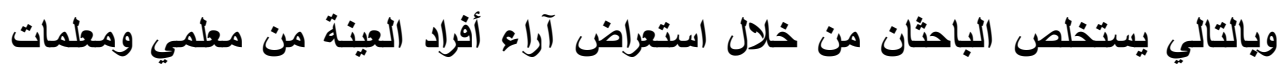

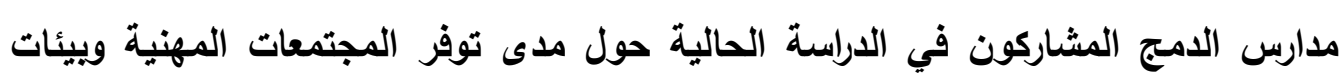

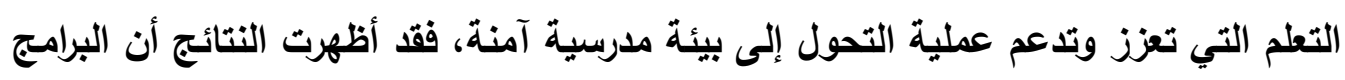

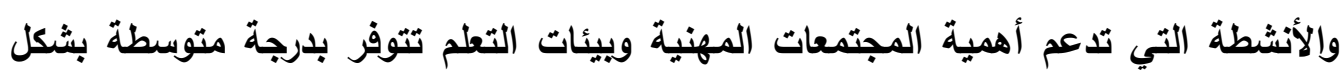

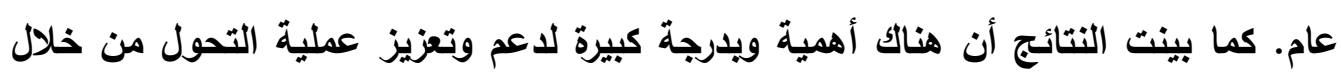

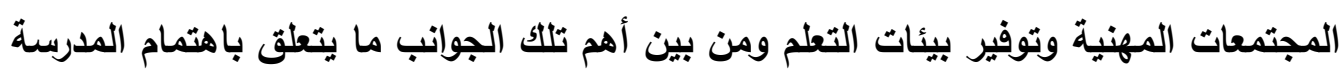

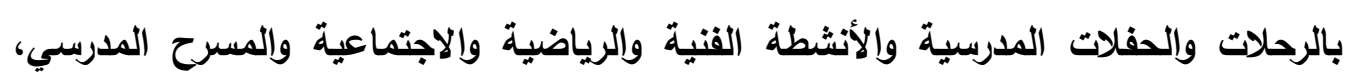
إضافة إلى الاهتمام بالهويات المختلفة كالرسم والتمثيل والنتاء والألعاب.

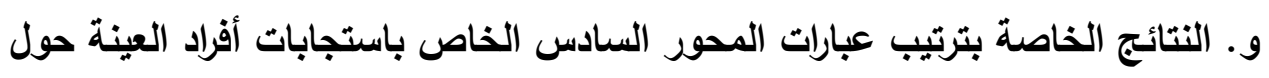

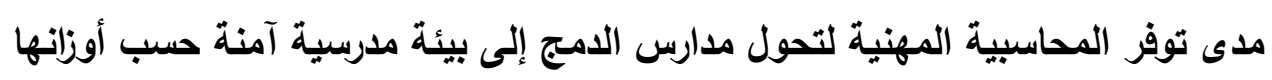

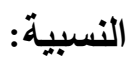


جدول رقم (1)

التكرارات والنسب المئوية و المتوسطات الحسابية والانحرافات المعيارية لاستجابات

أفراد العينة حول مدى توفر المحاسبية المهنية لتحول مدارس الامج إلى بيئة آمنة

\begin{tabular}{|c|c|c|c|c|c|c|c|c|}
\hline \multirow{2}{*}{ 氞: } & \multirow{2}{*}{ 高高 } & \multirow{2}{*}{$\overline{7} \overline{7}$} & \multicolumn{3}{|c|}{ خيارات الإجابة } & & & \multirow{2}{*}{ 盛 } \\
\hline & & & $\stackrel{-2}{3}$ & $\overline{7}$ & $\frac{2}{3}$ & & & \\
\hline \multirow{2}{*}{ 0 } & \multirow{2}{*}{$\cdot v^{\mathrm{V}}$} & \multirow{2}{*}{1.90} & 171 & אדי & Tre & 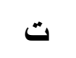 & \multirow{2}{*}{ 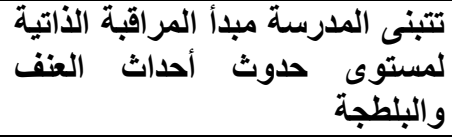 } & \multirow{2}{*}{$0 q$} \\
\hline & & & r^.q & $\leqslant V_{.} Y$ & rr.q & \% & & \\
\hline \multirow{2}{*}{7} & \multirow{2}{*}{$\cdot .74$} & \multirow{2}{*}{1.94} & $1 \leq \varepsilon$ & r. & $1 \cdot r$ & 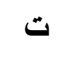 & \multirow{2}{*}{ مراجعة في والنقيح سياسة مواجهة } & \multirow{2}{*}{7.} \\
\hline & & & ro.9 & 00.7 & 11.0 & \% & & \\
\hline \multirow{2}{*}{$\wedge$} & \multirow{2}{*}{$\cdot \wedge$. } & \multirow{2}{*}{$1 . \wedge \varepsilon$} & rYq & 19. & $1 \mathrm{re}$ & $ت$ & \multirow{2}{*}{ 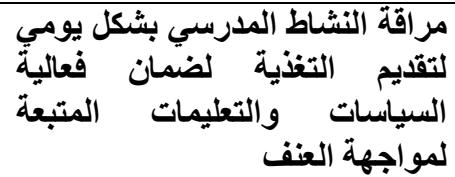 } & \multirow{2}{*}{71} \\
\hline & & & «1.1 & $r \leq .1$ & $Y \leq . \wedge$ & \% & & \\
\hline \multirow{2}{*}{$r$} & \multirow{2}{*}{$\cdot . \mathrm{TV}$} & \multirow{2}{*}{1.99} & 1 rq & $r \cdot 7$ & Irr & 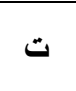 & \multirow{2}{*}{ 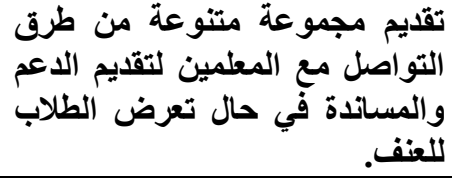 } & \multirow{2}{*}{ ז } \\
\hline & & & rT.Y & $0 \leqslant .9$ & r..9 & \%ن & & \\
\hline \multirow{2}{*}{9} & \multirow{2}{*}{.90} & \multirow{2}{*}{ l.Ar } & IVo & $r .7$ & VY & $ت$ & \multirow{2}{*}{ تشكليم نقاميج الوقاية مع العنف } & \multirow{2}{*}{ ז } \\
\hline & & & r..气 & 00. & $1 \% .7$ & \% & & \\
\hline \multirow{2}{*}{11} & \multirow{2}{*}{$\because \mathrm{V}^{\circ}$} & $1 . V r$ & ror & $r \cdot r$ & $1 \cdot r$ & 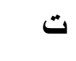 & تطوير جاهزية الطلاب لتسامح & 64 \\
\hline & & & $\{0 . \varepsilon$ & r.. & $11 . r$ & \%ن & وقبول & \\
\hline & & & 100 & $r \cdot r$ & $1 \ldots$ & ت & تحليد الجهة المسؤولة عن محاسبة & \\
\hline $\mathrm{v}$ & $.9 \mathrm{~V}$ & 1.9. & YV.A & $0 \leq . Y$ & $11_{.}$. & \% & أو استخذام أو الطنفلاب في حال الإساءة & 70 \\
\hline 1 & سم & $r$ & Yl & ro. & 119 & ت & محاسبة العاملين بالمدرسة عند & 4 \\
\hline 1 & 10.0 & 1.1 & $r . \Lambda$ & Tr.1 & Tr.\& & \% & 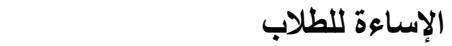 & 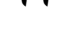 \\
\hline & & & YYO & $r \cdot \Lambda$ & IrE & $ت$ & تحديد البدائل التربوية ل لمعاقبة & \\
\hline 1. & $\because \mathrm{VV}$ & I.Ar & $\{\cdot$. & $r v . r$ & rY.r & \%ن & الطتخلاب العنف الضرورة بعيلا عن & TV \\
\hline 4 & Y & 191 & $1 \leq \cdot$ & rAN & $1 \% q$ & ت & وجود معايير واضحة ومعلنة & 71 \\
\hline 8 & 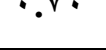 & אד. 1 & Yo.1 & 01.1 & YT.Y & \% & للمحاسبة تثمل العاملين والطلاب & , \\
\hline$r$ & דיר & r. & $11 \varepsilon$ & MIT & 141 & $ت$ & توعية العاملين والطلاب بالمدرسة & 79 \\
\hline 1 & 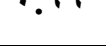 & $\because \cdot 1$ & $r \cdot .0$ & 09.9 & YT.O & \% & بضرورة تحمل مسؤولية أفعالهه. & 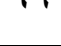 \\
\hline &. .07 & 1.94 & & & 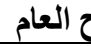 & 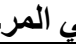 & المتوسط الحسيا & \\
\hline
\end{tabular}


بينت النتائج بالجدول رقم (11) أن استجابات أفراد العينة من معلمي ومعلمات مدارس الامج حول مدى توفر المحاسبية المهنية لتحول مدارس الدمج إلى بيئة مدرسية

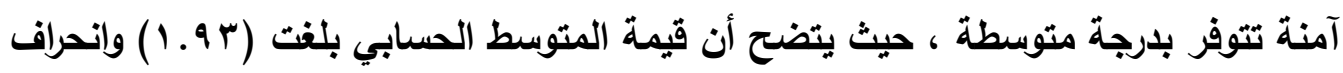

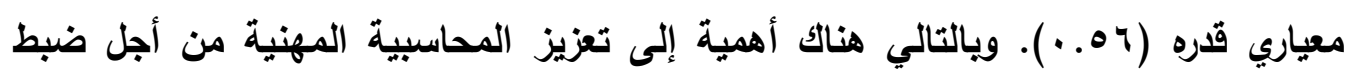
البيئة التعليمية بشكل تام وخاصة العاملين والطلاب.

وفيما يلي يتتاول الباحثان أبرز المؤثرات المتعلقة بأهمية توفر المحاسبية المهنية المهنية

التي تتعلق بتحول مدارس الدمج إلى بيئة مدرسية آمنة في ضوء وجهات نظر المعلمين

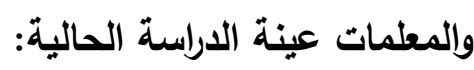
كشفت النتائج بالجدول رقم (11) أن العبارة رقم (7 7) " محاسبة العاملين بالمدرسة

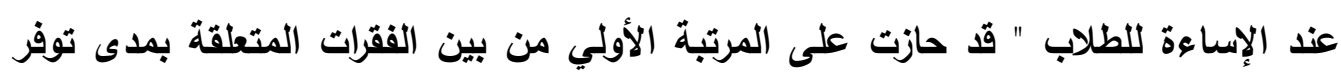

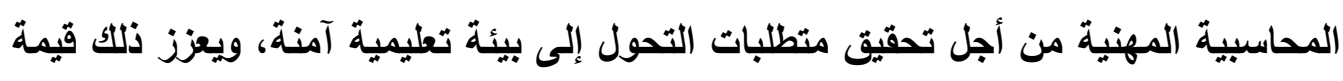
المتوسط العسابي لاستجابات أفراد العينة من المعلمين والمعلمات حيث بلغت (.r.r) واتحراف معياري قدره (rه. ·). ويالتالي يتبين مما سبق أن غالبية المعلمين والمعلمات

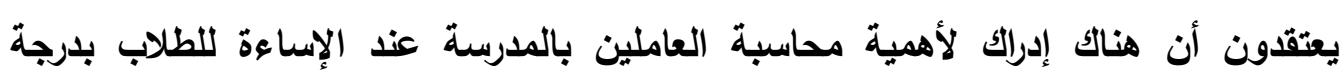

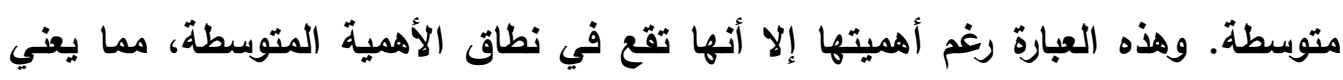

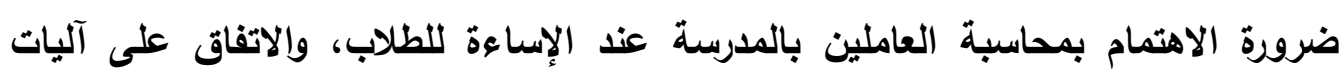
ويدائل تريوية لمحاسبة العاملين والطلاب بعيداً عن العنف أو الإهانة والتخويف والسخرية السية.

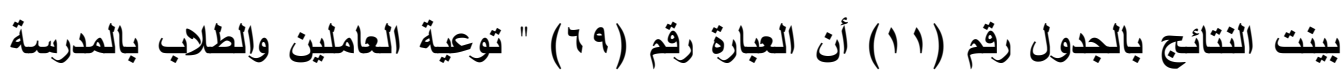
بضرورة تحمل مسؤولية أفعالهم" قد حازت على المرتبة الثانية من بين الفقرات المتعلقة بمدى باتى باتئ

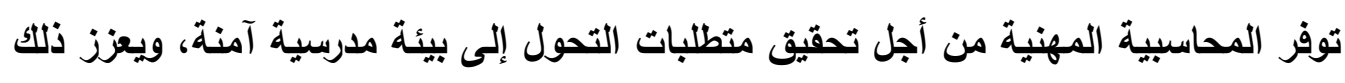

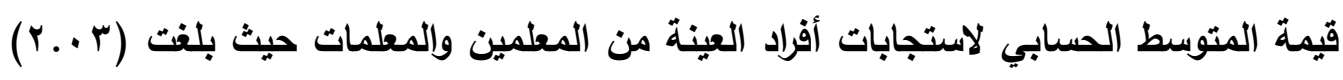

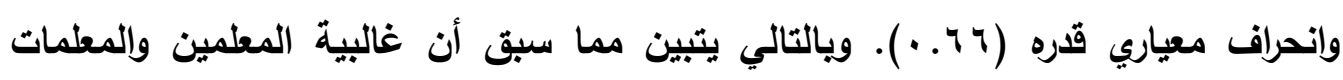
يعتقدن أن توعية العاملين والطلاب بالمدرسة بضرورة تحمل المسؤولية عن أفعالهم تثم بدرجة متوبطة. 
وفي ذات السياق، فقد بينت النتائج بالجدول رقم (11) أن العبارة رقم (Y T) " تقديم مجموعة متنوعة من طرق التواصل مع المعلمين لتقديم الاعم والمساندة في حال تعرض باض الطلاب للعنف". قد حازت على المرتبة الثالثة من بين الفقرات المتعلقة بمدى توفر المحاسبية المهنية من أجل تحقيق متطلبات التحول إلى بيئة مدرسية آمنة، ويعزز ذلك قيمة المتوسط الطئ الحسابي لاستجابات أفراد العينة من المعلمين والمعلمات حيث بلغت (9 9 ـ 1 ) وإنحراف معياري

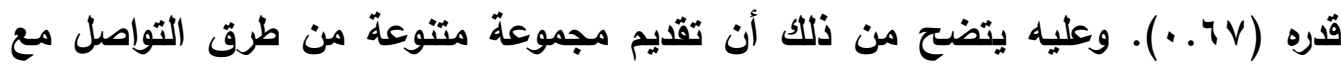
المعلمين لتقديم الدعم والمساندة في حال تعرض الطلاب للعنف يتم بلرجة متوسطة. لذا فإن هناك أهية كبيرة للتركيز على تقديم مجموعة متتوعة من طرق التواصل مع المعلمين لتقديم الاعم وإلمساندة إذا تعرض أي طالب في مدارس الامج للعنف في الوقت المناسب. بينما أظهرت النتائج بالجدول رقم (11) أن العبارة رقم (VIT) والتي نصت على" تحديد البدائل

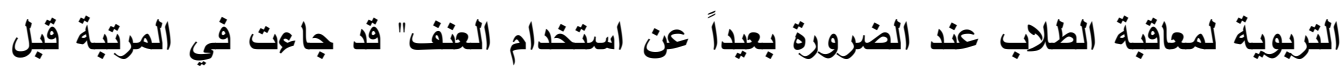
الأخيرة من بين الفقرات المتعلقة بمدى توفر المحاسبية المهنية من أجل تحقيق متطلبات التحول إلى بيئة مدرسية آمنة، ويعزز ذلك قيمة المتوسط الحسابي لاستجابات أفراد العينة

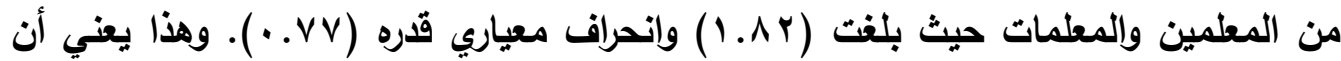
غالبية أفراد العينة وينسبة عـ . ؛ \% يرون أنه نادراً ما يتم تحديد البدائل التريوية لمعاقبة

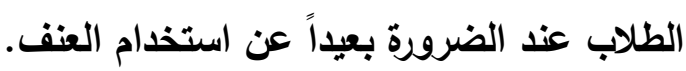

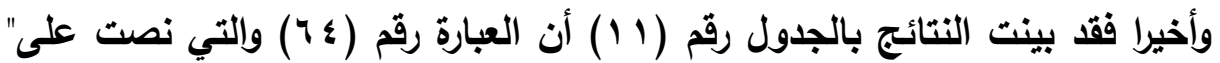
تطوير جاهزية الطلاب للتسامح وقبول الآخر ونبذ العنف " قد جاعت في المرتبة الأخيرة من بين الفقرات المتعلقة بمدى توفر المحاسبية المهنية من أجل تحقيق متطلبات التحول إلى بيئة مدرسية آمنة، ويعزز ذلك قيمة المتوسط الحسابي لاستجابات أفراد العينة من المعلمين

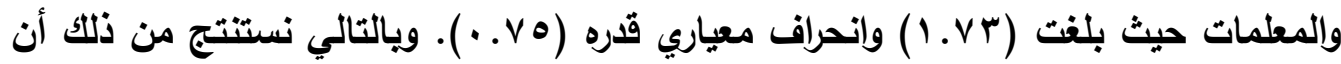
غالبية أفراد العينة وينسبة ؛ ـ0 ؛ \% يرون أنه نادراً ما يتم التفكير في تطوير جاهزية الطلاب للتسامح وقبول الآخر ونبذ العنف. 
وعليه يستخلص الباحثان من خلال تحليل استجابات أفراد العينة حول مدى توفر المحاسبية المهنية كأحد متطبات التحول، فقد أظهرت النتائج بثكل عام أن المحاسبية المهنية تتوفر بدرجة متوسطة وهي أقل من المأمول لتحقيق تحول مدارس الدمج إلى بيئة

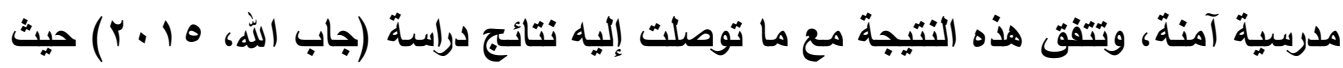

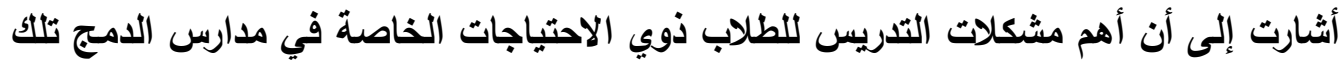

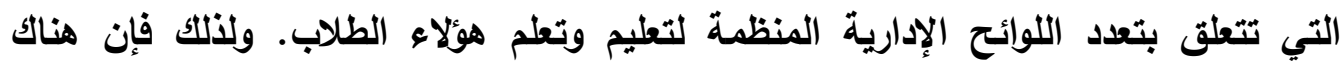

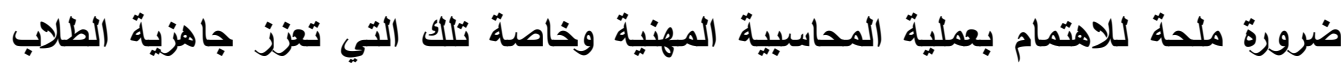
للتسامح وقبول الآخر ونبذ العنف، بالإضافة إلى تقديم مجموعة متنوعة من طرق التواصل مع المعلمين لتقيم الدعم والمساندة وذلك من أجل مواجهة العديد من القضايا المتعلقة بالعنف داخل البيئة المدرسية.

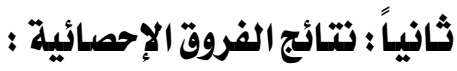
خصص الباحثان هذا الجزء لاختبار مدى وجود فروق ذات دلالة إحصائية بين آراء المعلمين والمعلمات حول منطلبات تحول مدارس الامج إلى بيئة مدرسية آمنة، تعزى

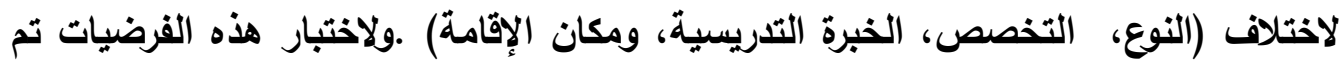

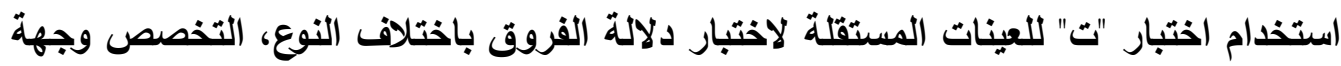
الإقامة ، بينما تم استخدام تحليل التباين أحادي الاتجاه لاختبار دلالة الفروق باختلاف الخار الخبرة

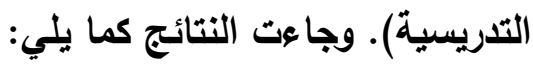
• النتائج الخاصة بالفروق بين استجابات أفراد العينة على مدى الأهمية لإجمالي الاستبانة

$$
\text { ومحاورها بحسب متغير النوع (ذكر - أنثى): }
$$




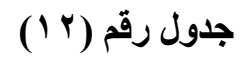

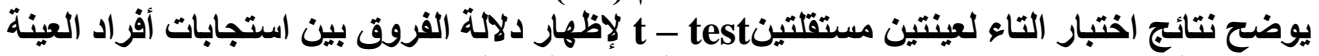

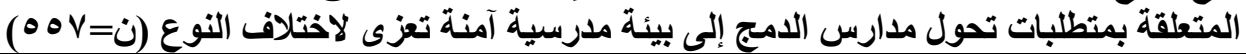

\begin{tabular}{|c|c|c|c|c|c|c|c|}
\hline \multirow{2}{*}{ الإحصائية } & \multirow{2}{*}{ الحرية } & \multirow{2}{*}{ قالمحسوبة } & \multicolumn{2}{|c|}{ أنثى } & \multicolumn{2}{|c|}{ ذكر } & \multirow[b]{2}{*}{ المحور } \\
\hline & & & الانحراف & المتوسط & الالحرياف & المتوسط & \\
\hline. $.1 \pi$ & 000 & $1.0 Y 1$ & $\cdot . r \wedge$ & 1.11 & $\because V V$ & 1.9. & الروئية والأهداف \\
\hline$\because \cdots$ & 000 & $7 . r 4 * *$ & $\cdot r \Delta$ & 1.10 & $\because .01$ & Y.11 & والتــــاصط والثعال \\
\hline$\because \cdots$ & 000 & $\varepsilon . \leqslant V Y * *$ &.$r q$ & 1.61 & . & 1.94 & القيادة المهنية \\
\hline$\because \cdots$ & 000 & $-7 . \varepsilon \cdot * *$ & ${ }^{\mu}$ & Y.દ. & .07 & r.Ir & 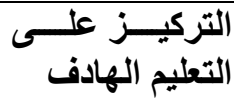 \\
\hline$\because \cdots$ & 000 & $7 . v \cdot * *$ & $\because 0$. & 1.09 &. .70 & 1.90 & 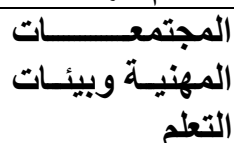 \\
\hline$\because 99$ & 000 & $1.70 \leqslant$ &.$r r$ & 1.11 & .70 & 1.97 & المهنية \\
\hline
\end{tabular}

**تثير إلى أن الفرق دال إحصائياً عند مستوى المعنوية (1 .. )

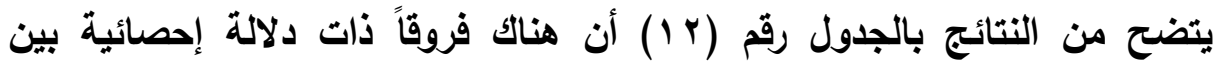
المعلمين (الأكور) والمعلمات (الإناث) المشاركين في الدراسة حول مجالات تحول مدارس الدمج إلى بيئة مدرسية آمنة عند مستوى المعنوية (1 (..) التي تثمل: الترابط والثثة والتواصل الفعال، القيادة المهنية، والمجتمعات المهنية وييئات التعلم. كما أظهرت النتائج أن الن أغلب الفروق تعود لصالح المعلمين (الأكور) ما عدا التركيز على التعليم الهادف، فإن الفروق تعود لصالح المعلمات. وريما تعود هذه النتيجة إلى زيادة أعداد أفراد العينة من المعلمين، وتوليهم إدارة مدارس الدمج في كثير من الأحيان، وتوفر مقومات التواصل بين إنى المعلمين بصورة أيسر من المعلمات. كما بينت النتائج عدم وجود فروق ذات دلالة إحصائية في محور الروئية والأهداف، والمحاسبية المهنية بين الذكور والإناث. وريما تعود هذه النتيجة إلى ارتباط هذين المحورين

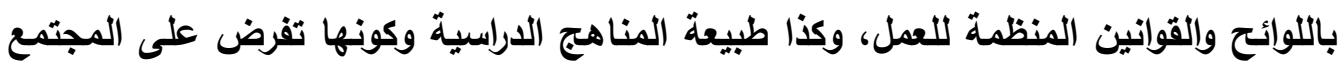
المدرسي من السلطة التريوية، لذا يستوي المعلمون والمعلمات في مدارس الامج في العمل 
النتائج الخاصة بالفروق بين استجابات أفراد العينة على مدى الأهمية لإجمالي الاستبانة

$$
\text { ومحاورها بحسب متغير التخصص (علمي - أدبي): }
$$

يوضح نتائج اختبار التاء لعينتين مستقلتين test

\begin{tabular}{|c|c|c|c|c|c|c|c|}
\hline \multirow{2}{*}{ الإحصائية } & \multirow{2}{*}{ الحرية } & \multirow{2}{*}{ قالمحسوبة ت } & \multicolumn{2}{|c|}{ أدبي } & \multicolumn{2}{|c|}{ علمي } & \\
\hline & & & الالاحيراف & المتوسط & الالانحراف المياري & المتوسط & \\
\hline$\because \vee \wedge$ & 000 & $-\bullet . \Upsilon \wedge$. & .91 & $1 . \wedge \Lambda$ & $.7 \leq$ & $1 . \wedge 7$ & والأهدوافة \\
\hline$\because \cdots \wedge$ & 000 & $-r . \neg \vee \backslash * *$ & 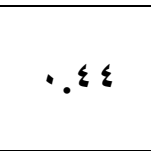 & $r . \bullet \Lambda$ & .0 & $1.9 \mathrm{~V}$ & 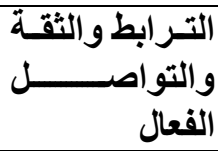 \\
\hline$\cdot . r \varepsilon$ & 000 & $-\cdot .90 r$ &. $.0 \mathrm{~V}$ & $1 . \wedge 1$ & .00 & $1 . \wedge \varepsilon$ & القيادة المهنية \\
\hline$\because 91$ & $0 \Delta 0$ & $1.70 \mathrm{~V}$ & $\because 0$. & r.11 & $.0 r$ & r.Yo & التطليم الهـادف علـى \\
\hline$\because \cdots$ & 000 & $-r . V \mu r * *$ & .01 & $1.9 \leq$ &. .79 & $1 . V \varepsilon$ & المجنئة وبيئـات \\
\hline$\because \varepsilon$ & 000 & $-r . \cdot 1 \Lambda *$ & $.0 \leqslant$ & 1.99 & $.0 \mathrm{~V}$ & 1.19 & المهنية \\
\hline
\end{tabular}

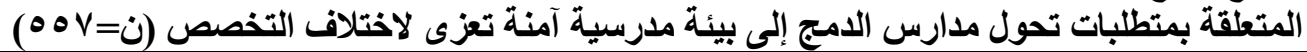

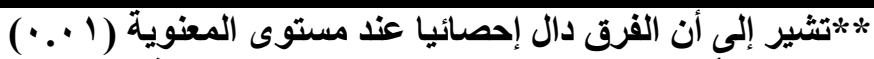

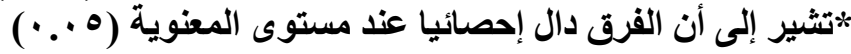

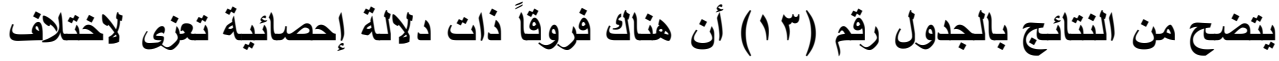
التخصص لاى المعلمين والمعلمات المشاركين في الدراسة حول متطلبات تحول مدارس الدمج إلى بيئة مدرسية آمنة في مجالات الترابط والثقة والتواصل الفعال، والمجتمعات المهنية وييئات التعلم والمحاسبية المهنية. كما بينت النتائج أن جميع الفروق تعود لصالح التخصصات الأدبية. وهذا يبين أن المعلمين والمعلمات الذين يحملون تخصصات أدبية لايهم إدراك واستيعاب لمتطلبات تحول مدارس الدمج إلى بيئة مدرسية آمنة مقارنة بالحاصلين على تخصص علمي. وربما تعزى هذه النتيجة إلى طبيعة الدراسات الأدبية التي تثمل التربية الخاصة، والإرشاد النفسي، وعلم النفس والصحة النفسية ، وارتباط هذه الدراسات بالتعليم وفق نظام الامج ، ووعي ذوي التخصصات الأدبية بمتطلبات الدمج والبيئة المدرسية اللازمة لله. كما بينت النتائج عدم وجود فروق ذات دلالة إحصائية في محور الروئية والأهداف، 
ومحور القيادة المهنية. وريما يعود ذلك إلى ارتباط هذين المحورين باللوائح والقوانين المنظمة للعمل من ناحية، ويالمهارات القيادية والسمات الشخصية، والتنمية المهنية المستمرة لكلا التخصصين (الأدبي وإلعلمي ) من ناحية أخرى. النتائج الخاصة بالفروق بين استجابات أفراد العينة على مدى الأهمية لإجمالي الاستبانة ومحاورها بحسب مكان الإقامة:

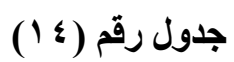

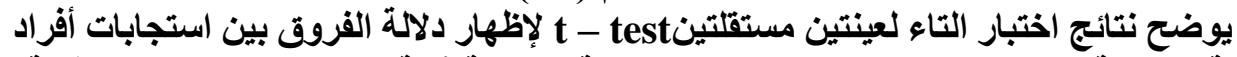
العينة المتعلقة بمنطلبات تحول مدارس الامج إلى بيئة مدرسية آمنة تعزى لاختيلاف لإنس مكان الإقامة $(0 \Delta V=\dot{0})$

\begin{tabular}{|c|c|c|c|c|c|c|c|}
\hline \multirow{2}{*}{ الإحصائية } & \multirow{2}{*}{ الحرجية } & \multirow{2}{*}{ قالمحسوبة ت } & \multicolumn{2}{|c|}{ السعودية } & \multicolumn{2}{|c|}{ مصر } & \\
\hline & & & الانحياري & المتوسط & الالحعراف & المتوسط & \\
\hline$\because \cdots$ & 000 & $-\mu 1 . \diamond \wedge * *$ & $\because \leqslant r$ & r.01 & $\cdot r \Lambda$ & $1 . \leqslant \varepsilon$ & والأهدأفية \\
\hline$\because \cdots$ & 000 & $-Y 1 . r V * *$ & $\because 0$. & r.s. & $\cdot r^{1}$ & 1.10 & والتوالثقة \\
\hline$\because \cdots$ & 000 & $-Y \leqslant . r . * * *$ & $\cdot .49$ & Y.r & $\cdot r$. & $1.0 r$ & المهنية \\
\hline$\because \cdots$ & 000 & $-\Lambda . \leqslant \Psi r * *$ & $\because \leqslant 0$ & $r . \leqslant r$ & .01 & $r . \cdot \Lambda$ & 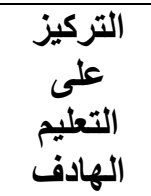 \\
\hline$\because \cdots$ & 000 & $-r 0.9 \leqslant * *$ & .01 & r.rq & ه r. & $1 . \leqslant \varepsilon$ & المجنتمعات \\
\hline$\because \cdots$ & 000 & $-19 . \vee Y \neg * *$ & .04 & T.rV & & $1.7 \varepsilon$ & المحاسبية \\
\hline
\end{tabular}

** تشير إلى أن الفرق دال إحصائيا عند مستوى المعنوية (1 •. ) 
أظهرت النتائج بالجدول رقم (؛ () أن هناك فروقاً ذات دلالة إحصائية عند مستوى

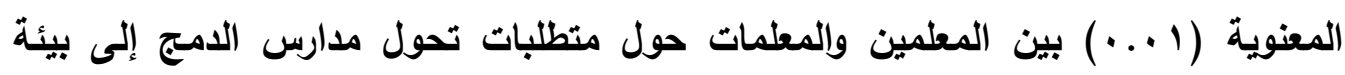

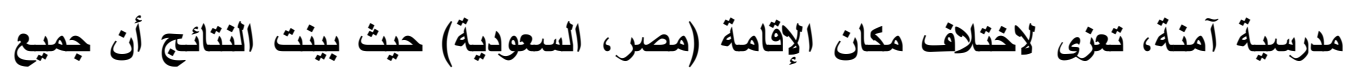

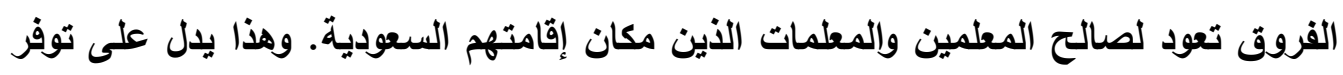

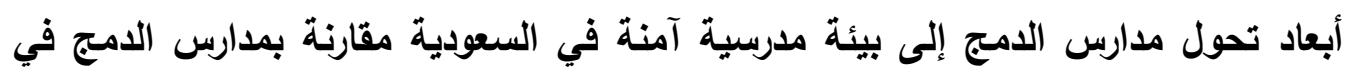

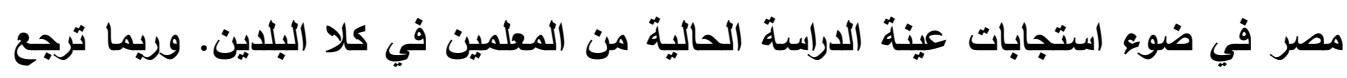

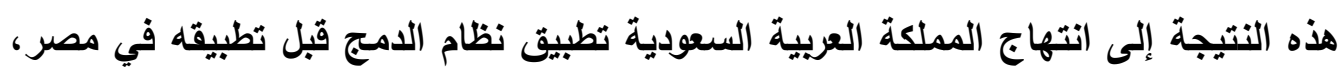

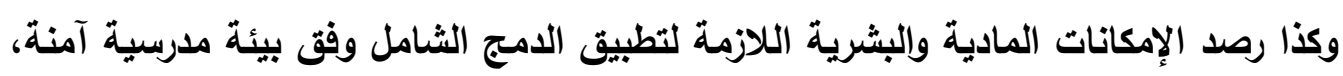

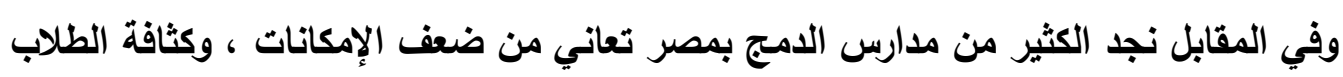

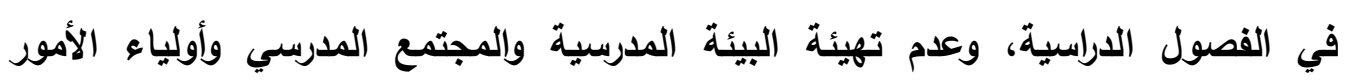
والطلاب لتطبيق نظام الدمج. • النتائج الخاصة بالفروق بين استجابات أفراد العينة على مدى الأهمية لإجمالي الاستبانة ومحاورها بحسب الخبرة التدريسية : 


\section{تصور مقترح لتحول مدارس الدمج إلى بيئة مدرسية آمنة .}

جدول رقم (10)

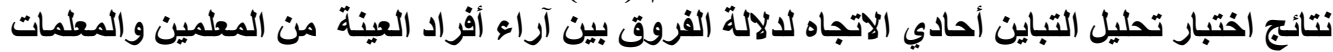

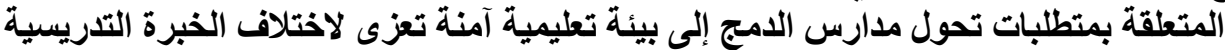

\begin{tabular}{|c|c|c|c|c|c|c|}
\hline الإحصائية & قيمة فـ & المربعات & الحرية & المربعات & مصدر التباين & \\
\hline \multirow{3}{*}{$\because \cdots$} & \multirow{3}{*}{$0 \leq . \leq * *$} & $19 . \mathrm{VPq}$ & r & $r q . \varepsilon V V$ & المجموعات & \multirow{3}{*}{ والأردافية } \\
\hline & & • ט & $00\}$ & r.r.rrq & المجموعات & \\
\hline & & & 007 & $r \leqslant 1 . \wedge 17$ & الإجمالى & \\
\hline \multirow{3}{*}{$\because \cdots$} & \multirow{3}{*}{$1 V .09 * *$} & r.va. & $r$ & $\vee . \bullet \wedge I$ & المجموعات & \multirow{3}{*}{ 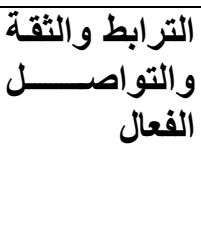 } \\
\hline & &.$r 10$ & $00 \leqslant$ & 119.471 & المجموعات & \\
\hline & & & 007 & $1 Y 7.9 \leqslant Y$ & الإجمالي & \\
\hline \multirow{3}{*}{$\because \cdots$} & \multirow{3}{*}{$79 . \wedge 1 * *$} & 18.070 & $r$ & וr & المجموعات & \multirow[t]{3}{*}{ القيادة المهنية } \\
\hline & &.$r \otimes r$ & $00 \leqslant$ & 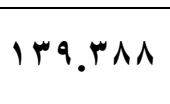 & المجموعات & \\
\hline & & & 009 & $1 V \varepsilon .019$ & الإجمالى & \\
\hline \multirow{3}{*}{$\because \cdots$} & \multirow{3}{*}{ Y I $\leqslant .9 \leqslant * *$} & r. & $r$ & Y0.YVE & المجموعات & \multirow[t]{3}{*}{ التُليميز اللهادف على } \\
\hline & & $.10 r$ & $00 \leqslant$ & $\Lambda \varepsilon .|Y|$ & المجموعات & \\
\hline & & & 009 & $1 \leqslant 9.490$ & الإجمالي & \\
\hline \multirow{3}{*}{$\because \cdots$} & \multirow{3}{*}{$r \cdot . r \wedge * *$} & $v .0 .1$ & r & $10 . . r$ & المجموعات & \multirow{3}{*}{ 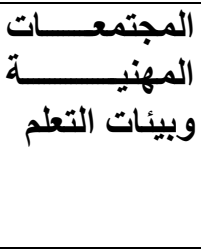 } \\
\hline & & . & $00 \leqslant$ & $r \cdot r . q .$. & المجموعات & \\
\hline & & & 009 & $r 11.9 \cdot r$ & الإجمالي & \\
\hline \multirow{3}{*}{$\because \cdots$} & \multirow{3}{*}{ Q7. } & $r r . r \leq 0$ & $r$ & $\varepsilon \varepsilon .719$ & المجموعات & \multirow[t]{3}{*}{ المهنية المــــية } \\
\hline & & . & $00 \leqslant$ & Ir & المجموعات & \\
\hline & & & 009 & IVY.YYY & الإجمالي & \\
\hline
\end{tabular}

**ثير إلى أن الفرق دال إحصائيا عند مستوى المعنوية (1 • . ( ) 
كشفت نتائج تحليل التباين أحادي الاتجاه (ANOVA) بالجدول رقم (0 1) أن هناك فروقاً ذات دلالة إحصائية عند مستوى المعنوية ( ( . . ) بين المعلمين والمعلمات المشاركين في الدراسة حول متطلبات تحول مدارس الدمج إلى بيئة مدرسية آمنة، تعزى لاختلاف الخبرة

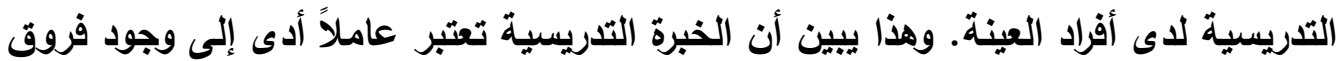
جوهرية بين أفراد العينة حول تحول مدارس الدمج إلى بيئة مدرسية آمنة. وللتعرف على دلالة الفروق واتجاهها، تم إجراء اختبار المقارنات البعدية باستخدام أسلوب إتلي أقل فرق معنوي (LSD) وجاءت النتائج كما هو مبين بالجدول التالي: جلول رقم (1 1 (1)

يوضح نتائج اختبار أقل فرق معنوي لدلالة الفروق واتجاهها

\begin{tabular}{|c|c|c|c|c|}
\hline \multicolumn{4}{|c|}{ الروية والأهداف } & \multirow[b]{3}{*}{ سنوات الخبرة } \\
\hline \multicolumn{3}{|c|}{ فرق المتوسط } & \multirow[b]{2}{*}{ الحسبابي الحتوسط } & \\
\hline أكثر من & •ـ إلى · ا سنوات & 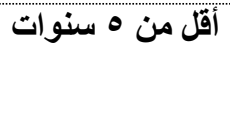 & & \\
\hline. $.7 V *$ & $1.19 *$ & - & Ү. ४ & أقل من • سنوات \\
\hline$-\bullet \Delta r *$ & - & $-1.19 *$ & 1.29 & •ـ إلى • ا سنوات \\
\hline- &.$\Delta ץ *$ & $-\cdot .7 V *$ & Y. I & أكثر من · ا سنوات \\
\hline \multicolumn{4}{|c|}{ التز ابط والثقة والتواصل الفعال } & \\
\hline$\because .0 Y *$ & $\because \vee \cdot *$ & - & $Y .0 \Lambda$ & أقل من • سنوات \\
\hline.$- .11 *$ & - & $-\cdot . \vee \cdot *$ & $1 . \wedge \wedge$ & •ـ إلى • 1 سنوات \\
\hline- & $\because .1 *$ & $-\cdot .0 Y *$ & $Y .9$ & أكثر من · ا سنوات \\
\hline \multicolumn{4}{|c|}{ القيادة المهنية } & \\
\hline$\because V Y *$ & $1.19 *$ & - & Y.V. & أقل من • سنوات \\
\hline$-\cdot . \Lambda \wedge *$ & - & $-1.19 *$ & 1.01 & 0- إلي · 1 سنوات \\
\hline- & $\because 乞 \Lambda *$ & $-\cdot V Y *$ & 1.91 & أكثر من · ا سنوات \\
\hline \multicolumn{4}{|c|}{ التركيز على التعليم التهادف } & \\
\hline$\because r r *$ & $\because 9 \vee *$ & - & Y.. $\mathrm{V}$ & أقل من • سنوات \\
\hline$-\bullet V \leq *$ & - & $-\cdot .9 \vee *$ & $1 . V \cdot$ & 0- إلى • ا سنوات \\
\hline- & $\because \vee Y *$ & $-\cdot . r \mu *$ & Y.\& & أكثر من · ا سنوات \\
\hline \multicolumn{4}{|c|}{ المجتمعات المهنية وبيئات التعلم } & \\
\hline$\because \vee 9 *$ & $1 . r *$ & -- & Y. . V & أقل من • سنوات \\
\hline$-\cdot . Y r *$ & - & $-1 . \cdot r *$ & $1.7 \varepsilon$ & •ـ إلى • ا سنوات \\
\hline- & $\because r r *$ &.$- \vee \vee 9 *$ & $1 . \wedge \wedge$ & أكثر من · ا سنوات \\
\hline \multicolumn{4}{|c|}{ المحاسبية المهنية } & \\
\hline$\because .7 * *$ & $1.1 v *$ & - & Y.V. & أقل من • سنوات \\
\hline$-\cdot . \Delta V *$ & - & $-1.1 v *$ & $1.0 Y$ & •ـ إلى · ا سنوات \\
\hline- & $\because . \bullet \vee *$ & $-\cdot .7 \cdot *$ & Y. 9 & أكثر من · 1 سنوات \\
\hline
\end{tabular}


يوضح الجدول رقم ( ا 1) نتائج اختبار الفروق المتعددة بين المعلمات والمعلمات وفقاً لسنوات الخبرة، حيث يتبين أن الفروق جوهرية على مستوى كل متطلبات تحول مدارس لهات

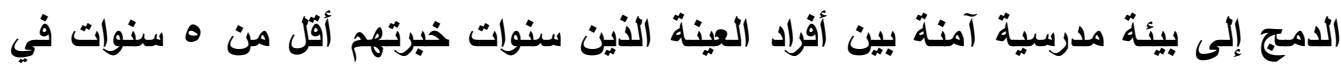
جانب ويبن كلاً من الذين سنوات خبرتهم (0 - م ـ 1) سنوات و الذين لديهم سنوات خبرة أكثر من · 1 سنوات، وذلك لصالح مجموعة المعلمين الذين سنوات خبرتهم أقل من ه سنوات. وهذا يعني أن المعلمين والمعلمين الذين سنوات خبرتهم أقل من ه سنوات يعتقدون أن هذه هـونه المتطلبات تتوفر بلرجة أكبر مقارنة بالمعلمين الذين سنوات خبرتهم أعلى منهم ، وريما ترجع هذه النتيجة إلى أنها الفئة التي تمارس التدريس بنصاب تدريسي كامل يتطلب التواجد بصفة

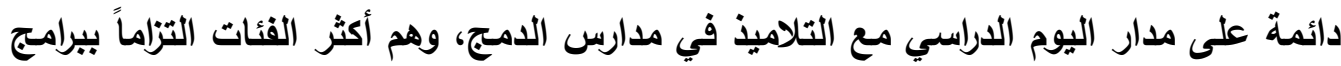

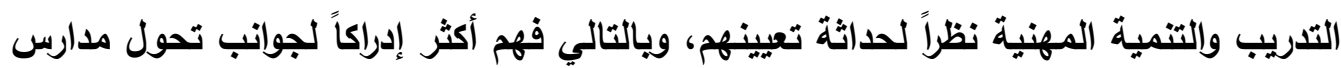

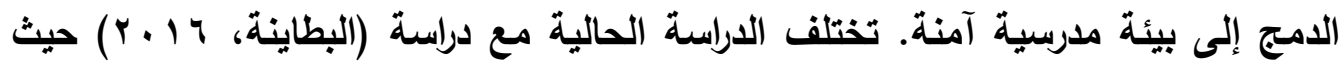

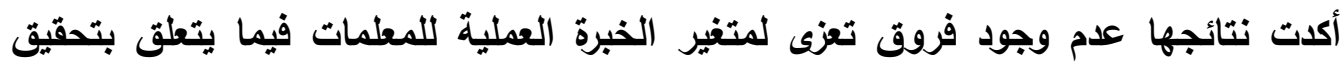
متطلبات البيئة المدرسية الآمنة.

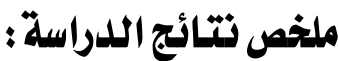

في ضوء تحليل بيانات الاراسة والوقوف على آراء أفراد العينة من المعلمين والمعلمات المشاركين في الاراسة الحالية، فقد خلصت الدراسة إلى النتائج التالية: 1 أظهرت نتائج الدراسة أن الروئية والأهداف تتوفر بلرجة متوسطة من أجل تحول مدارس الامجج إلى بيئة مدرسية آمنة، وهذا يعني أن التحول إلى بيئة مدرسية آمنة تلبي

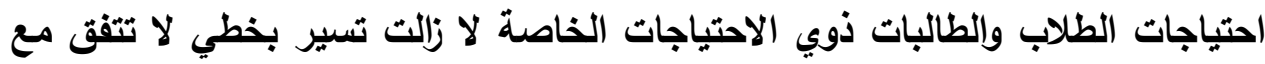
أهداف وروئة التحول نحو بيئة مدرسية آمنة تقدم ما تتطلبه الجوانب التعليمية والتريوية للعاملين والطلاب في مدارس الامج. r. بينت نتائج الاراسة أن الترابط والثقة والتواصل الفعال كأحد المتطلبات المتعلقة بتحول مدارس الامج إلى بيئة مدرسية آمنة يتحقى بدرجة متوسطة، مما يشير إلى ضرورة الاهتمام بتعزيز عملية الترابط والثقة والتواصل الفعال بين كافة الأطراف المهتمة بتحول مدارس الامهج إلى بيئة مدرسية آمنة. 
r. كثفت نتائج الدراسة أن القيادة المهنية كأحد متطلبات التحول إلى بيئة مدرسية آمنة تتوفر بدرجة متوسطة، مما يتطلب إعداد وتدريب القيادة المهنية اللازمة التي تقود عملية التحول من أجل تحقيق أهداف التحول التعليمية والتربوية.

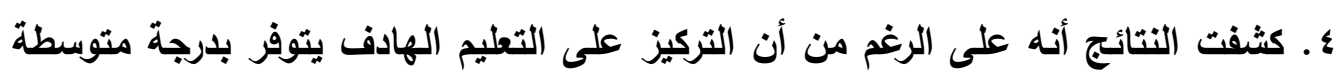
بشكل عام، إلا أن النتائج قد بينت أن أهم المؤشرات الإيجابية التي تعكس مدى التهين التركيز

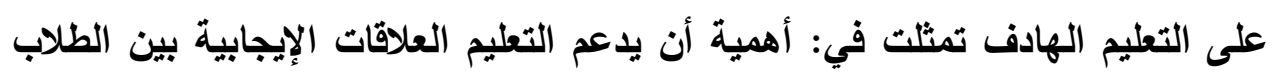

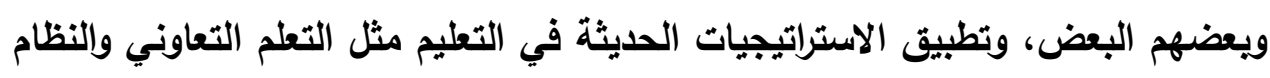
النشط والتعلم القائم على حل المشكلات، بالإضافة إلى إبراز جواتب المنهج المدرئي التي تؤكد على التسامح والسلام واحترام الآخر. كما أظهرث النتائج أن هناك حاجة إلى إلى إلى توفير الوسائل والمصادر التعليمية التي تتناسب مع قدرات التلاميذ وإمكاناتهم، بالإضافة إلى إثراء الأنشطة الطلابية بالبرامج التي تستوعب التلاميذ ذوي الاحتياجات الخاصة

وتلبي رغباتهم.

هـفيما يتعلق بمدى توفر المجتمعات المهنية وبيئات التعلم التي تعزز وتدعم تحول مدارس

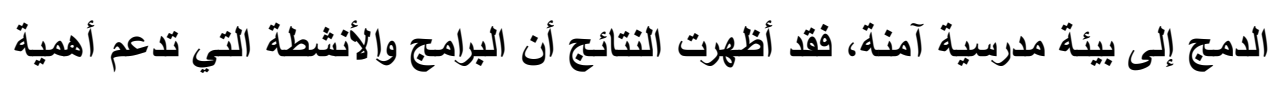

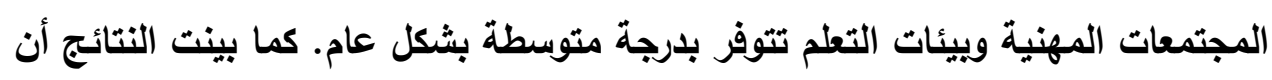
هناك أهمية ويدرجة كبيرة لاعم وتعزيز عملية التحول من خلال توفير المجتمعات المهنية وييئات التعلم ومن بين مؤشراته: اهتمام المدرسة بالرحلات والحفلات المدرسية والأنشطة الفنية والرياضية والاجتماعية والمسرح المدرسي، إضافة إلى الاهئ الاتمام

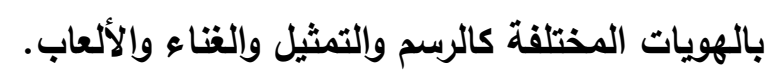

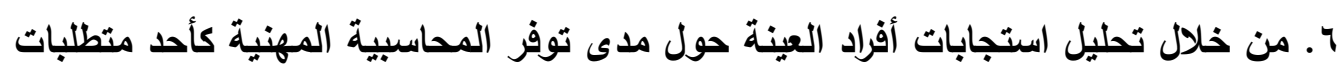

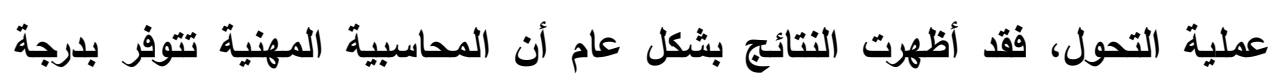
متوسطة وهي أقل من المأمول لتحقيق التحول إلى بيئة مدرسية آمنة. ولذلك هناك

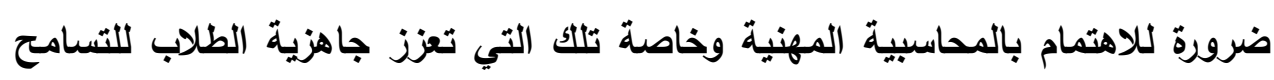
وقبول الآخر ونبذ العنف، بالإضافة إلى تقديم مجموعة متنوعة من طرق التواصل مع دعادئ المعلمين لتقديم الدعم والمساندة وذلك من أجل مواجهة العديد من القضايا المتعلقة بالعنف داخل البيئة المدرسية. 
V. أظهرت نتائج الدراسة أن هنات فروقاً ذات دلالة إحصائية بين المعلمين والمعلمات المشاركين في الدراسة حول متطلبات تحول مدارس الدمج إلى بيئة مدرسية آمنة عند

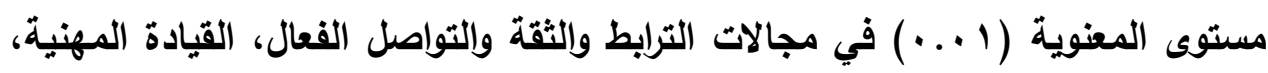

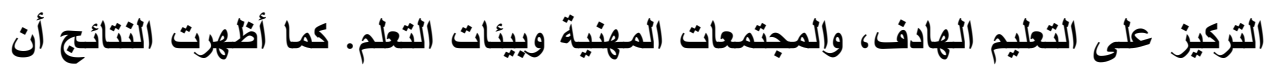
أغلب الفروق تعود لصالح المعلمين (الأكور) ما عدا التركيز على التعليم الهادف، فإن الفروق تعود لصالح المعلمات. كما بينت النتائج عدم وجود فروق ذات دلاتلة الهالة إحصائية في محور الترابط والثقة والتواصل الفعال، والمحاسبية المهنية بين الأكور والإناث.

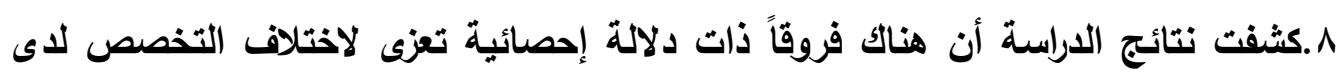
المعلمين والمعلمات المشاركين في الدراسة حول متطلبات تحول مدارس الدمج إلى بيئة مدرسية آمنة في مجالات الترابط والثقة والتتواصل الفعال، والمجتمعات المهنية وييئات

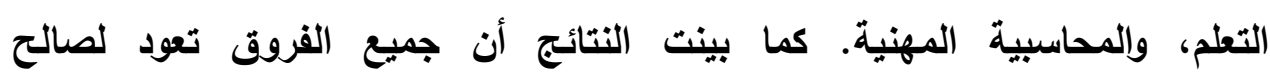
التخصصات الأدبية. وهذا يبين أن المعلمين والمعلمات الذين يحملون تخصصات أدبية لديهم إدراك واستيعاب لمتطلبات تحول مدارس الدمج إلى بيئة مدرسية آمنة مقارنة

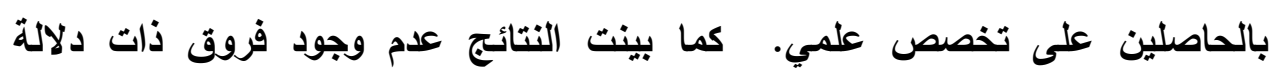
إحصائية في محور الروئية والأهداف، ومحور القيادة المهنية. 9. بينت نتائج الدراسة أن هناك فروقاً ذات دلالة إحصائية عند مستوى المعنوية (1 ( . .) بين المعلمين والمعلمات حول متطلبات تحول مدارس الدمج إلى بيئة تعليمية آمنة، تعزى لاختلاف مكان الإقامة (مصر، السعودية) حيث بينت النتائج أن جميع الفروق

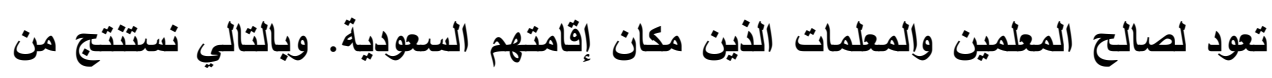
ذلك أن المعلمين والمعلمات الذين مكان إقامتهم السعودية لايهم تصور بأن متطلبات تحول مدارس الامج إلى بيئة تعليمية آمنة تتوفر بشكل أكبر يختلف عن مدى توفرها

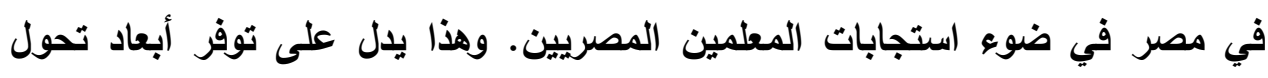

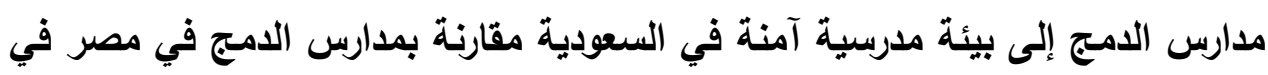
ضوء استجابات عينة الدراسة الحالية من المعلمين في كلا البلاين. 
• 1 . أظهرت نتائج تحليل التباين أحادي الاتجاه (ANOVA) أن هناك فروقاً ذات دلالة

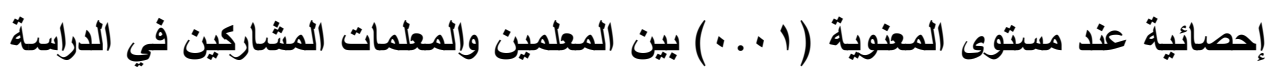

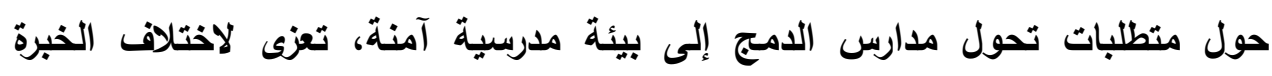

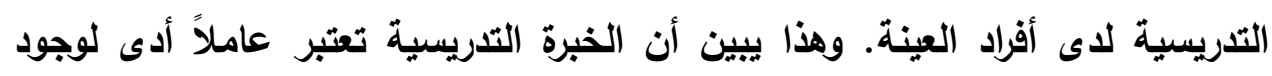

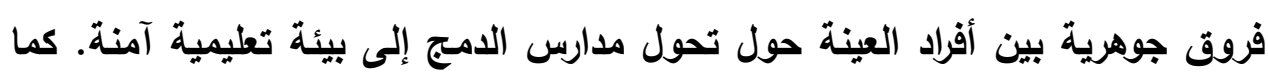

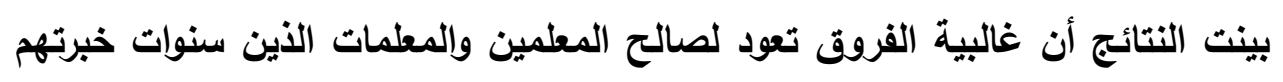
أقل من • سنوات.

تاسعاً: تصور مقترح لتحول مدارس الدمج إلى بيئة مدرسية آمنة.

تضهيد:

في ضوء ما يهاف إليه البحث الحالي من تقديم تصور مقترح لتحول مدارس الدمج

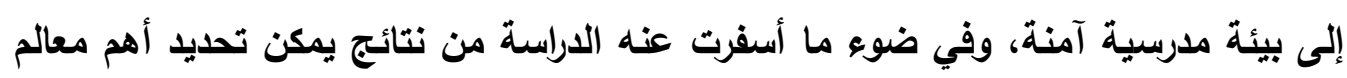

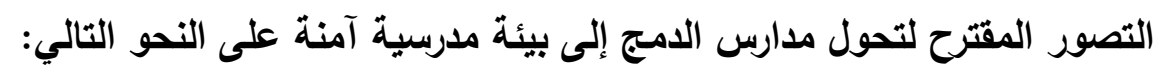
أ. فلسفة التصور المقترح ومرتكزاته :

تنطلق فلسفة التصور المقترح من واقع أن المؤسسات التعليمية بصفة عامة، ومدارس آلماتس

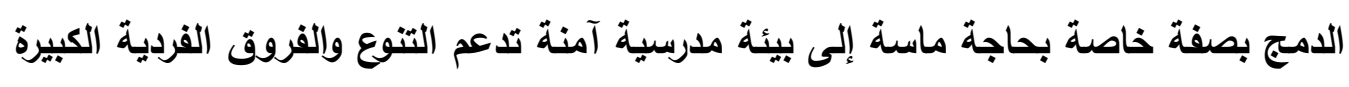

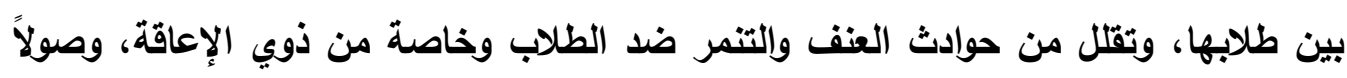

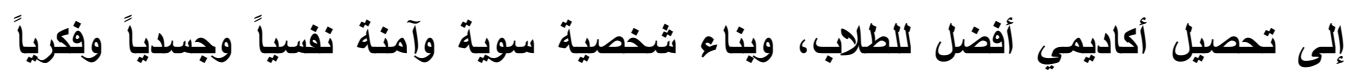

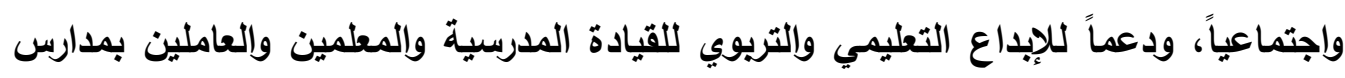

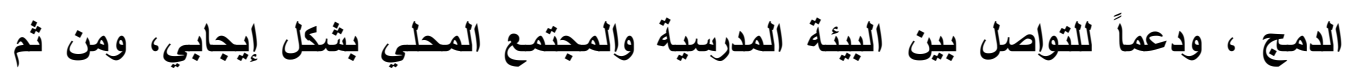
الإسهام في نجاح نظام الدمج وإلد من سلبياته. 


\section{تصور مقترح لتحول مدارس الدمج إلى بيئة مدرسية آمنة .}

ب. أهداف التصور المقترح :

يهذف التصور المقترح إلى تحقيق الأهداف التالية :

ا ـ مراجعة روئة وأهداف التعليم في مدارس الامج، بحيث تتضمن الالتزام بتحقيق

بيئة مدرسية آمنة وفق خطة منظمة ومرنة ومتدرجة.

r ـ دعم تحول البيئة المدرسية في مدارس الدمج إلى بيئات تعلم ومجتمعات مهنية. r. تطوير القيادة المهنية للاضطلاع بالأدوار والمسؤوليات اللازمة لتحقيق بيئة مدرسية آمنة في مدارس الامجر.

ع. رفع كفاعة المعلمين والعاملين بمدارس الدمج في مجال الاتصال والتواصل الفعال مع بعضهم البعض ومع الطلاب وأعضاء المجتمع المحلي. هـ تطبيق المحاسبية المهنية وفق لوائح وقوانين واضحة ومنظمة للمجتمع المدرسي في جو يسوده الألفة والمودة ، بعيداً عن العنف والتهم والسخرية. والحث على استخدام البدائل التربوية للعنف.

ج. جوانب التصور المقترح : بعد تحديد فلسفة التصور المقترح وأهدافه، سوف يتتاول الباحثان الجوانب المقترحة لتحول مدارس الدمج إلى بيئة مدرسية آمنة وهي كالتالي:

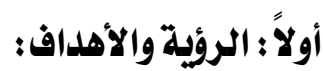

- تهيئة الطلاب والعاملين للتفاعل الإيجابي مع بعضهم ومع أقرانهم من ذوي الاحتياجات الخاصة، ويناء اتجاهات إيجابية نحوهم. - تضمين روئة مدارس الدمج وأهدافها توفير بيئة مدرسية آمنة وخالية من العنف التفابه والاستقواء والتنمر . - توضيح اللوائح والقوانين المنظمة للبيئة المدرسية، وتعريف الطلاب والعاملين بقواعد السلوك المقبول والسلوك غير المقبول لتوفير بيئة مدرسية آمنة.

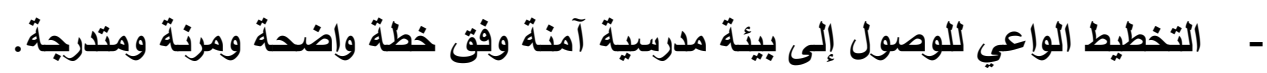
- إعلان المدرسة الدامجة أن للجميع الحق في الشعور بالأمن البذني والنفسي والفكري والاجتماعي. 
- توضيح البدائل التريوية للعقاب باستخدام العنف مثل: الحرمان من ممارسة الأنشطة والهوايات لفترة معينة، أو التكليف بواجبات مدرسية أكثر من زملائهم.

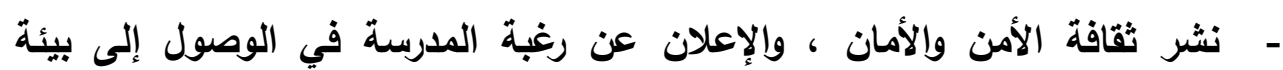
مدرسية خالية من العنف. - التأكيا على دور المعلم في إدارة مواقف العنف في المدرسة، وتبصيره بقواعد الانضباط المدرسي البديلة للعنف أو التخويف والسخرية. - التعاون بين أعضاء المجتمع المدرسي وأعضاء المجتمع المحلي والطلاب للحد من انتشار العنف بين الطلاب ويعضهم البعض ويينهم وبين العاملين بمدارس الدمج. ثانياً : دعم الترابط والثقة والتواصل الفعال بيز العامليز بمدارس الدمج والطلاب : - تعمل إدارة المدارس الدامجة والعاملين على إثعار الطالب بأهميته كعضو في المجتمع المدرسي، وتلبية احتياجاته واهتماماته.

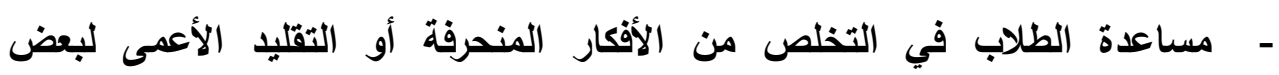
السلوكيات غير الأخلاقية المكتسبة من بعض وسائل الإعلام ووسائل التواصل الاجتماعي. - إكساب الطلاب والعاملين مهارات التواصل الفعال. وآداب الحوار واحترام حقوق الآخرين وتقدير خصوصياتهم. - استخدام المعلمين والعاملين بمدارس الامج لغة مناسبة ويعيدة عن الإهانة أو الاحتقار في التعامل مع الطلاب. - المبادرة إلى اكتثاف أسباب العنف بين الطلاب ويعضهم البعض، أو بينهم وبين المعلمين. - تحفيز الطلاب على التواصل مع المعلمين وإدارة المدرسة في حال تعرض الطالب للعنف أو التنمر، وتعريفهم بالتصرف الصحيح والمقبول حال تعرضهم للعنف داخل المدرسة أو خارجها. - استثمار الأنشطة الطلابية في تعزيز الأخوة والتسامح والتعاون والأمن بين الطلاب والمعلمين. - قيام المعلم بلوره الإرشادي تجاه الطلاب العاديين وذوي الاحتياجات الخاصة. 
- عقد اجتماعات دورية ولقاءات ومحاضرات مع العاملين لمناقثة المشكلات التي

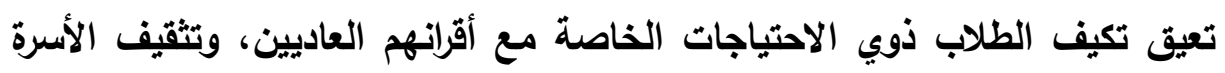

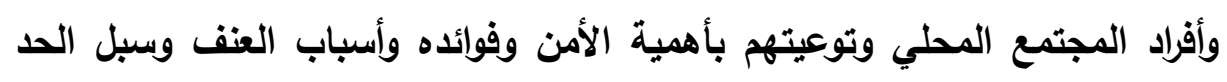
منها.

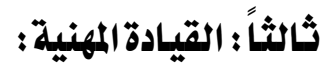

- تحرص إدارة المدرسة على العمل بروح الفريق للوصول إلى الأمن البدني والنفسي لألعاملين والطلاب. -

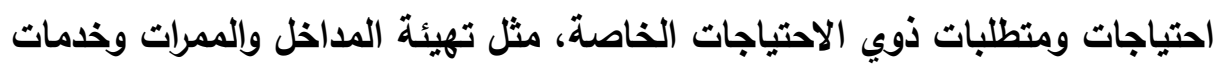

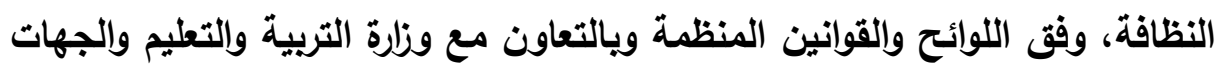
المعنية بالامج. - ت تنق إدارة الدرسة مع الإدارات والجهات المعنية والجمعيات الخيرية لتزويد الأطفال المعاقين بالأجهزة التعويضية والمعينات الطبية اللازمة. - تأخذ إدارة المدرسة المبادرات لحل مشكلات الطلاب وتدريب العاملين والطلاب على العلى الانضباط الذاتي. - - تنفيذ اللوائح والقوانين ضد الممارسين للعنف اللفظي أو البدني أو المعنوي من

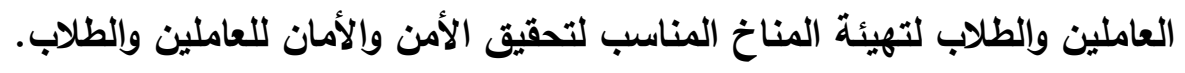

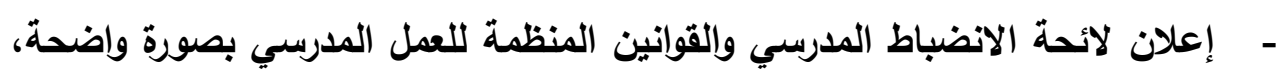

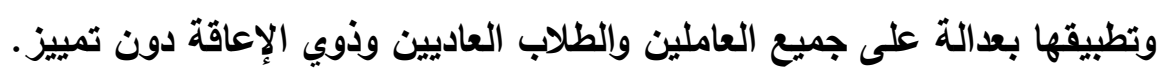

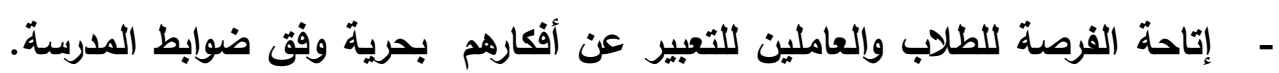
وفوفق نمط إداري ديمقراطي. - دعوة أولياء الأمور إلى المشاركة في الأنثطة المدرسية وتقديم الدعم المغنوي والمادي للطلاب وخاصة من ذوي الإعاقة.

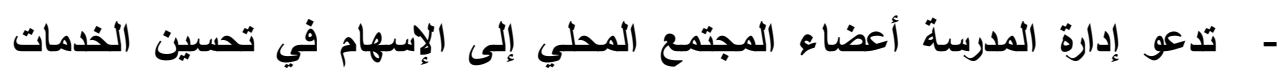

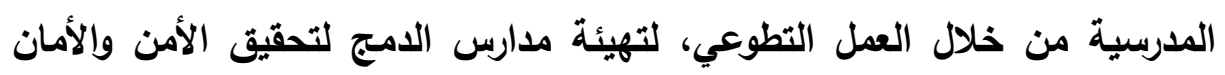

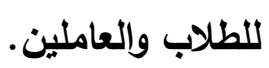


- تعمل إدارة المدرسة بالتسيق مع الجهات المختصة على الاهتمام بالتدخل الطبي الوقائي والعلاجي وإجراء الفحوصات الطبية الدورية لجميع الطلاب بالمدرسة.

$$
\text { رابعاً : التركيز على التعليم الهادف : }
$$

- تطبيق استراتيجيات التدريس المجربة والمتنوعة ، التي تناسب الموقف التعليمي وحاجات الطلاب وإمكاناتهم، وإكسابهم مهارات حل المشكلات والاستقصاء والتعلم من خلال تطبيقها داخل الموقف التعليمي ، وريط هذه الاستراتيجيات بواقعه ومشكلاته المعاصرة التي تمس حاجاته بشكل كبير · - استخدام استراتيجيات حديثة في إدارة الصف بعيداً عن العنف. - إبراز جوانب المنهج الدراسي التي تؤكد على التسامع والسلام وإحترام الآخر. - أن يتابع المعلم تقدم الطلاب وتحسين تحصيأهم ومهاراتهم وفق إمكاتياتهم وقدراتهم من خلال توفير البيئة المدرسية الداعمة لعمليتي التعليم والتعلم، والمحفزة للتقدم الدراسي والتحصيل الأكاديمي. - استخدام الأساليب الوقائية والعلاجية لتعديل سلوك الطلاب المخالفين قبل إيقاع العقوية عليهم. - احتواء الأنشطة الطلابية على برامج تستوعب التلاميذ ذوي الإعاقة.

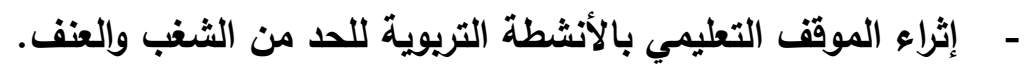
- الإشراف على تنفيذ البرنامج الدراسي بالمدرسة. - استخدام الوسائل والمصادر التعليمية لتناسب جميع الطلاب على اختلاف قدراتهم وإمكاناتهم، وتراعي الفروق الفردية الكبيرة بينهم. 


\section{تصور مقترح لتحول مدارس الدمج إلى بيئة مدرسية آمنة .}

خامساً : المجتمعات المهنية وبيئات التعلم :

- تبني العاملين بالمدرسة التعددية وإلتنوع والأفكار والحلول الإبداعية من خلال التعامل باحترام وعدالة وكرامة مع الطلاب. - ترعى الأكاديمية المهزية للمعلمين ووزارة التربية وإلتعليم إمداد الهيئة التعليمية بالمدرسة ببرامج ودورات تدريبية مهنية واضحة ومحددة تدعم التعلم المستمر، وسبل دعم البيئة المدرسية الآمنة. - الاستفادة من تجارب البيئات الأخرى على اختلاف مكوناتها وفلسفاتها في الحد من العنف لايها، وتوفير الجو الآمن بين أفرادها بشكل علمي وديمقراطي فاعل وآمن. - ترسيخ القيم وإلمبادئ الداعمة للأمن المدرسي لاى الطلاب مثل تحمل المسؤولية، والتسامح، وأدب الحوار، واحترام خصوصية الآخرين، والحفاظ على الممتلكات العامة، وذلك بأن يراها الطالب سلوكاً يمارس من معلميه والعاملين بمدارس الدمج.

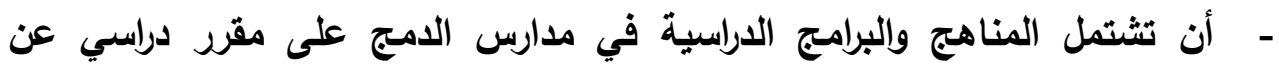
التسامح والإيثار ونبذ العنف، ومقومات البيئة المدرسية الآمنة، وأن يكون الالتزام الخلقي والسلوكي أساسًا في تقويم الطلاب في مدارس الامبج. - - التخطيط الواعي للارتقاء بنوعية وجودة العلاقات بين الأفراد داخل المدرسة. - - تدعيم الثراكة مع أولياء أمور الطلاب للحد من العنف والسيطرة عليه. - - تعزيز القيادة الطلابية وملكية الطالب. - استخدام التكنولوجيا في دعم العملية التعليمية بشكل متكامل في جوانبها التعليمية والإدارية. - إتاحة الفرصة للطلاب للقيام بالأنشطة المختلفة في (المكتبة - المعمل - الملعبغرفة (المصادر) . - اهتمام المدرسة بالرحلات والحفلات المدرسية والأنشطة الفنية والرياضية والاجتماعية والمسرح المدرسي والثهوايات الخاصة كالرسم والتمثيل والغتاء والألعاب. 
سادساً : المحاسبية المهنية :

- ت تتبنى المدرسة مبدأ المراقبة الأتية لمستوى حدوث أحداث العنف والبلطجة. - مراجعة وتثقيح سياسة مواجهة العنف في المدرسة، ومراقبة النشاط المدرسي بثكل يومي لتقديم التغذية الراجعة لضمان فعالية السياسات والعمليات المتبعة لمواجهة العنف.

- - تقويم برامج الوقاية من العنف ضد الطلاب والعاملين بمدارس الامج بشكل نقدي.

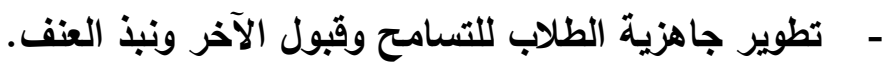

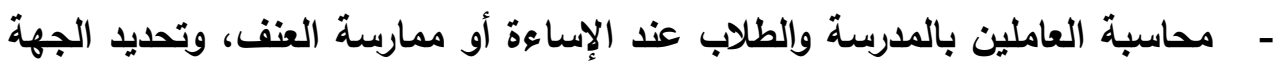
المسؤولة عن محاسبة العاملين أو الطلاب في حال الإساءة أو استخدام العنف. - وجود معاييز واضحة ومعلنة للمحاسبة تشمل العاملين والطلاب، وتوعية العاملين والطلاب بالمدرسة بضرورة تحمل نتائج أفعالهم.

د. آليات تنفيذ التصور المقترح :

- توفير وقت محدد خلال اليوم الدراسي لمناقشة مشكلات الطلاب والعاملين بمدراس الدمج، وسبل معالجتها أو الحد منها أو إحالة المشكلة إلى المختصين. - محارية الثائعات والفكر المتطرف في مدارس الدمج، وذلك بتفنيد الثائعات في حدود الاختصاص، وتعليم الطلاب الحكم النقدي على الأمور، والموضوعية، وتحري لاقة فيما يقال وينشر، والحصول على المعلومات من مصادر رسمية وموثقة. - توفير بيئة مريحة للمعلمين ، وتقديم الدعم المادي والمعنوي لهم ، وعدم إرهاقهم بأعمال إدارية يمكن أن يقوم بها غيرهم. - تنسيق ورش عمل للأمن المدرسي توضح علاقة الأمن المدرسي بجودة التعليم، وتؤكد الحاجة إلى الاعم المجتمعي للمدرسة، وتعمل على تعريف العاملين بثأن مسؤولياتهم الأمنية المحددة، ودعوة رجال الثرطة والقضاة والمحامين ومسؤولي الخدمات الصحية والإنسانية لشرح النظام القضائي للأحداث وعلاقته بالمدرسة ودهية الآمنة. 
- رعاية حلقات البحث التي تدار داخل الفصول ، وإستخدام دراسة الحالة الفعلية مثل

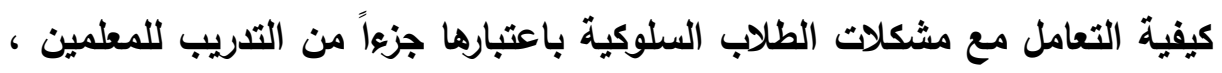
بما يساعدهم على التعامل بشكل أكثر فاعلية مع المواقف المختلفة المهددة للأمن. - إنشاء صندوق للاقتراحات لتحسين مناخ الأمن داخل المدرسة ، والرد على كل الرسائل التي ترد به وتوجيه الشكر لأصحابها.

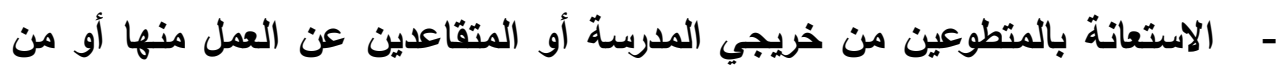
رجال المجتمع المحلي للمساعدة في الأنشطة التطوعية الخاصة بلدعم الأمن المدرسي. تصميم برامج لتعزيز مسؤولية الطلاب نحو الأمن المدرسي ، وتثكيل جماعة الطلاب

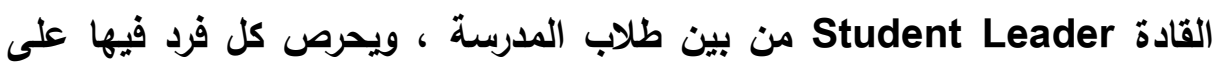
تشجيع الأنشطة المتعلقة بالأمن المدرسي وتصميمها بين أقرانهم وزملائهم، ويمكن أيضاً لاتحاد طلاب المدرسة تثكيل لجنة للتعرف على المشكلات الأمنية والسعي إلى ولى ولى حلها. تثجيع الطلاب على المشاركة في اتخاذ القرارات المتعلقة بإدارة المدرسة ، وذلك عن طريق اشتراك ممثلين عن الطلاب عند المناقشة والتخطيط. - - تنسيق محاكم للطلاب داخل المدرسة يشكلها الطلاب أنفسهم ، ويكون منهم القضاة والمحامون وممثلو الادعاء وموظقو المحكمة،، ويدريهم على ذلك النظام القضائي المحلي وتنظر تلك المحاكم في بعض المخالفات وإصدار أحكام بشأنها. تثكيل فروع محلية من جماعات الأمن الطلابية التي تؤدي أنشطة أمنية لتأمين طلاب المدرسة ضد العنف ، وتعاطي المخدرات ، وضد حوادث الطرق التي قد في فئ تتعرض لها الحافلات المدرسية. - تشكيل نظام الرفاق Buddy System ، وذلك بتحديد طلاب قدامى لاستقبال الطلاب الجد لتسهيل عملية الانتقال بالنسبة إليهم. - إجراء حملة تجميلية للمدرسة وللحي المجاور، ينفذها الطلاب بأنفسهم، ويمساعدة وتوجيه من إدارة المدرسة، مثل: صيانة المبنى المدرسي، وموقف ركن السيارات ، ويعض الأماكن الأخرى خارج المدرسة. 
- تثجيع الطلاب على الإبلاغ عن أي مخالفات أمنية بالمدرسة عن طريق خط هاتفي

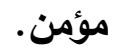
- حث رجال الأعمال والجمعيات الخيرية على تقديم الاعم المادي والمعنوي لمدارس الامج وتوفير متطلبات المدرسة الآمنة، وتنمية ثقافة العمل التطوعي لاى العادي العاملين والطلاب . - الإثراف على تتفيذ خطة الأمن والانضباط المدرسي من قبل مدير المدرسة والوكلاء والأخصائيين الاجتماعيين والنفسيين، والثراكة مع مجلس الآباء ويعض ألفائن أفراد المجتمع المحلي من المهتمين بمجالات العمل الخيري. - التحفيز المادي والمعنوي للمعلم المنضبط والطالب المثالي ، لتثنجيع الالتزام الذلقي والقانوني بين الطلاب والعاملين بمدارس الامج.

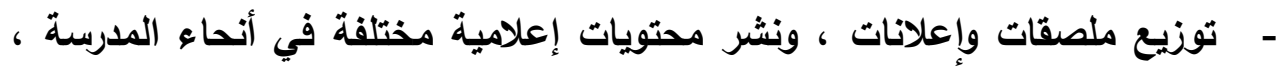
بمشاركة العاملين والطلاب وأولياء الأمور، لحث المجتمع المدرسي على التزات التزام التعليمات والتحذير من ممارسة العنف أو التنمر. - تحديد وتوضيح وإعلان البائل التريوية للعنف المدرسي، وتقليم الوسائل اللازمة

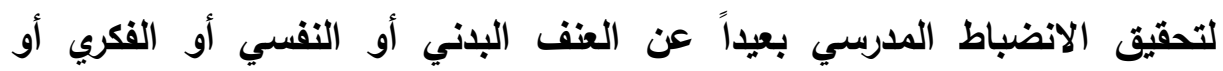

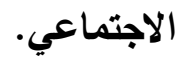

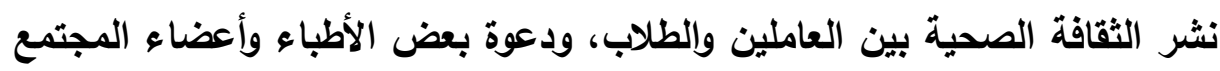
المحلي للمشاركة في أعمال التوعية الصحية وسبل الوقاية من الأمراض والأويئة. - اختيار قيادات مدارس الدمج من المتخصصين في مجال التربية الخاصة ، أو ممن التمال

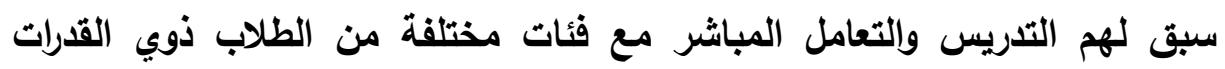
والإمكانات والاهتمامات المتباينة. - مراعاة الطبيعة الجغرافية للطلاب والعاملين في البيئات المختلفة، وتطبيق لوائح الانضباط العدرسي بما يتوافق مع طبيعة كل منطقة.

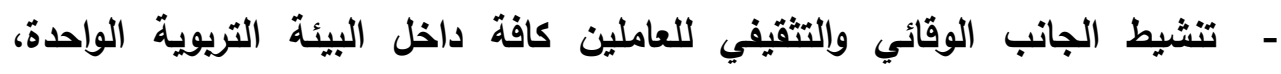

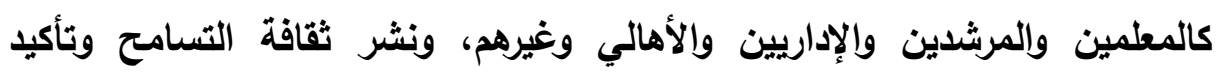


تطبيقها داخل البيئة المدرسية وخارجها، والتتسيق الفاعل بين المجالس الأسرية والمدرسية ، وتنظيم الورشات واللقاءات وتفعيلها بين كافة الأطراف. - تدريب العاملين في البيئة المدرسية حول التعامل مع الطلاب وأفراد المدرسة، وإكسابهم المهارات المناسبة لكيفية التعامل وخفض وتيرة العنف وتوفير الجو الآمن داخل البيئة التربوية. - استخدام وتفعيل أساليب التعزيز المادية والمعنوية وتأكيا تطبيقها داخل البيئة

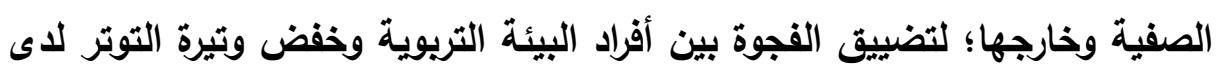
الطلاب ، ويناء جسور الثقة بينهم مع جذبهم للبيئة التريوية في نفوسهم وذواتهم. - استخدام وتفعيل أساليب تعديل السلوك، والبعد عن العقاب البدني والإيمائي واللفظي، كالعزيز السلبي والتصحيح الزائد والمباريات الصفية وتكلفة الاستجابة وغيرها.

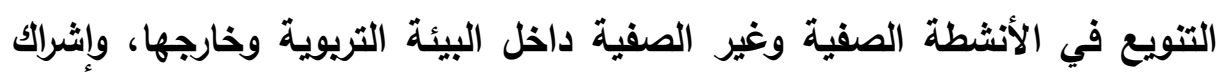
الطلاب فيها مع إسناد الدور الملائم لحاجاتهم وميولهم وإمكاناتهم ، كالمخيمات الكثفية، واللجان المدرسية المتنوعة، والاستفادة من وسائل الإعلام والاتصالات

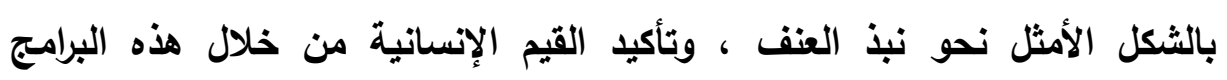
والتطبيقات. - شيوع الجو الديمقراطي بين أفراد البيئة التربوية الواحدة، ونشر مبدأ حرية التعبير والاختيار، وتفعيل المجالس الطلابية والبرلمانات الطلابية، وعدم إثعار الطالب بأنه

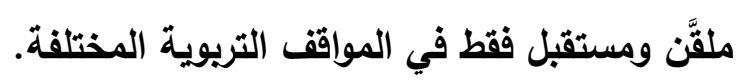
تفعيل دور الإرشاد المدرسي، لأنه بمثابة خط الدفاع بين الطالب والسلوك غير ومئه

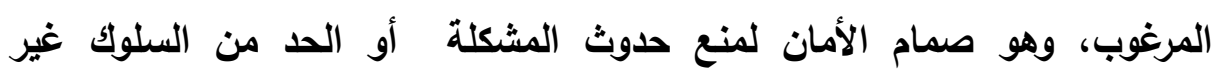
المرغوب.

- تفعيل دور لجنة الانضباط المدرسي، وتطبيق لوائح وتعليمات نظام الانضباط

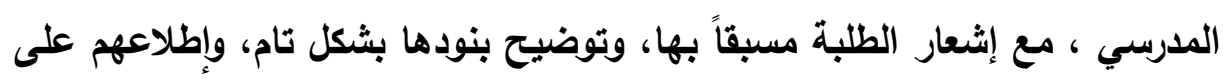
ما يستجد من تظورات وتعديلات جديدة فيها. - أن يحتوي المنهج على مجموعة من القيم والمفاهيم الأمنية التي يمكن أن تصبح

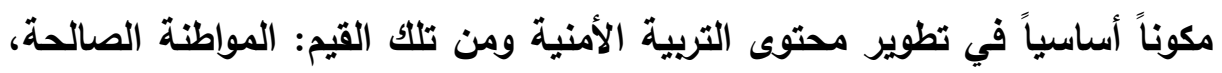


طاعة ولي الأمر، الحفاظ على الممتلكات العامة، الاستقرار الاجتماعي، احترام

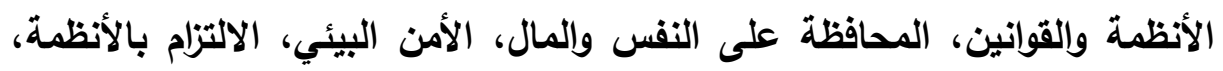

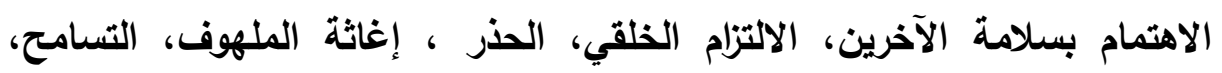

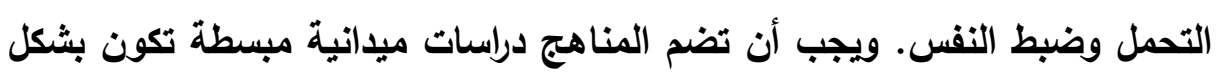
مشروعات تضع الحلول المناسبة لمشكلات اجتماعية معينة مثل ظاهرة العنف، والانحراف، والتفكث العائلي ، والمخدرات وغيرها. - أن يتضمن مقرر التربية الوطنية بعض الأبعاد السلوكية والنفسية والمعرفية للتربية

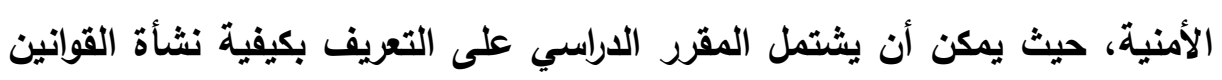

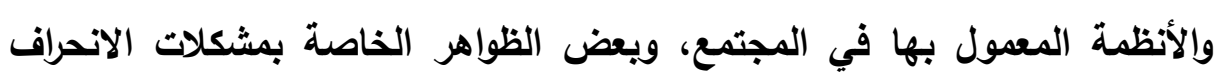

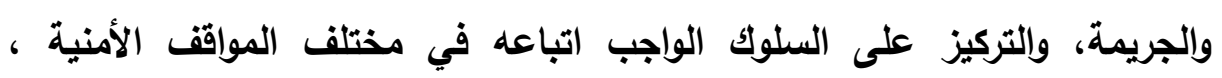
والتوعية بخطر الوقوع ضحية لبعض الجرائم والحوادث.

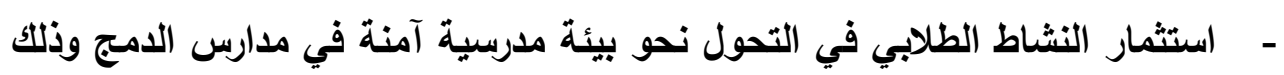

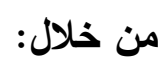
- الإذاعة المدرسية : إذ يمكن تقديم عدد من الكلمات التوجيهية بخصوص بعض المشكلات الأمنية ، وغرس بعض المضاده : المفاهيم الإيجابية.

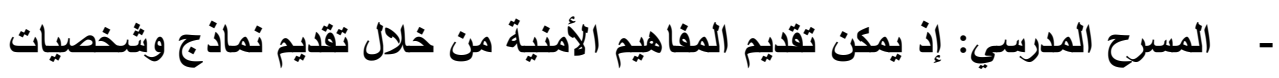

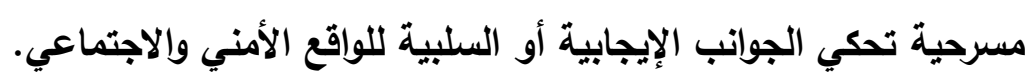

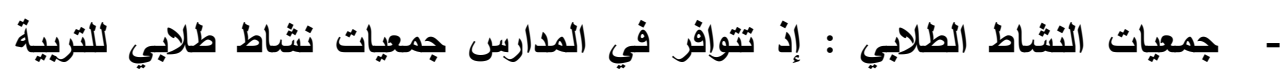
الإسلامية ، وللمواد الاجتماعية ، والعلوم، ويمكن تأسيس جمعية الانضباط أو الأمن

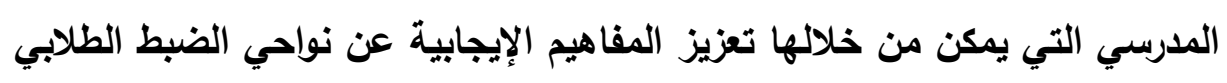
والاجتماعي. - الصحف المدرسية وصفحات الإنترنت المدرسية ، حيث يشارك الطلاب في عرض

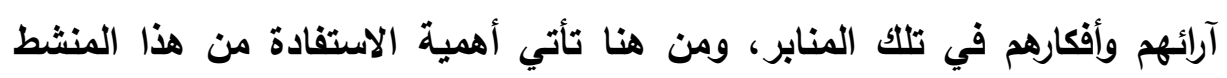
التعليمي في كتابة بعض المقالات والأفكار التي تؤكد على قيمة الأمن والمواطنة. 


\section{المراجع}

أولاً: المراجع العربية

1. ابن منظور ، محمد بن مكرم بن منظور الإفريقي المصري جمال الدين أبو الفضل.(ع (ع الهــ).

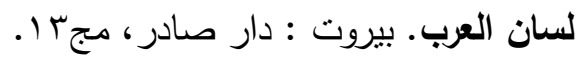

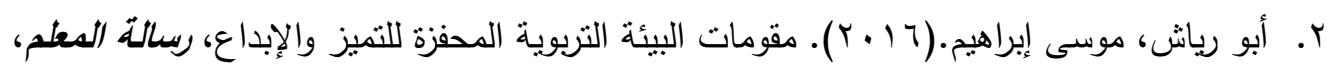

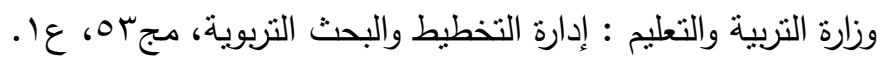

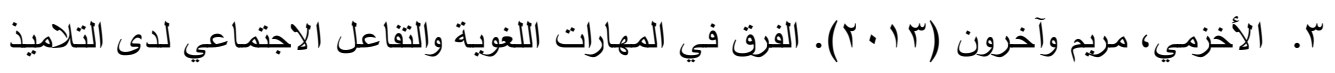

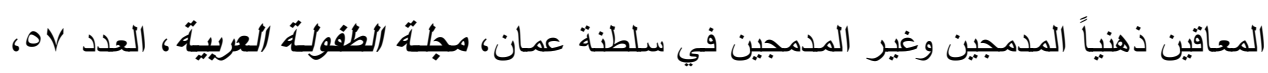
الكويت.

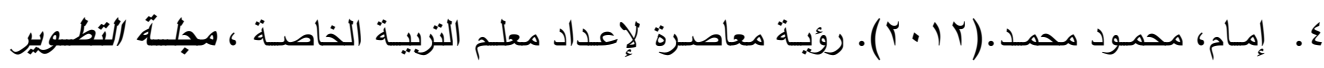

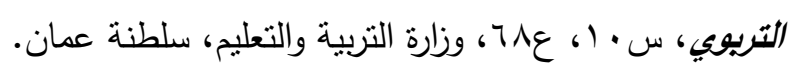

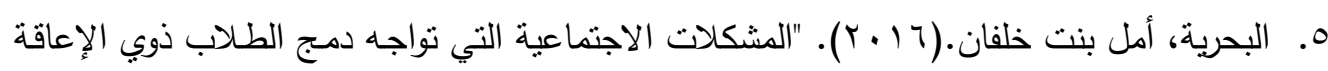

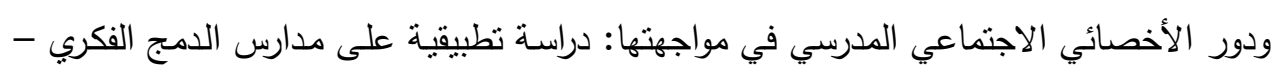

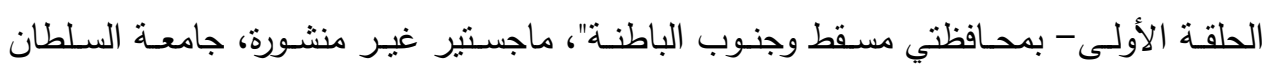
قابوس، كلية الآداب والعلوم الاجتماعية.

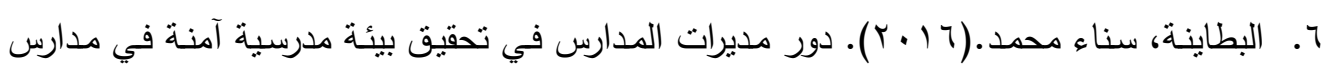

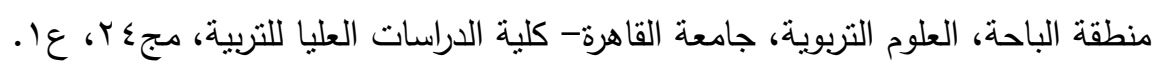

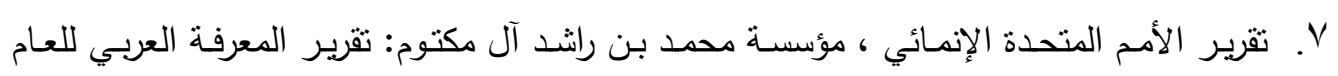

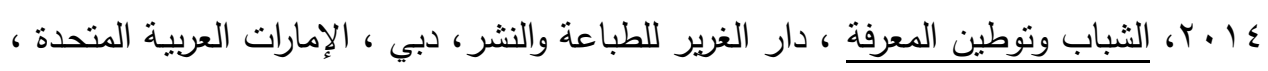
ص ص M

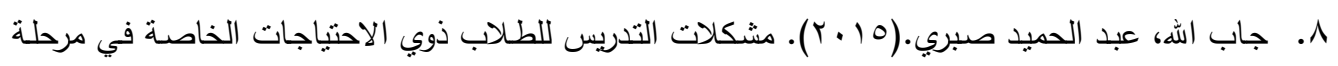

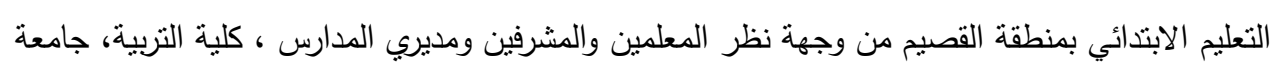

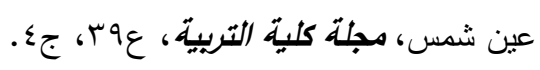

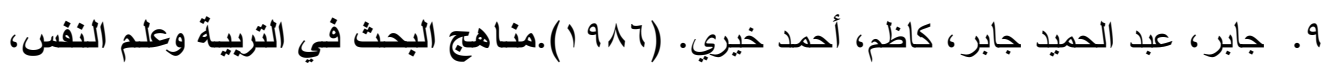
دار النهضة العربية: القاهرة.

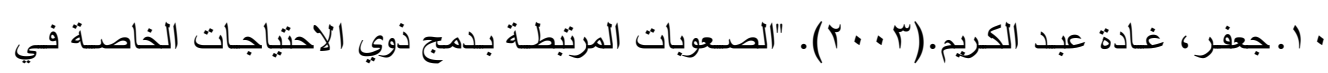

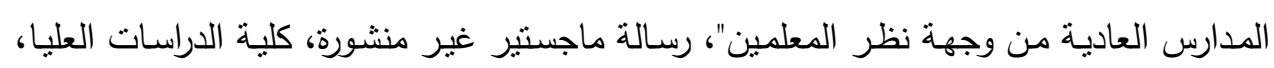

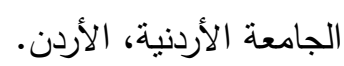




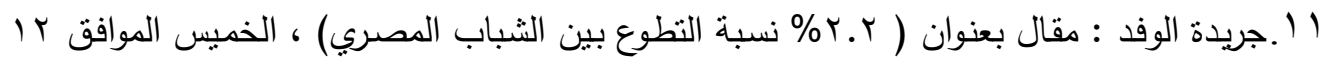

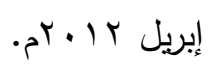

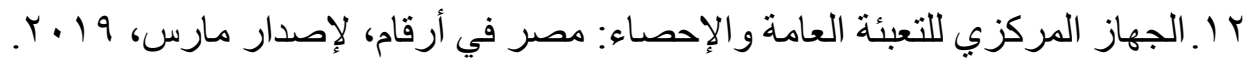

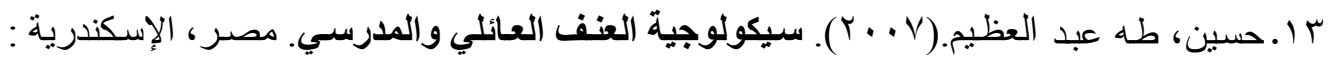
دار الجامعة الجديدة.

ـ ا. خزاعلة، عبد العزيز .(991 (1). أمن الطقل العربي، الرياض: أكاديمية نايف العربية للعلوم الأمنية.

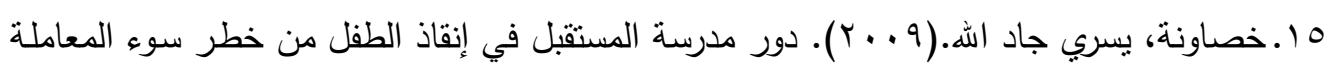

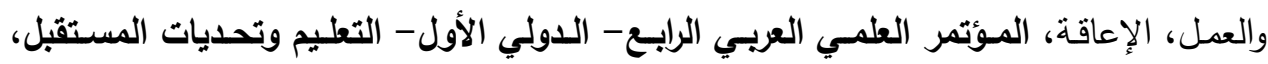

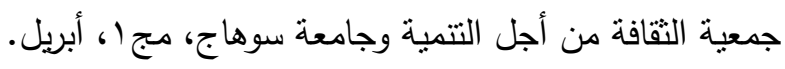

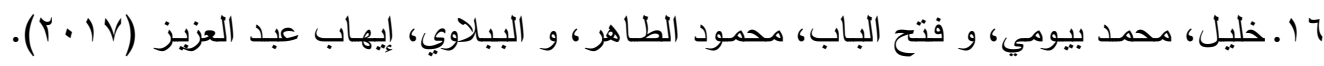

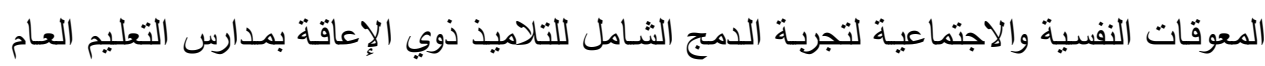

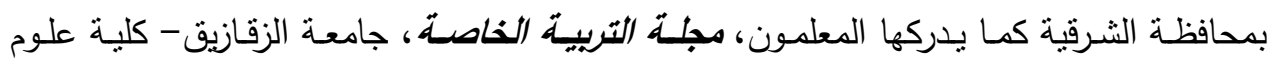

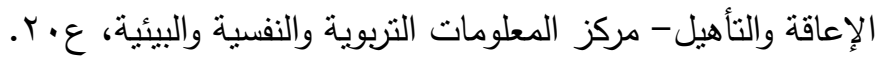

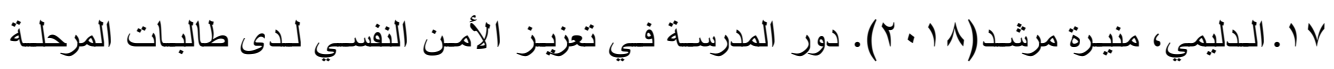

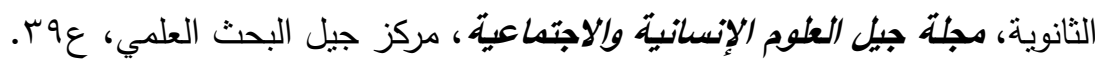

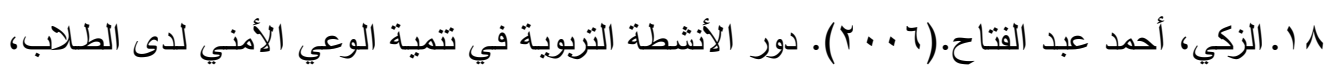

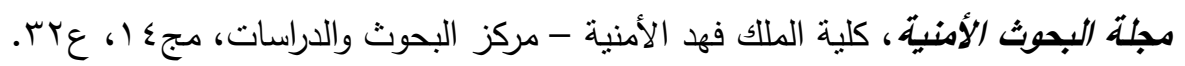

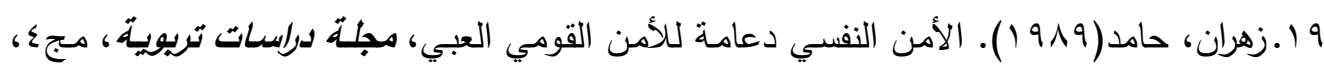

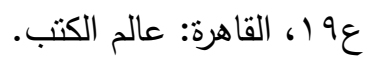
Read from: ..زهـرن، حامــ. الأمـن النفسي والتزبيـة الأمنيـة (للمـواطن والثـرطي). .https://almajd.ps/news1261/ 10-3-2020/11:54 AM.

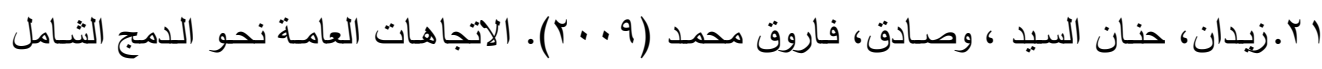

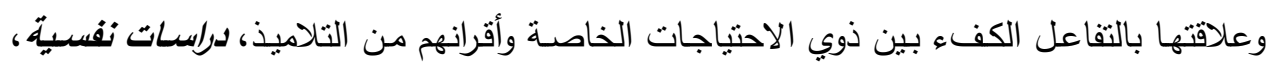

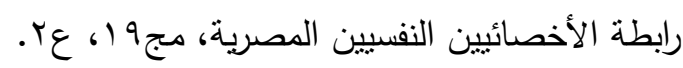
r r. سلمان، فؤاد مصطفى (1990) . "درجة تحقيق حاجة الإحساس بالأمن لدى أعضاء هيئة التدريس في الجامعات الأردنية"، رسالة ماجستير غير منشورة، جامعة اليرموك، إربد، الأردن. 
r r. السناني، محمد بن مسلم بن سليمان.(10 • (1). دور المدرسة الثانوية في تحقيق التربية الأمنية

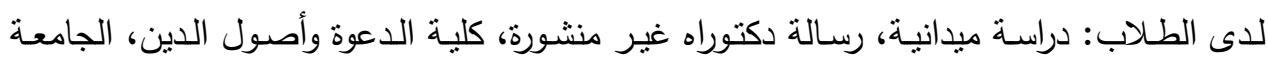
الإسلامية بالمدينة المنورة، السعودية.

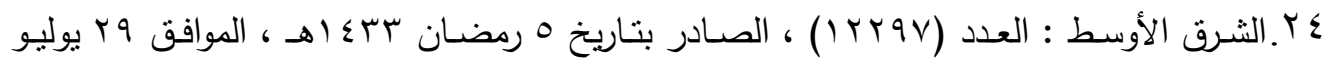

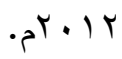

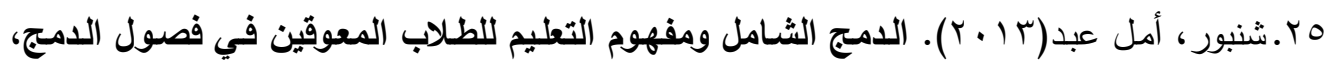
عالم الكتب الحديث، إربد، الأردن.

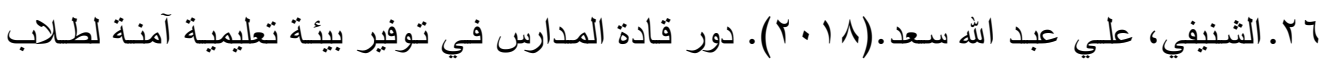

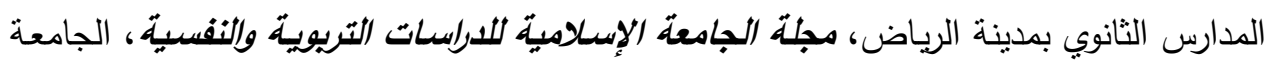

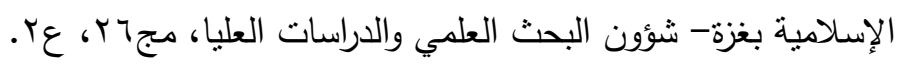

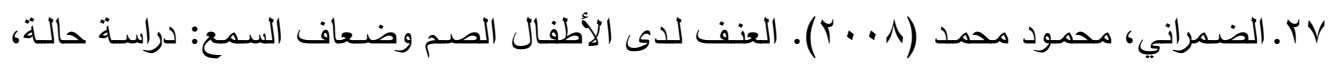

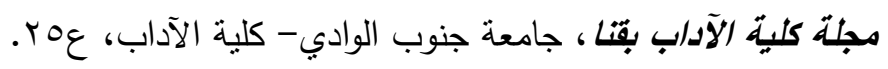

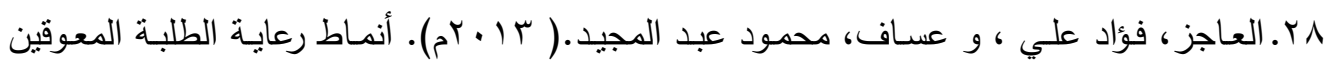

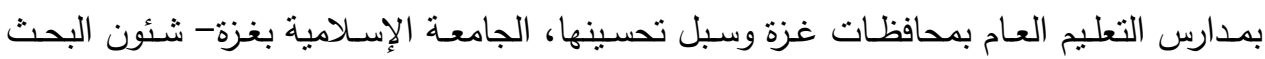

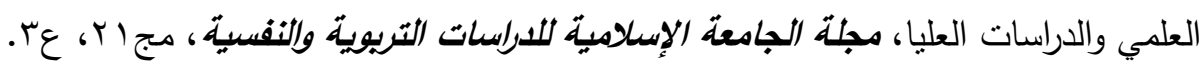

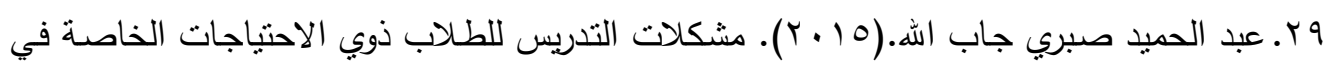
مرحلة التعليم الابتدائي بمنطقة القصيم من وجهة نظر المعلمين والمشرفين ومديري المدارس، كلية

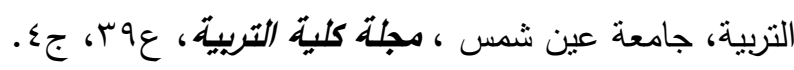

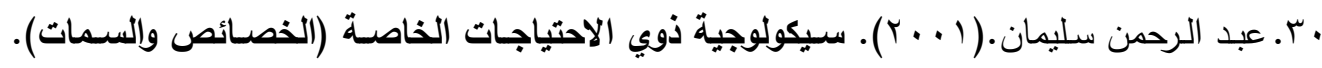
القاهرة : مكتبة الزهراء.

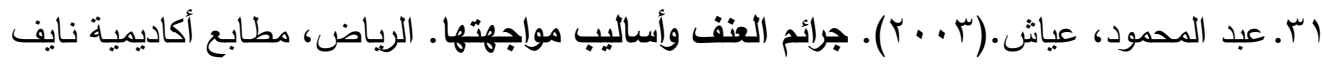
العربية للعلوم الأمنية.

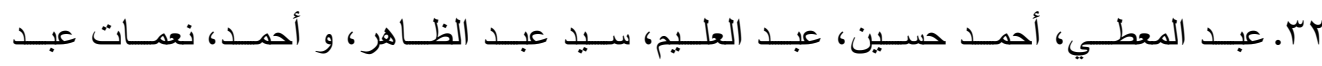

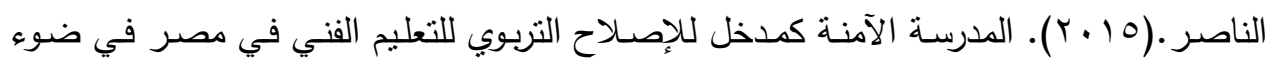

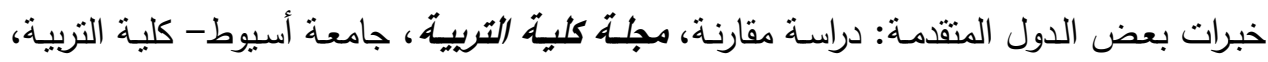

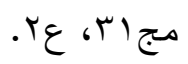




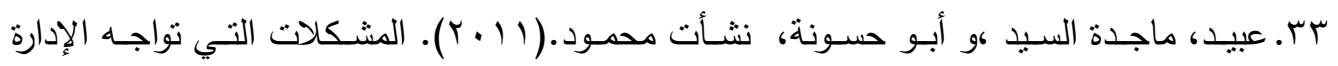

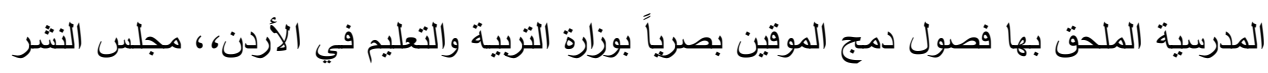

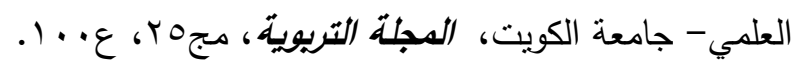

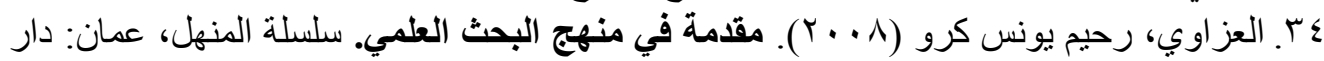
دجلة.

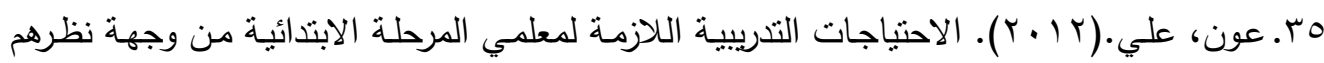

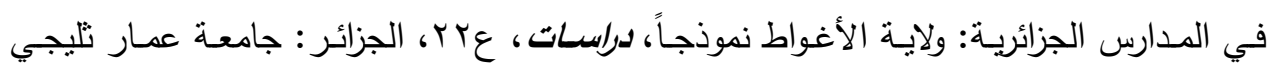
بالأغواط.

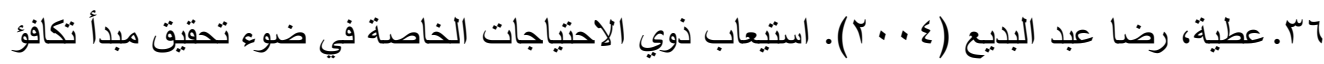
الفرص التعليمية "دراسة مقارنة بين مصر والسويد"، رسالة ماجستير غير منشورة ، كلية التربية ، جامعة الزقازيق.

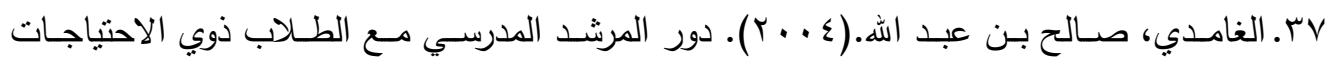

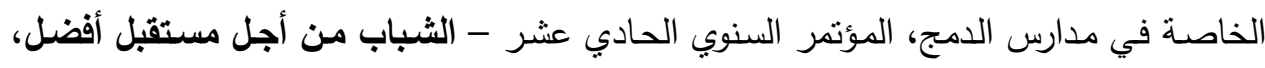

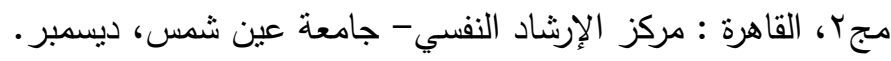

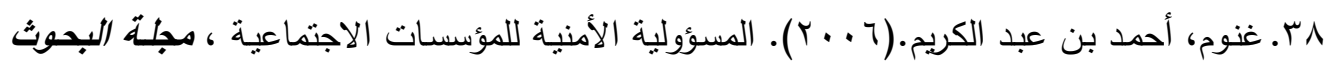

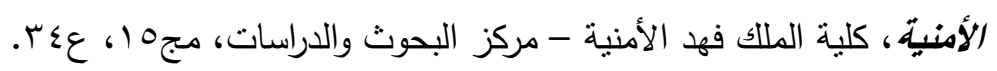

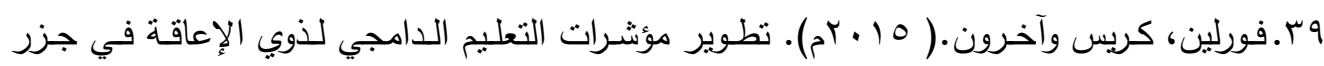

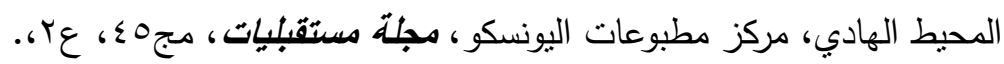

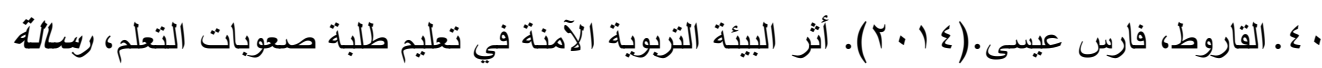

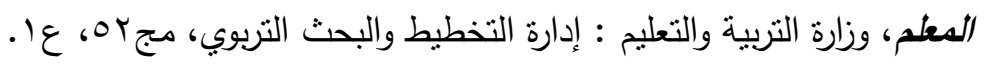
اء ـ القريطي، عبد المطلب أمين( • • ( ). دمج ذوي الاحتياجات الخاصة في في التعليم العام: دواعيه

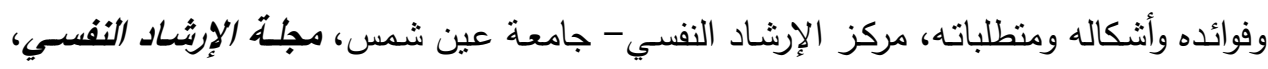
r r

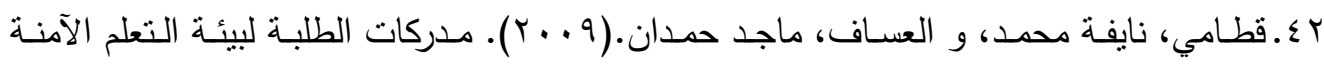

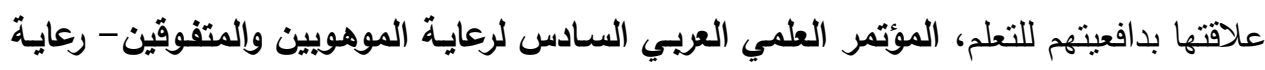

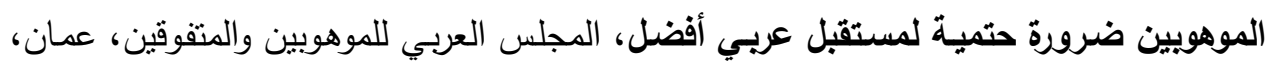

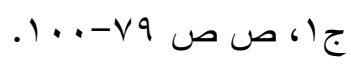




\section{تصور مقترح لتحول مدارس الدمج إلى بيئة مدرسية آمنة .}

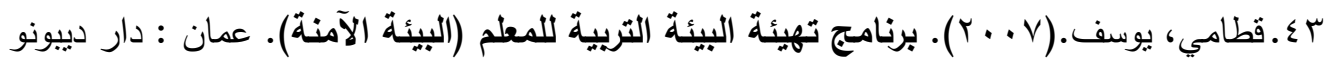
للنشر والتوزيع.

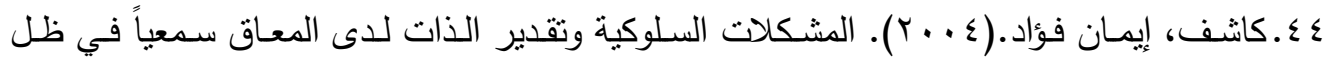

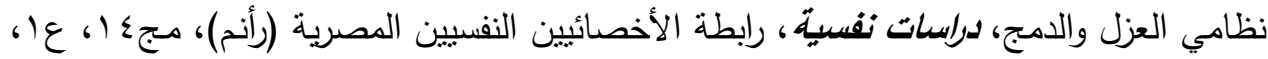
ص • ص

هـ ـ مجاهد، محمد عطوة (1 . . ץ). المدرسة والمجتمع في ضوء مفاهيم الجودة. مصر : الإسكندرية:

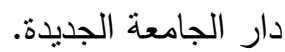

؟ ـ. محمد، محمد النصر ، و خليل، عبد الناصر أحمد.(10 • ب). رؤية تربوية مقترحة لمتطلبات تحقيق التربية الأمنية بمرحلة التعليم الابتدائي، مجلة العلوم التريوية، جامعة جنوب الوادي- كلية التربية

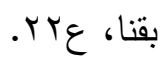

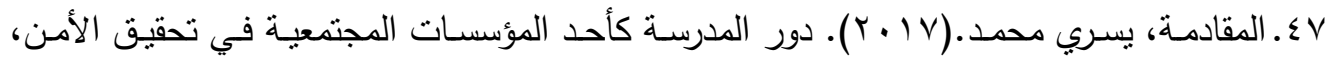

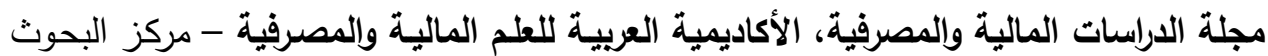

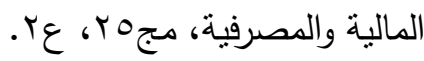

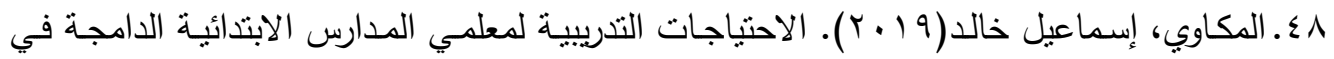

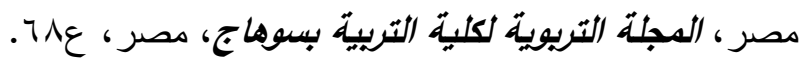

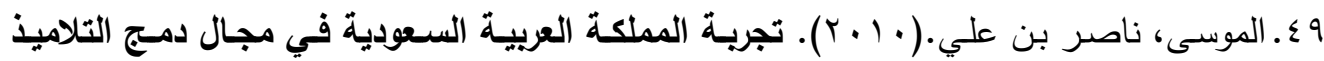
(قصة نجاح). المملكة العربية السعودية، الرياض : مكتب التربية العربي لدول الخليج.

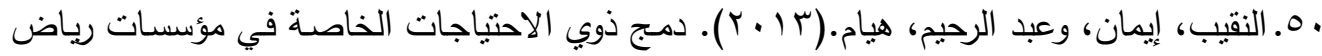

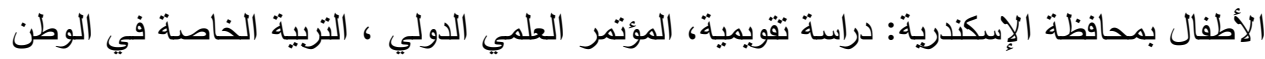

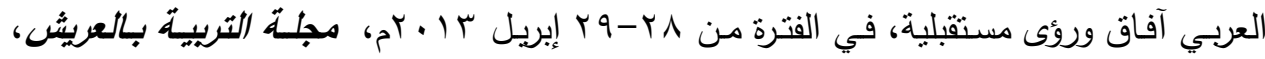
جامعة جنوب الوادي. 10. هلل، شعبان أحمد(1) • ( ). منطلبات تطبيق المدرسة الآمنة بمؤسسات التربية الخاصة بمصر ،

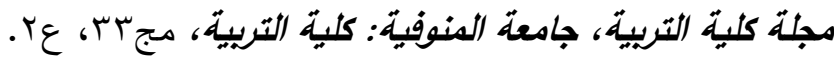

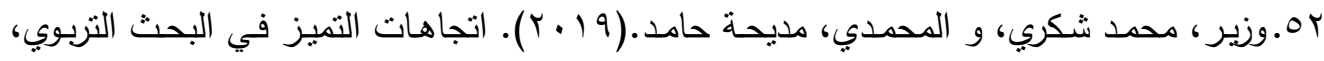

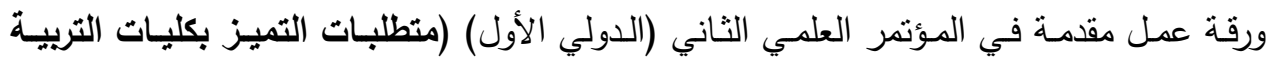

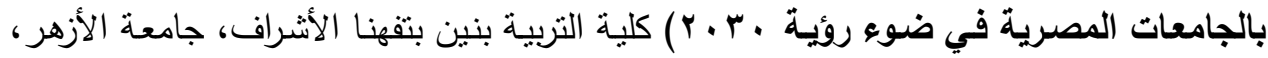
في الفترة من r-r أكتوبر . 


\section{تصور مقترح لتحول مدارس الدمج إلى بيئة مدرسية آمنة.}

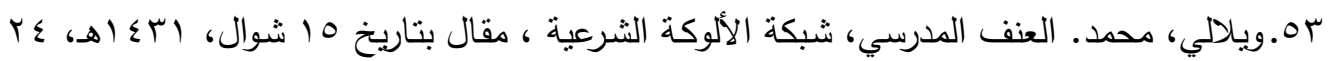

Read

From:

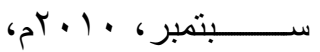

https://www.alukah.net/sharia/0/26488/1-21-2-2020/11:52AM.

\section{ثانياً : المراجع الأجنبية}

54. Brandt, R. (1995). Punished by rewards. "Educational Leadership, 53(1), 13-16.

55. Bucher, K. T. \& manning, M. L.(2003). Challenges and Suggestions for safe schools. The Clearing House, 76(3), PP. 160-164.

56. Dwyer, K. D., Osher, \& C. Warger.(1998). Early Warning, Timely Response: A Guide to Safe Schools. Washington, DC: U.S. Department of Education. PP. 3-5.

57. Dwyer, K. D., Osher, \& C. Warger.(1998). Early Warning, Timely Response: A Guide to Safe Schools. Washington, DC: U.S. Department of Education. P.2.

58. Gietz, C., \& Mclnosh, K.,(2014). Relations Between Student Perceptions of their School environment and academic achievement. Canadian. Journal of School Psychology, 29(3), 161-176.

59. Koth, C.W., Bradshaw, C. P., \& Leaf, P.J.(2008). A Multilevel study of Predicators of Student Perceptions of School Climate: the effect of classroom - level factors. Journal of Educational Psychology, 100(1), 96.

60. Merrill, M. L, Taylor, N. L., Martin, A. J., Maxim, L. A.,...\&\& Wells, M. E., (2012). A mixed-method exploration of functioning in safe schools/healthy students partnership. Evaluation and program Planning, 35(2), 280-286.

61. Moghadam Fahimeh; Bagheri Somayeh.(2018). Students satisfaction about the performance of advisor professors. Journal of clinical \& diagnostic research, sep. Vol. (2), Issue 9, PP.7-8.

62. National Research Council, (NRC), (1996). National Science Education Standards, Washington DC: National Academy-Press.

63. National School Safety Center(1999). Working together to create safe schools, Westlake Village, CA, P.3.

64. Parker, L., E., \& Lepper, M., (1992). Effects of Fantasy Contexts on Children's Learning and Motivation: Making Learning More fun, Journal of Personality and Social Psychology, 62, PP. 625-633.

65. Purkey, W.W.(1999).Creating Safe Schools Through Invitational Education, ERIC Digest, ED435946.

66. Read from: moe.gov.eg/departments/Unit-merger/index.html. 7-122018/ 10:08 AM. 


\section{تصور مقترح لتحول مدارس الدمج إلى بيئة مدرسية آمنة.}

67. Readiness and Emergency Management for Schools. Teaching Assistance Center (REMS), (2018). Student Perceptions of Safety and Their impact on creating a safe School Environment. Student Perceptions of Safety Fact sheet. ERIC, ED593833, 1-6.

68. Sapon-Shevin, M. (2010). Because We Can Change the World: A Practical Guide to Building Cooperative, Inclusive Classroom Communities, Corwin Press.

69. Sindhi, S.A.(2013). Creating Safe School Environment: Role of School Principals. Tibet Journal, 38(1-2), 77-89.

70. Smith, I., M.(2002). The Effect of School Safety on the Learning Environment of Middle School, U.S. department of Education, educational resources information center (ERIC, ED471557).

71. Souderton Area School District.(2001). What is Safe School?, Read From : http://www.soudertonsd.org/tools/parents/safety/index.cfm, 21/02/2020.

72. Squelch. J. (2001). Do school governing bodies have a duty to create safe schools? An education law perspective: current issues in education law and policy. Perspectives in Education, 19(1), 137-149.

73. Thomas, M. \& Bauer, A., (1994). Learners with the disabilities, A social systems perspective of special education. Washington, DC: Alexander Graham Bell Association for the Deaf. 